\title{
Physical Characterization And Steam Chemical Reactivity Of Carbon Fiber Composites
}

\author{
R. J. Pawelko \\ R. A. Anderl \\ G. R. Smolik
}

May 2001

Idaho National Engineering and Environmental Laboratory Bechtel BWXT Idaho, LLC 


\title{
PHYSICAL CHARACTERIZATION AND STEAM CHEMICAL REACTIVITY OF CARBON FIBER COMPOSITES
}

\author{
R. J. Pawelko, R. A. Anderl and G. R. Smolik \\ Idaho National Engineering and Environmental Laboratory \\ P. O. Box 1625 \\ Idaho Falls, ID 83415-7113
}

Published May 10, 2001

Prepared for the

Forschungszentrum Karlsruhe $\mathrm{GmbH}$

Under WFO Project \#00-904/00-187

And for the

U.S. Department of Energy

Office of Science

Under DOE Idaho Operations Office

Contract DE-AC07-99ID13727 


\section{ACKNOWLEDGMENTS}

The experimental work that is reported here is the result of a collaborative research effort to investigate steam oxidation of PFC materials for advanced tokamaks like the International Thermonuclear Experimental Reactor (ITER). This work was supported by a Work for Others (WFO) Agreement between Bechtel BWXT Idaho, LLC, prime operating contractor of the Idaho National Engineering and Environmental Laboratory (INEEL), and Forschungszentrum Karlsruhe GmbH. Principal European collaborators were Dr. Francesco Scaffidi-Argentina and Dr. Giovanni Piazza of Forschungszentrum Karlsruhe. Dr. Scaffidi-Argentina provided the initial motivation for this work and facilitated the WFO project along with Dr. Piazza. In addition, the carbon fiber composite material used in these experiments was provided by Dr. Chung H. Wu (EFDACSU, Garching, Germany). 


\section{SUMMARY}

This report documents experiments and analyses that have been done at the Idaho National Engineering and Environmental Laboratory (INEEL) to measure the steam chemical reactivity of two types of carbon fiber composites, NS31 and NB31, proposed for use at the divertor strike points in an ITER-like tokamak. These materials are 3D CFCs constituted by a NOVOLTEX preform and densified by pyrocarbon infiltration and heat treatment. NS31 differs from NB31 in that the final infiltration was done with liquid silicon to reduce the porosity and enhance the thermal conductivity of the CFC. Our approach in this work was twofold: (1) physical characterization measurements of the specimens and (2) measurements of the chemical reactivity of specimens exposed to steam.

Two types of physical characterization measurements were made: (1) BET specific surface areas based on $\mathrm{Kr}$ gas adsorption measurements and (2) bulk densities and porosities based on immersion density measurements using water. The BET measurements and analyses gave specific surface areas of $0.15 \mathrm{~m}^{2} / \mathrm{g}(+/-14 \%)$ for NS31 carbon fiber composite and $0.15 \mathrm{~m}^{2} / \mathrm{g}(+/-7 \%)$ for the NB31 carbon fiber composite. Ratios of these measured specific surface areas to the geometric surface areas for the NS31 and NB31 samples were $332(+/-10 \%)$ and $335(+/-13 \%)$, respectively, indicating that both carbon fiber composite types have high specific surface areas relative to their geometric surface areas. The measurement of comparable BET specific surface areas for the two materials is surprising because the infiltration of Si into NS31 reduced the porosity considerably. However, based on microscopic analyses, we observed a similar microstructure for the two materials and evidence of micro-cracking along different material interfaces including that surrounding the voids filled with Si. Such microcracking would provide gas access to the porosity network in each material resulting in gas adsorption on possibily equivalent internal surfaces.

Immersion density measurements were conducted on the NS31 and NB31 carbon fiber composite samples. These measurements and analyses gave bulk densities of $2.13 \mathrm{~g} / \mathrm{cc}+/-(0.7 \%)$ for the NS31 and $1.95 \mathrm{~g} / \mathrm{cc}+/-(0.6 \%)$ for the NB31 samples. The immersion density measurements were in excellent agreement with densities derived from mass and dimensional measurements. These measurements also indicated open porosity values of $1.8 \%+/-(19 \%)$ for the NS31 and $6.2 \%+/-(7 \%)$ for the NB31 samples. The density difference between NS31 and NB31 can be accounted for by the Si that filled a substantial fraction of the porosity in the NS31 composite.

Characterization of the CFC material microstructure was done using optical microscopy and scanning electron microscopy (SEM), and elemental composition was measured using energy-dispersive X-ray (EDX) spectrometry. The microstructure for the NB31 composite consisted of the fiber structure surrounded by an impregnated matrix composed principally of carbon. The composite structure contained sizable voids, porosity and cracks along different material interfaces. These measurements revealed that the microstructure was similar for the NS31 composite with one major difference. Voids and substantial porosity were observed in NB37, whereas, the porosity of NS31 
was filled with $\mathrm{Si}$, a fraction of which may have been converted to $\mathrm{SiC}$ resulting from $\mathrm{C}$ diffusion into the Si at elevated temperature. However, micro-cracks along material interfaces were still present in the NS31 material.

Chemical reactivity experiments were performed for the NS31 and NB31 carbon fiber composite samples exposed to steam at temperatures ranging from $800^{\circ} \mathrm{C}$ to $1100^{\circ} \mathrm{C} . \mathrm{H}_{2}$, $\mathrm{CO}$, and $\mathrm{CO}_{2}$ generation rates were derived from mass-spectrometer measurements. Carbon reaction rates were determined from measurements of sample weight-loss. These experiments showed a carbon-steam reactivity behavior primarily dependent on the test temperature. The observed kinetic behavior for $\mathrm{H}_{2}$ and $\mathrm{CO}_{2}$ generation was very similar for both CFC's at all test temperatures, however this behavior differed from that for $\mathrm{CO}$ generation. $\mathrm{CO}_{2}$ is most likely produced via $\mathrm{CO} /$ steam interactions in the hot zone of the furnace. Consequently, the kinetic behavior for the $\mathrm{CO}$ and $\mathrm{CO}_{2}$ observed signals is probably related to both the $\mathrm{CFC} /$ steam reaction and to the $\mathrm{CO} /$ steam reaction, with both the residence time and furnace temperature being important parameters.

Average $\mathrm{H}_{2}$ generation rates and carbon reaction rates were computed for the NS31 and NB31 CFC samples, and these results were compared in Arrhenius plots as a function of test temperature. At $800^{\circ} \mathrm{C}$, the hydrogen generation rates and carbon reaction rates were factors of 5 and 3 higher, respectively, for NS31 compared to NB31. The higher rate for $\mathrm{NS} 31$ at $800^{\circ} \mathrm{C}$ could be due to oxidation of the Si that was introduced into the porosity during material fabrication. However the rates for the two materials were comparable at $900^{\circ} \mathrm{C}$. For test temperatures of 1000 and $1100^{\circ} \mathrm{C}$, the $\mathrm{H}_{2}$ generation rates and carbon reaction rates for NB31 were about a factor of 2 higher than those for NS31. This trend toward reduced oxidation for NS31 at high temperatures could be due to the influence of reduced porosity and $\mathrm{SiO}_{2}$ formation in NS31, factors that could affect mass transport and diffusion of the steam and the gaseous reaction products.

The results from this work were compared with previous studies for DUNLOP, FMI HDFG and FMI 4D carbon fiber composite samples. At $1100^{\circ} \mathrm{C}$, the steam reactivity for DUNLOP, FMI HDFG and FMI 4D was substantially higher than that for NS31 and NB31 CFC's. Extrapolation of the results for NS31 and NB31 to higher temperature was in reasonable agreement with previous measurements for DUNLOP, FMI HDFG and FMI $4 \mathrm{D}$ at $1300^{\circ} \mathrm{C}$. Noting that NS31 is more dense and less porous than NB31 and that the NS31 and NB 31 materials are more dense than the previously tested materials, it is tempting to conclude that the reactivity at $1100^{\circ} \mathrm{C}$ is inversely proportional to the material density. However, there were substantial differences in the experimental conditions between the present experiments and the previous ones that could have affected the absolute reaction rates. For example, the steam flow velocity was substantially higher in the earlier experiments, a condition that could have contributed to an enhancement of the reactivity. This comparison suggests the need for additional measurements on all materials at common experimental conditions.

The results of these studies are relevant to the use of CFC materials in the divertor regions of an ITER-like tokamak, in particular to an evaluation of the PFC materials under steam ingress accident conditions. The infiltration of Si into the CFC matrix for 
NS31 resulted in a more-dense, less porous CFC than NB31. NS31 appeared to be more resistant to steam oxidation at temperatures at 1000 and $1100{ }^{\circ} \mathrm{C}$ by about a factor of 2 . This trend could be a possible advantage for use of NS31. However, NS31 was more reactive at $800{ }^{\circ} \mathrm{C}$. The results suggest that further studies are important to unambiguously establish the role that Si plays in the steam reactivity process at all tokamak-relevant temperatures. 


\subsection{INTRODUCTION}

Evaluation of the safety hazards for advanced tokamaks includes an assessment of the failures of plasma-facing-component (PFC) materials due to various accident scenarios. In particular, accident scenarios that result in water or steam exposure of hot PFC is of concern for ITER-like tokamak designs that include carbon fiber composites as a candidate PFC material at the divertor strike points. This accident type is of concern because steam interactions with hot carbon can produce significant quantities of hydrogen. As discussed by Clark et al. [1], the primary steam reactions with graphite are as follows:

$$
\begin{aligned}
& \text { Eq. (1a) } \mathrm{C}+\mathrm{H}_{2} \mathrm{O} \rightarrow \mathrm{CO}+\mathrm{H}_{2} \\
& \text { Eq. (1b) } \mathrm{C}+2 \mathrm{H}_{2} \mathrm{O} \rightarrow \mathrm{CO}_{2}+2 \mathrm{H}_{2}
\end{aligned}
$$

with a possible secondary reaction between steam and $\mathrm{CO}$;

$$
\text { Eq. (1c) } \mathrm{CO}+\mathrm{H}_{2} \mathrm{O} \rightarrow \mathrm{CO}_{2}+\mathrm{H}_{2} \text {. }
$$

Assessment of the consequences of such accident scenarios is typically done by means of accident model simulation [2] and the use of experimentally-derived chemical reactivity data for the various forms of carbon fiber composites that may be used in advanced tokamaks.

One purpose of our work in the Fusion Safety Program at the Idaho National Engineering and Environmental Laboratory (INEEL) has been to provide basic data on chemical reaction rates and the associated hydrogen production (in the case of steam) for candidate PFC materials. In previous studies [3,4] conducted at the INEEL, carbon steam reaction rates for several graphites and carbon-based composites were measured at temperatures between $1000^{\circ} \mathrm{C}$ and $1700^{\circ} \mathrm{C}$. The present report extends this work to include the results of steam oxidation experiments for two carbon fiber composites (CFCs), namely, (NS31 and NB31), that were tested from $800^{\circ} \mathrm{C}$ to $1100^{\circ} \mathrm{C}$.

Arrangement of this document is as follows. Section 2.0 presents a description of the carbon fiber samples, a description of the physical characterization techniques, and the results of our specific-surface-area and immersion-density measurements. Section 3.0 includes a description of the experimental approach for the steam chemical reactivity experiments and provides tables and graphical presentations of the measured $\mathrm{H}_{2}, \mathrm{CO}$, and $\mathrm{CO}_{2}$ generation data. Section 3.0 also includes a summary of the average hydrogen generation rates for the carbon composites samples based on measured geometric and BET surface areas. A discussion of the experimental results and a comparison of these results to previous studies [3,4] are presented in Section 4.0. References are listed in Section 5.0. 


\subsection{DESCRIPTION AND CHARACTERIZATION OF CARBON FIBER COMPOSITE MATERIAL}

\subsection{Description}

NS31 and NB31 [5] are advanced 3D carbon fiber composites with high thermal conductivity that have been developed by S.E.P. (Société Européenne de Propulsion) and Dunlop. The carbon fiber composite sample material was obtained from Dr. Chung Wu (EFDA-CSU, Garching, Germany), as facilitated by Dr. Francesco Scaffidi-Argentina (Forschungszentrum, Karlsruhe). The following is a short description provided by Dr. G. Piazza (Forschungszentrum, Karlsruhe) of the carbon fiber composites (CFC) and the processes used to produce them.

NB31 is a 3D CFC constituted by a NOVOLTEX preform, with P55 ex-pitch fibers in the $\mathrm{x}$-direction and ex-PAN fibers in the y-direction, then a needling to give an orientation in the $\mathrm{z}$-direction. The volume fraction of fibers is $35 \%: 27 \%$ in the $\mathrm{x}$-direction, $4 \%$ in the $\mathrm{y}$-direction and $4 \%$ in the $\mathrm{z}$-direction. Then there is a densification by chemical infiltration of pyrocarbon at $1000^{\circ} \mathrm{C}$ followed by a heat treatment at $2800^{\circ} \mathrm{C}$. The last phase of densification is made by chemical infiltration of pyrocarbon at $1000^{\circ} \mathrm{C}$ followed by a pitch impregnation at 1000 bars $/ 1000^{\circ} \mathrm{C}$. The density of NB31 is about $1.91 \mathrm{~g} / \mathrm{cm}^{3}$.

NS31 is a 3D CFC that has undergone a final infiltration of liquid silicon leading partly to the formation of silicon carbide (10-12 at.\% Si). The porosity of this material is very low, about $1 \%$, and its density is about $2.09 \mathrm{~g} / \mathrm{cm}^{3}$. Its thermal conductivity at $298 \mathrm{~K}$ is as high as $220 \mathrm{~W} / \mathrm{m} \mathrm{K}$.

The carbon fiber composite materials arrived in the form of blocks approximately $7.5-\mathrm{cm}$ long by $5.0 \mathrm{~cm}$ wide by $2.5 \mathrm{~cm}$ thick. A diamond bladed circular saw was used to cut the material to nominal sample dimensions of $2.5-\mathrm{cm}$ long by $8-\mathrm{mm}$ wide by 3 to $4-\mathrm{mm}$ thick to accommodate both the BET specific surface area and the steam reactivity measurement systems. Each sample was weighed and measured using a micrometer. The mass, physical dimensions, geometric surface area, and density of the test samples are presented in Table 1. Based on the physical measurements for these samples, the average densities for the CFC materials were determined to be $2.13+/-2 \%$ for NS31 and $1.96+/-1 \%$ for NB31. Also included in Table 1 for comparison are the BET measured specific surface areas and the ratios of specific surface area to geometric surface area for each sample.

Characterization of the CFC material microstructure was done using optical microscopy and scanning electron microscopy (SEM), and elemental composition was measured using energy-dispersive X-ray (EDX) spectrometry. The key results of these measurements and analyses are summarized in Appendix A. The microstructure for the NB31 composite comprised the fiber structure surrounded by an impregnated matrix composed principally of carbon. The composite structure contained sizable voids, porosity and cracks along different material interfaces. These measurements revealed 
that the microstructure was similar for the NS31 composite with one major difference, the pores were filled with silicon in NS31 and there were indications of carbon diffusion into the silicon and the formation of SiC. However, micro-cracks along material interfaces were still present in the NS31 material.

Table 1. Physical description of the NS31 and NB31 carbon fiber samples.

\begin{tabular}{|c|c|c|c|c|c|c|c|}
\hline \multirow{2}{*}{$\begin{array}{c}\text { Sample } \\
\text { ID }\end{array}$} & \multirow{2}{*}{$\begin{array}{l}\text { Mass } \\
(\mathrm{g})\end{array}$} & \multicolumn{3}{|c|}{ Physical Dimensions } & \multicolumn{2}{|c|}{ BET Analysis } & \multirow{2}{*}{$\begin{array}{c}\text { Ratio } \\
\text { SSA/SA }\end{array}$} \\
\hline & & $\begin{array}{l}\mathbf{L} \times \mathbf{W} \times \mathbf{T} \\
\quad(\mathrm{cm})\end{array}$ & $\left|\begin{array}{c}\text { Surface } \\
\text { Area }\left(\mathrm{cm}^{2}\right)\end{array}\right|$ & $\begin{array}{l}\text { Density } \\
(\mathrm{g} / \mathrm{cc})\end{array}$ & $\begin{array}{l}\text { Spec. Su } \\
\left(\mathbf{m}^{2} / \mathbf{g}\right)\end{array}$ & $\begin{array}{l}\text { Area } \\
\left(\mathbf{c m}^{2}\right)\end{array}$ & \\
\hline NS31-1 & 1.7103 & $2.497 \times 0.851 \times 0.370$ & 6.727 & 2.18 & 0.1549 & 2649.3 & 393.8 \\
\hline NS31-2 & 1.7025 & $2.496 \times 0.846 \times 0.383$ & 6.783 & 2.11 & 0.1309 & 2228.6 & 328.6 \\
\hline NS31-3 & 1.6493 & $2.496 \times 0.798 \times 0.389$ & 6.545 & 2.13 & 0.1477 & 2436.0 & 372.2 \\
\hline NS31-4 & 1.4798 & $2.474 \times 0.795 \times 0.359$ & 6.275 & 2.10 & 0.1361 & 2014.0 & 321.0 \\
\hline NS31-5 & 1.2894 & $2.527 \times 0.761 \times 0.323$ & 5.974 & 2.07 & 0.1306 & 1684.0 & 281.9 \\
\hline NS31-6 & 1.7875 & $2.521 \times 0.798 \times 0.417$ & 6.790 & 2.13 & 0.1187 & 2121.8 & 312.5 \\
\hline NS31-7 & 1.3953 & $2.482 \times 0.806 \times 0.322$ & 6.117 & 2.17 & 0.1390 & 1939.5 & 317.1 \\
\hline NS31-8 & 1.2441 & $2.499 \times 0.792 \times 0.298$ & 5.921 & 2.11 & 0.1540 & 1915.3 & 323.5 \\
\hline NS31-9 & 0.9857 & $2.496 \times 0.784 \times 0.234$ & 5.446 & 2.16 & 0.1887 & 1860.0 & 341.5 \\
\hline NB31-1 & 1.7790 & $2.455 \times 0.813 \times 0.448$ & 6.924 & 1.99 & 0.1526 & 2714.8 & 392.1 \\
\hline NB31-2 & 1.5394 & $2.481 \times 0.868 \times 0.367$ & 6.762 & 1.95 & 0.1460 & 2247.5 & 332.4 \\
\hline NB31-3 & 1.6751 & $2.481 \times 0.844 \times 0.411$ & 6.916 & 1.95 & 0.1356 & 2271.4 & 328.4 \\
\hline NB31-4 & 1.7989 & $2.500 \times 0.814 \times 0.456$ & 7.089 & 1.94 & 0.1609 & 2894.4 & 408.3 \\
\hline NB31-5 & 1.4295 & $2.490 \times 0.809 \times 0.362$ & 6.420 & 1.96 & 0.1483 & 2119.9 & 330.2 \\
\hline NB31-6 & 1.1714 & $2.458 \times 0.808 \times 0.301$ & 5.940 & 1.96 & 0.1497 & 1753.6 & 295.2 \\
\hline NB31-7 & 1.2779 & $2.455 \times 0.805 \times 0.329$ & 6.094 & 1.97 & 0.1436 & 1835.1 & 301.1 \\
\hline NB31-8 & 1.5032 & $2.456 \times 0.825 \times 0.375$ & 6.514 & 1.98 & 0.1275 & 1916.6 & 294.2 \\
\hline
\end{tabular}

\subsection{BET Specific Surface Area}

Specific surface areas were measured using a gas-adsorption method developed by Brunauer, Emmett and Teller, (BET), [6]. Extensive details of this measurement approach and application to other fusion-relevant materials are reported elsewhere $[7,8]$. However, for completeness, a description of the measurement and analysis approach is given here.

The instrument used for these measurements was a Micromeritics Model ASAP 2010 Accelerated Surface Area and Porosimetry system. The design of this system is based on the static volumetric method for determining the volume of gas adsorbed on a sample. For our measurements, $\mathrm{Kr}$ was used as the adsorptive gas and the adsorption measurements were made with the specimens at liquid nitrogen temperature $(77 \mathrm{~K})$. Typically, measurements were made for a relative pressure ranging from 0.02 to 0.5 , where the relative pressure, $\mathrm{P}_{\text {rel }}$, is defined as the actual adsorptive gas pressure, $\mathrm{P}$, divided by the saturation vapor pressure, $\mathrm{P}_{\mathrm{o}}$, for the adsorptive gas at the analysis 
temperature. $\mathrm{P}_{\mathrm{o}}$ for $\mathrm{Kr}$ is about 1.8 torr at liquid nitrogen temperature. Usually, twentyfive measurements of the gas adsorption isotherm were made over the designated pressure range using an automated analysis sequence that was controlled by the ASAP 2010 instrument computer.

A typical measurement sequence entailed the following steps.

(1) Prior to gas-adsorption analysis, the sample was degassed in its sample tube. This was done on the degas section of the ASAP 2010 instrument. During this step, the sample tube was evacuated to about 3 millitorr and the sample was heated to about $350^{\circ} \mathrm{C}$ for several hours until sample degassing stopped.

(2) After sample degassing, the sample tube was cooled to ambient temperature and backfilled with high purity $\mathrm{N}_{2}$.

(3) The sample tube was removed from the degas port and transferred to the analysis port of the instrument.

(4) The automated analysis sequence was initiated with the instrument control computer.

(5) Following termination of the analysis sequence, the sample tube was degassed at $350^{\circ} \mathrm{C}$ for one hour on the analysis port. The sample tube was allowed to cool to ambient temperature and a second automated analysis sequence was initiated.

(6) For some samples a third degas at $350^{\circ} \mathrm{C}$ for one hour on the analysis port was conducted. This was followed by a third automated analysis sequence.

The method used to analyze the adsorption isotherm data for a specimen is that proposed by Brunauer, Emmett and Teller [6], commonly referred to as the BET method. This method is incorporated in the instrument computer analysis software. According to this formalism, the adsorbed gas quantity is related to the relative pressure by Eq. (2).

Eq. (2) $\left[\mathrm{P}_{\text {rel }} /\left(\mathrm{V}_{\mathrm{a}}\left(1-\mathrm{P}_{\text {rel }}\right)\right)\right]=1 /\left(\mathrm{V}_{\mathrm{m}} \mathrm{C}\right)+\left[(\mathrm{C}-1) /\left(\mathrm{V}_{\mathrm{m}} \mathrm{C}\right)\right] \mathrm{P}_{\text {rel }}$

In this equation $\mathrm{P}_{\text {rel }}$ is defined as $\mathrm{P} / \mathrm{P}_{\mathrm{o}} ; \mathrm{V}_{\mathrm{a}}$ is the gas volume adsorbed at pressure $\mathrm{P} ; \mathrm{V}_{\mathrm{m}}$ is the adsorbed gas volume corresponding to monolayer coverage; and $\mathrm{C}$ is a thermodynamic function given by Eq. (3), with $\mathrm{q}_{1}$ equal to the first layer heat of adsorption and $\mathrm{q}_{\mathrm{L}}$ equal to the heat of liquefaction of the adsorptive.

$$
\text { Eq. (3) } \quad C \propto \exp \left(\mathrm{q}_{1}-\mathrm{q}_{\mathrm{L}}\right) / \mathrm{RT}
$$

To obtain the BET parameters $\mathrm{V}_{\mathrm{m}}$ and $\mathrm{C}$ that are relevant to surface-area determination for a test specimen, the gas adsorption data are first transformed by the expression $\left[\mathrm{P}_{\text {rel }} /\left(\mathrm{V}_{\mathrm{a}}\left(1-\mathrm{P}_{\text {rel }}\right)\right)\right]$. If the adsorption data satisfy the criteria for BET analysis, the 
transformed data are linear as a function of $\mathrm{P}_{\text {rel }}$, with the intercept, $\mathrm{y}_{\text {int }}$, and the slope, $\mathrm{S}$, given by Eqs. (4) and (5), respectively.

$$
\begin{aligned}
& \text { Eq. (4) } \quad \mathrm{y}_{\mathrm{int}}=1 /\left(\mathrm{V}_{\mathrm{m}} \mathrm{C}\right) \\
& \text { Eq. (5) } \mathrm{S}=(\mathrm{C}-1) /\left(\mathrm{V}_{\mathrm{m}} \mathrm{C}\right)
\end{aligned}
$$

Consequently, a linear fit is made to the transformed adsorption data to obtain the intercept and slope values from which $\mathrm{V}_{\mathrm{m}}$ and $\mathrm{C}$ can be easily derived. Using the value of $\mathrm{V}_{\mathrm{m}}$, the BET specific surface area, $\mathrm{SA}$, is derived using Eq. (6);

$$
\text { Eq. (6) } \mathrm{SA}=\mathrm{V}_{\mathrm{m}} \sigma \mathrm{N}_{\mathrm{A}} /\left(\mathrm{mV}_{\mathrm{o}}\right) \text {, }
$$

where $\sigma$ is the area occupied by a single adsorbed molecule; $\mathrm{N}_{\mathrm{A}}$ is Avogadro's number, $6.022 \times 10^{23}$ molecules per mole; $m$ is the sample mass in grams; and Vo, the ideal gas molar volume, is $22414 \mathrm{~cm}^{3} /$ mole. For analyses with $\mathrm{Kr}$ as the adsorptive gas, $\sigma$ is 0.21 $\mathrm{nm}^{2}$ and for $\mathrm{N}_{2}, \sigma$ is $0.162 \mathrm{~nm}^{2}$.

Results of the BET specific surface area analyses are summarized in Table 2. This table shows that multiple measurements were made for each of the test samples. For example, the sample identified as NS31-1 was measured three times corresponding to runs 1-3. The measured BET specific surface area of each sample increased with subsequent runs in an analysis sequence. These first run values are indicated in italic-print and are not included in the calculated average BET specific surface area for each sample type. Only the second and third measurement runs were included in the average values. The average specific surface area for each carbon fiber composite type is given by the bold-print numbers in the BET column along with the standard deviation of the average value.

In addition to the derived specific surface areas, Table 2 includes a tabulation of the parameters that were obtained from analysis of the gas-adsorption data, namely, the slope, Y-intercept, C, VM, and linear-fit correlation. These derived parameters, defined in previous paragraphs, provided the basis for computation of the BET specific surface areas using Eqs. 4-6.

Calibration of the Micromeritics ASAP 2010 instrument was checked routinely with a powdered alumina reference standard that was supplied by Micromeritics. Based on a multi-point BET analyses of $\mathrm{Kr}$ gas adsorption isotherm data, the specific surface area of this material was quoted as $0.48+/-0.03 \mathrm{~m}^{2} / \mathrm{g}$. Our calibration measurements were made both prior to and following the measurement series using a 1.1102-g sample of the alumina material. The sample tube configuration was identical for the calibration and test sample materials. Values of $0.457 \mathrm{~m}^{2} / \mathrm{g}$ and $0.471 \mathrm{~m}^{2} / \mathrm{g}$ were derived from the calibration measurements. These results are in agreement with the specification of the reference material. 
Table 2. BET surface analysis data using krypton as the adsorbent gas.

\begin{tabular}{|c|c|c|c|c|c|c|c|c|}
\hline $\begin{array}{c}\text { Sample } \\
\text { ID }\end{array}$ & $\begin{array}{l}\text { Mass } \\
\text { (g) }\end{array}$ & $\begin{array}{c}\text { BET SSA } \\
(\mathrm{m} 2 / \mathrm{g})\end{array}$ & $\begin{array}{c}\text { Slope } \\
(\mathrm{g} / \mathrm{cm} 3)\end{array}$ & $\begin{array}{c}\text { Y-Intercept } \\
(\mathrm{g} / \mathrm{cm} 3)\end{array}$ & $\mathrm{C}$ & $\begin{array}{c}\mathrm{VM} \\
(\mathrm{cm} 3 / \mathrm{g})\end{array}$ & $\begin{array}{c}\text { Correl. } \\
\text { Coeff. }\end{array}$ & $\begin{array}{l}\text { Data } \\
\text { Points }\end{array}$ \\
\hline NS31-1-1 & 1.7103 & 0.1047 & 55.1593 & -1.2832 & -41.984 & 0.0186 & 0.99935 & 13 \\
\hline NS31-1-2 & 1.7103 & 0.1504 & 37.6934 & -0.1843 & 203.493 & 0.0267 & 0.99980 & 11 \\
\hline NS31-1-3 & 1.7103 & 0.1594 & 35.3548 & 0.0449 & 798.155 & 0.0282 & 0.99954 & 13 \\
\hline NS31-2-1 & 1.7025 & 0.0787 & 75.0266 & -3.3204 & -21.595 & 0.0139 & 0.99834 & 12 \\
\hline NS31-2-2 & 1.7025 & 0.1183 & 47.9960 & -0.2878 & -165.743 & 0.0210 & 0.99936 & 10 \\
\hline NS31-2-3 & 1.7025 & 0.1434 & 39.3654 & -0.0193 & -2038.302 & 0.0254 & 0.99951 & 13 \\
\hline NS31-3-1 & 1.6493 & 0.0775 & 76.3717 & -3.5570 & -20.471 & 0.0137 & 0.99934 & 15 \\
\hline NS31-3-2 & 1.6493 & 0.1385 & 40.8335 & -0.0841 & -484.531 & 0.0245 & 0.99985 & 10 \\
\hline NS31-3-3 & 1.6493 & 0.1568 & 35.9816 & 0.0130 & 2764.179 & 0.0278 & 0.99987 & 11 \\
\hline NS31-4-1 & 1.4798 & 0.0776 & 74.9790 & -2.2990 & -31.613 & 0.0138 & 0.99900 & 10 \\
\hline NS31-4-2 & 1.4798 & 0.1301 & 43.4836 & -0.1003 & -432.660 & 0.0231 & 0.99974 & 11 \\
\hline NS31-4-3 & 1.4798 & 0.1421 & 39.8531 & -0.1371 & -289.749 & 0.0252 & 0.99985 & 11 \\
\hline NS31-5-1 & 1.2894 & 0.0676 & 87.9906 & -4.5101 & -18.510 & 0.0120 & 0.99851 & 11 \\
\hline NS31-5-2 & 1.2894 & 0.1263 & 44.6620 & 0.0008 & 54758.216 & 0.0224 & 0.99987 & 10 \\
\hline NS31-5-3 & 1.2894 & 0.1349 & 41.8656 & -0.0354 & -1183.242 & 0.0239 & 0.99990 & 10 \\
\hline NS31-6-1 & 1.7875 & 0.0570 & 103.7735 & -4.7667 & -20.771 & 0.0101 & 0.99808 & 10 \\
\hline NS31-6-2 & 1.7875 & 0.1187 & 47.6650 & -0.1239 & -383.583 & 0.0210 & 0.99975 & 11 \\
\hline NS31-7-1 & 1.3953 & 0.0719 & 82.8900 & -4.4190 & -17.758 & 0.0127 & 0.99825 & 12 \\
\hline NS31-7-2 & 1.3953 & 0.1390 & 40.9516 & -0.3452 & -117.639 & 0.0246 & 0.99976 & 9 \\
\hline NS31-8-1 & 1.2441 & 0.1110 & 51.1457 & -0.2869 & -177.296 & 0.0197 & 0.99955 & 9 \\
\hline NS31-8-2 & 1.2441 & 0.1503 & 37.6305 & -0.0953 & -393.975 & 0.0266 & 0.99986 & 11 \\
\hline NS31-8-3 & 1.2441 & 0.1576 & 35.8756 & -0.0626 & -572.243 & 0.0279 & 0.99988 & 9 \\
\hline NS31-9-1 & 0.9857 & 0.1626 & 34.6174 & 0.0854 & 406.382 & 0.0288 & 0.99995 & 10 \\
\hline NS31-9-2 & 0.9857 & 0.1837 & 30.8112 & -0.0921 & -333.618 & 0.0326 & 0.99998 & 8 \\
\hline NS31-9-3 & 0.9857 & 0.1937 & 29.1373 & -0.0115 & -2543.512 & 0.0343 & 0.99995 & 10 \\
\hline NS31 & Average & \multicolumn{2}{|c|}{$0.15+/-0.02$} & & & & & \\
\hline NB31-1-1 & 1.779 & 0.0910 & 63.5439 & -1.5304 & -40.520 & 0.0161 & 0.99827 & 11 \\
\hline NB31-1-2 & 1.779 & 0.1487 & 37.9884 & -0.0304 & -1247.288 & 0.0263 & 0.99979 & 11 \\
\hline NB31-1-3 & 1.779 & 0.1565 & 36.1167 & -0.0561 & -642.334 & 0.0277 & 0.99987 & 11 \\
\hline NB31-2-1 & 1.5394 & 0.0794 & 74.0301 & -2.9728 & -23.902 & 0.0141 & 0.99815 & 11 \\
\hline NB31-2-2 & 1.5394 & 0.1428 & 39.5095 & 0.0021 & 18860.621 & 0.0253 & 0.99978 & 10 \\
\hline NB31-2-3 & 1.5394 & 0.1492 & 37.8847 & -0.0527 & -717.270 & 0.0264 & 0.99988 & 10 \\
\hline NB31-3-1 & 1.6751 & 0.0851 & 70.0721 & -3.7308 & -17.782 & 0.0151 & 0.99824 & 11 \\
\hline NB31-3-2 & 1.6751 & 0.1356 & 41.9143 & -0.2882 & -144.433 & 0.0240 & 0.99963 & 10 \\
\hline NB31-4-1 & 1.7989 & 0.1431 & 39.4601 & -0.0289 & -1363.922 & 0.0254 & 0.99970 & 10 \\
\hline NB31-4-2 & 1.7989 & 0.1609 & 35.2940 & 0.2319 & -151.202 & 0.0285 & 0.99994 & 9 \\
\hline NB31-5-1 & 1.4295 & 0.0947 & 61.2975 & -1.6812 & -35.462 & 0.0168 & 0.99916 & 11 \\
\hline NB31-5-2 & 1.4295 & 0.1483 & 38.1116 & -0.0507 & -750.675 & 0.0263 & 0.99986 & 11 \\
\hline NB31-6-1 & 1.1714 & 0.0849 & 68.4275 & -1.9922 & -33.348 & 0.0151 & 0.99922 & 10 \\
\hline NB31-6-2 & 1.1714 & 0.1497 & 37.7493 & -0.0600 & 628.563 & 0.0265 & 0.99986 & 10 \\
\hline NB31-7-1 & 1.2779 & 0.0655 & 91.6411 & -5.5056 & -15.645 & 0.0116 & 0.99827 & 11 \\
\hline NB31-7-2 & 1.2779 & 0.1436 & 39.4944 & -0.2065 & -190.215 & 0.0255 & 0.99993 & 9 \\
\hline NB31-8-1 & 1.5032 & 0.0841 & 69.5349 & -2.4739 & -27.108 & 0.0149 & 0.99902 & 11 \\
\hline NB31-8-2 & 1.5032 & 0.1275 & 44.8564 & -0.5910 & -74.903 & 0.0226 & 0.99972 & 9 \\
\hline NB31 & Average & \multicolumn{2}{|c|}{$0.15+/-0.01$} & & & & & \\
\hline
\end{tabular}


We observe some variability in the BET values derived from the various runs for a specific sample. The measured specific surface area for a given sample increases with each subsequent run in an analysis sequence. The exact reason for this difference is not known but we suspect it relates to porosity of the CFC samples and to variation in the available gas adsorption sites, with the site availability a function of gas or air exposures and of bake-out conditions. Initial bake out of a sample was done for several hours at $350^{\circ} \mathrm{C}$ on the degas port of the instrument. Following the initial bake out, the sample tube was transferred to the analysis port for gas adsorption measurements and initial BET analyses. For the second and third runs of an analysis, the sample tube was not demounted from the analysis port of the instrument. Instead, it was pumped on and degassed at $350^{\circ} \mathrm{C}$ for 60 minutes prior to each subsequent analysis sequence. We note that the results from the second and third analyses are more consistent. This additional degassing of the sample during the analysis sequence may contribute to more consistent analysis conditions for the gas adsorption measurements.

Based on the analysis results in Table 2, we recommend the following average specific surface area values and relative uncertainties for the carbon fiber composite samples: $\mathrm{NS} 31,0.15+/-0.02 \mathrm{~m}^{2} / \mathrm{g}$; and NB31, $0.15+/-0.01 \mathrm{~m}^{2} / \mathrm{g}$. Estimation of the absolute uncertainties for these BET values should also include the uncertainty associated with the calibration reference material, namely, $6 \%$.

\subsection{Immersion Density Measurements}

Liquid immersion density measurements were made to obtain bulk densities and apparent porosities for materials. For our measurements we used water as the immersion fluid and added "photoflo" to decrease the surface tension. This approach is based on measuring the mass of a specimen under three conditions: dry, saturated with water, and immersed in water. The following steps were used to obtain reliable mass measurements for the three conditions.

(1) Dry each specimen by pumping on it in a vacuum desiccator overnight.

(2) Measure the dry mass after the specimen is removed from the vacuum desiccator.

(3) Saturate the specimen with water. Infiltration of the specimen pores with water required (a) removal of air from the pores by exposing the specimen to a vacuum, (b) immersing the specimen in water while under vacuum, (c) additional pumping on the specimen while immersed in water, and (d) pressurizing the water to ambient pressure to force liquid penetration into the specimen pores.

(4) Remove the specimen from the water vessel and transfer it to a microbalance hanger that is suspended in water. Measure the saturated mass while the specimen is immersed in water. 
(5) Remove the specimen from the hanger, quickly remove residual water from the specimen surface, and measure the saturated mass of the specimen by placing it on the dry pan of the microbalance.

A calibrated Mettler model AE100 microbalance (0.0001-g precision), equipped with an immersion density setup, was used for the mass measurements. A calibrated thermometer was used to measure the water temperature of the immersion bath on the microbalance setup.

The following equations were used to derive the bulk density, $\rho_{\mathrm{b}}$, the apparent or open porosity, $\mathrm{P}_{\mathrm{o}}$, and the apparent density, $\rho_{\mathrm{a}}$, from measurements of the dry mass, $\mathrm{M}_{\mathrm{d}}$, the saturated mass, $M_{s}$, the immersed saturated mass, $M_{i s}$, and the density of water, $\rho_{w}$.

$$
\begin{aligned}
& \text { Eq. (7) } \rho_{b}=\left[M_{d} /\left(M_{s}-M_{i s}\right)\right] \times \rho_{w} \\
& \text { Eq. (8) } \rho_{a}=\left[M_{d} /\left(M_{d}-M_{i s}\right)\right] \times \rho_{w} \\
& \text { Eq. (9) } \quad \text { Po }=\left[\left(M_{s}-M_{d}\right) /\left(M_{s}-M_{i s}\right)\right] \times 100 \%
\end{aligned}
$$

Results of the immersion-density measurements on the NS31 and NB31 carbon fiber composite samples are summarized in Table 3. This table shows that two measurements were made for each of the test samples. The results presented in Table 3 indicate that for the NS31 and NB31 test specimens the bulk density, open porosity, and apparent density values for each sample type vary somewhat from sample to sample. The apparent density corresponds to the material density minus that component of the sample volume that is open to water penetration. We acknowledge that use of water may not provide an absolute measurement of the graphite open porosity because pore size may limit the penetrability of the water into deep pores. The average bulk density, open porosity, and apparent density values for each carbon fiber composite type are given by the bold-print numbers along with the standard deviation and percent standard deviation. Based on our measurements presented in Table 3, we recommend the following average values for bulk density and open porosity for the test samples: NS31, $2.13+/-0.02 \mathrm{~g} / \mathrm{cc}$ density, $1.8 \%$ open porosity; and NB31, $1.95+/-0.1 \mathrm{~g} / \mathrm{cc}$ density, $6.2 \%$ open porosity. These density results are in excellent agreement with those based on physical measurements and on values provided with the material. 
Table 3. Density/porosity analysis from water-immersion, density measurements.

\begin{tabular}{|c|c|c|c|c|c|c|c|}
\hline $\begin{array}{c}\text { Sample } \\
\text { ID }\end{array}$ & $\begin{array}{c}\text { Mass } \\
\text { Dry } \\
\text { (g) }\end{array}$ & $\begin{array}{c}\text { Mass } \\
\text { Sat. Im. } \\
\text { (g) }\end{array}$ & $\begin{array}{c}\text { Mass } \\
\text { Sat. } \\
\text { (g) }\end{array}$ & $\begin{array}{c}\text { Density } \\
\text { Water } \\
\text { (g/cc) }\end{array}$ & $\begin{array}{c}\text { Bulk } \\
\text { Density } \\
\text { (g/cc) }\end{array}$ & $\begin{array}{c}\text { Open } \\
\text { Porosity } \\
\text { (\%) }\end{array}$ & $\begin{array}{c}\text { Appar. } \\
\text { Density } \\
\text { (g/cc) }\end{array}$ \\
\hline & & & & & & & \\
NS31-1-1 & 1.7100 & 0.9309 & 1.7272 & 0.9980 & 2.143 & 2.160 & 2.190 \\
NS31-1-2 & 1.7100 & 0.9298 & 1.7267 & 0.9978 & 2.141 & 2.096 & 2.187 \\
NS31-2-1 & 1.7024 & 0.9119 & 1.7143 & 0.9980 & 2.117 & 1.483 & 2.149 \\
NS31-2-2 & 1.7023 & 0.9118 & 1.7148 & 0.9978 & 2.115 & 1.557 & 2.149 \\
& & & & Average & $\mathbf{2 . 1 3}$ & $\mathbf{1 . 8}$ & $\mathbf{2 . 1 7}$ \\
& & & & STD & $\mathbf{0 . 0 2}$ & $\mathbf{0 . 4}$ & $\mathbf{0 . 0 2}$ \\
& & & & $\mathbf{\%}$ STD & $\mathbf{0 . 7}$ & $\mathbf{1 9}$ & $\mathbf{1 . 1}$ \\
NB31-1-1 & 1.7787 & 0.9253 & 1.8330 & 0.9980 & 1.956 & 5.982 & 2.080 \\
NB31-1-2 & 1.7788 & 0.9238 & 1.8302 & 0.9981 & 1.959 & 5.671 & 2.077 \\
NB31-2-1 & 1.5393 & 0.7986 & 1.5922 & 0.9982 & 1.936 & 6.666 & 2.074 \\
NB31-2-2 & 1.5392 & 0.7960 & 1.5890 & 0.9985 & 1.938 & 6.280 & 2.068 \\
& & & & Average & $\mathbf{1 . 9 5}$ & $\mathbf{6 . 2}$ & $\mathbf{2 . 0 8}$ \\
& & & & STD & $\mathbf{0 . 0 1}$ & $\mathbf{0 . 4}$ & $\mathbf{0 . 0 1}$ \\
& & & & $\mathbf{0}$ STD & $\mathbf{0 . 6}$ & $\mathbf{7}$ & $\mathbf{0 . 3}$ \\
\hline
\end{tabular}

\subsection{STEAM CHEMICAL REACTIVITY MEASUREMENTS}

\subsection{Steam Chemical Reactivity Experimental System}

Steam chemical reactivity measurements for carbon fiber composite samples were conducted with an experimental system that was originally developed for measuring both hydrogen generation rates and tritium mobilization rates for irradiated $\mathrm{Be}[9,10]$. As illustrated in Figure 1, the system comprises a flow-through, integrated assembly with components set up in an inert-gas glovebox and in a Class-A laboratory hood. An argon carrier gas sweeps elemental gases from the hot sample reaction chamber through a process line equipped with condensers, a cryotrap, and instrumentation for gas analyses. Steam introduced upstream from the sample furnace reacts with the hot specimen inside the quartz reaction chamber and is condensed in two Friedrich condensers downstream from the sample furnace. The argon carrier gas transports the reaction gases through the remaining system process line. Hydrogen generation rates are obtained from measurements with an on-line mass spectrometer that analyzes the gas composition in the system process line. For the experiments that are documented in this report, the tritium instrumentation was not used because no tritium measurements were required.

Typical system operating parameters include the following: line pressure (660-675 torr), Ar carrier-gas flow rate (100 std cc/min), steam flow rate $(2500 \mathrm{std}-\mathrm{cc} / \mathrm{min}$ for a water throughput of $2 \mathrm{cc} / \mathrm{min})$, and steam-generator temperature $\left(350^{\circ} \mathrm{C}\right)$. The reactionchamber tube furnace is operable from $25^{\circ} \mathrm{C}$ to $1200^{\circ} \mathrm{C}$. For these conditions, the system response time is about $6 \mathrm{~min}$. and the $\mathrm{H}_{2}$ detection sensitivity is about 3 ppm of $\mathrm{H}_{2}$ in Ar. For a steam reactivity experiment, a carbon fiber composite sample is fitted into a 
platinum wire harness which is then connected to a quartz rod assembly that is used to suspend the sample at the center of the reaction-chamber hot zone. Temperatures in the reaction chamber sample region are based on prior measurements with a Type-K thermocouple (TC) located at the sample position, and referenced to the tube furnace control TC temperature. Additional details concerning the performance of this experimental system are found in a previously published report [9] that serves as a Quality Assurance document for the chemical-reactivity measurements.

On-line analysis of the gas composition in the system process line was achieved by using a quadrupole mass spectrometer (QMS) and a precision sampling valve. Accurate determination of the quantities of gases generated or released in the system hinged on two factors: (1) accurate measurement of the pressure and flow rates in the process line and (2) calibration of the QMS and sampling valve setting for each experiment. Pressure measurements in the process line were made with a capacitance manometer and the atmospheric pressure was checked daily via consultation with the INEEL standards and calibration laboratory. Carrier gas flow rates were controlled with a calibrated mass flowmeter and they were checked prior to each experiment with the bubble-tube flow meter. Absolute calibration of the QMS/sampling valve for $\mathrm{H}_{2}$ was done using $\mathrm{Ar}-\mathrm{H}_{2}$ gas mixture standards in place of the high-purity argon carrier gas. Gas-mixture standards had $\mathrm{H}_{2}$ contents that varied from $50 \mathrm{ppm}$ to $959,248 \mathrm{ppm}$ to ensure a wide calibration range for the system. Absolute calibration of the $\mathrm{QMS} /$ sampling valve for $\mathrm{CO}$ was done using a $25.01 \% \mathrm{Ar}, 24.98 \% \mathrm{CO}, 24.99 \% \mathrm{He}$, and $25.01 \% \mathrm{H}_{2}$ primary calibration standard, while $\mathrm{CO}_{2}$ calibration was accomplished using a $25.05 \% \mathrm{Ar}, 24.98 \% \mathrm{CO}_{2}$, $24.98 \% \mathrm{He}$, and $24.99 \% \mathrm{H}_{2}$ primary calibration standard. Measured QMS mass peaks included mass- 2 for $\mathrm{H}_{2}$, mass-28 for $\mathrm{CO}$, mass- 40 for ${ }^{40} \mathrm{Ar}$, and mass- 44 for $\mathrm{CO}_{2}$. These measurements provided calibration curves relating mass- $2 /$ mass- 40 , mass- $28 /$ mass -40 , and mass-44/mass-40 peak-height ratios as a function of the $\mathrm{H}_{2}, \mathrm{CO}$, and $\mathrm{CO}_{2}$ concentrations in the Ar gas-mixture standards. Because of the wide range of calibration gas standards for $\mathrm{H}_{2}$ in Ar, calibration of the QMS was quite accurate, with estimated uncertainties of about $10 \%$ at the ppm $\mathrm{H}_{2}$ level and a few percent at the $10,000 \mathrm{ppm}_{2}$ level. Since only one calibration standard was used to calibrate the QMS/sampling valve for $\mathrm{CO}$ and $\mathrm{CO}_{2}$, the calibration of the QMS/sampling valve for $\mathrm{CO}$ and $\mathrm{CO}_{2}$ is not as accurate as it is for $\mathrm{H}_{2}$. All peak-height measurements were made relative to ${ }^{40} \mathrm{Ar}$, so relative trend data could be obtained for any gas species identified in the process stream. 


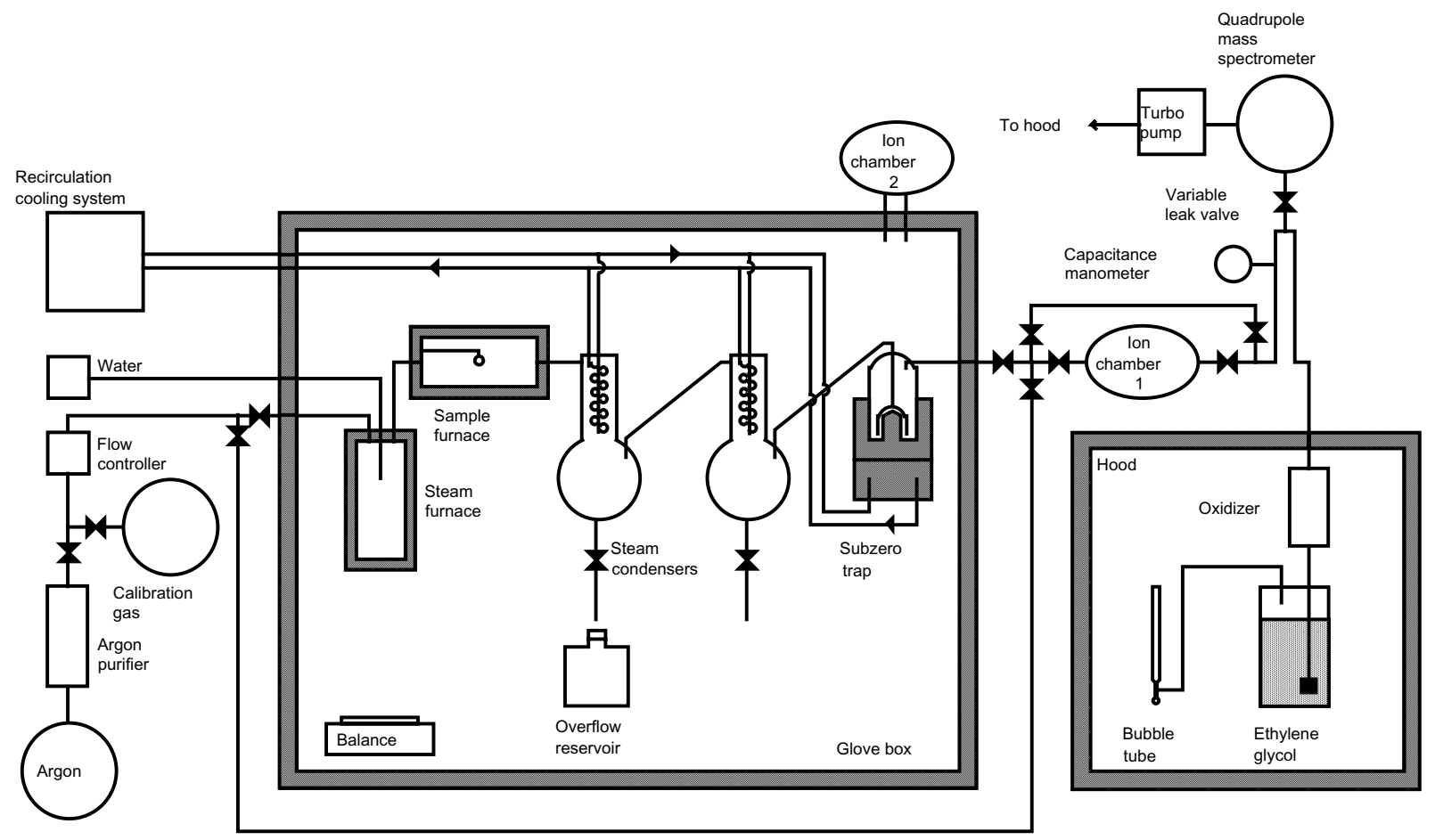

Figure 1. Schematic illustration of experimental system used in the steam reactivity tests for CFC specimens.

A computer-based, automated data acquisition system was used to acquire measurements with the QMS. Typically, the QMS was set to measure sequential mass spectra from 1$50 \mathrm{amu}$ in a histogram mode. A cycle time for a single mass spectrum was approximately $74 \mathrm{sec}$. Data were acquired as a function of elapsed time. Other parameters such as sample masses before and after a test, furnace temperatures, line pressures, carrier-gas flow rates, and selected QMS peak-heights were recorded in experiment logbooks.

Measurements with the QMS provided gas-concentration data as a function of elapsed time. Hence, these data provide kinetic information on $\mathrm{H}_{2}, \mathrm{CO}$, and $\mathrm{CO}_{2}$ generation rates. Integration of the QMS data yields the total quantities of $\mathrm{H}_{2}, \mathrm{CO}$, and $\mathrm{CO}_{2}$ generated. Measurements of the sample weight loss, taken to be a measure of the carbon consumed, provided a means of comparing the moles of carbon consumed to the moles of carbon released in the form of $\mathrm{CO}$ and $\mathrm{CO}_{2}$, provided the specific reaction mechanism is known and there is no weight loss due to spalling.

\subsection{Measurements and Results}

Steam chemical reactivity experiments were conducted for NS31 and NB31 carbon fiber composite samples at temperatures ranging from $800^{\circ} \mathrm{C}$ to $1100^{\circ} \mathrm{C}$. As described 
previously, each carbon fiber composite sample was connected with a platinum wire harness to a quartz rod assembly that was used to suspend the sample at the center of the reaction chamber hot zone. A summary of pertinent experimental parameters is given in Table 4. As shown in the first three columns of the table, each experiment is identified with a sample ID, a unique sample mass, and the test temperature for that sample. The fourth column lists the steam exposure times for each experiment. The steam exposure time corresponds to the time the water flow was on plus the time required to dry out the steam generator and reaction chamber. In most cases the dry-out time could be easily deduced from the mass-spectrometer $\mathrm{H}_{2}$ data. Column 5 lists the sample weight loss for each experiment, taken to be a measure of the carbon consumed resulting from the chemical reaction of steam with the carbon fiber composite sample. Column 6 lists the corresponding moles of carbon consumed, as derived from the weight-loss data. The total quantity of $\mathrm{H}_{2}$ generated during the experiments, as derived from the massspectrometer data, are listed in column 7 . Column 8 lists the corresponding moles of $\mathrm{H}_{2}$ generated, as derived from the mass-spectrometer data. Columns 9 and 10 list the total quantity of $\mathrm{CO}_{2}$ generated during the experiments, as derived from the mass-spectrometer data. The total quantity of $\mathrm{CO}$ generated during the experiments, as derived from the mass-spectrometer data, are listed in columns 11 and 12. The asterisks (*) in the $\mathrm{CO}_{2}$ and $\mathrm{CO}$ columns of Table 4 represent experiments in which electronic background noise prevented accurate $\mathrm{CO}_{2}$ and $\mathrm{CO}$ mass-spectrometer data from being obtained.

Table 4. Summary information for steam chemical reactivity experiments.

\begin{tabular}{|c|c|c|c|c|c|c|c|c|c|c|c|}
\hline \multirow{2}{*}{$\begin{array}{c}\text { Sample } \\
\text { ID }\end{array}$} & \multirow{2}{*}{$\begin{array}{c}\text { Mass } \\
\text { (g) }\end{array}$} & \multicolumn{2}{|c|}{ Steam exposure } & \multicolumn{2}{|c|}{ C Consumed } & \multicolumn{2}{|c|}{$\mathrm{H}_{2}$ Generated } & \multicolumn{2}{|c|}{$\mathrm{CO}_{2}$ Generated } & \multicolumn{2}{|c|}{ CO Generated } \\
\hline & & $\left({ }^{0} \mathrm{C}\right)$ & (min) & (g) & (moles) & (cc) & (moles) & (cc) & | (moles) & (cc) & (moles) \\
\hline NS31-3 & 1.6488 & 800 & 402 & 0.0040 & 3.33E-04 & 19.2 & $6.72 \mathrm{E}-04$ & $*$ & * & * & * \\
\hline NS31-9 & 0.9854 & 800 & 408 & 0.0029 & 2.42E-04 & 9.43 & $3.26 \mathrm{E}-04$ & 6.04 & $2.09 \mathrm{E}-04$ & 0.68 & $2.35 \mathrm{E}-05$ \\
\hline NS31-4 & 1.4794 & 900 & 342 & 0.0302 & $2.52 \mathrm{E}-03$ & 116.5 & $4.13 \mathrm{E}-03$ & * & $*$ & $*$ & * \\
\hline NS31-8 & 1.2436 & 900 & 345 & 0.0285 & $2.38 \mathrm{E}-03$ & 101.0 & $3.52 \mathrm{E}-03$ & 49.7 & $1.73 \mathrm{E}-03$ & 11.5 & $4.01 \mathrm{E}-04$ \\
\hline NS31-5 & 1.2892 & 1000 & 222 & 0.1575 & $1.31 \mathrm{E}-02$ & 524.1 & $1.83 \mathrm{E}-02$ & 221.9 & 7.74E-03 & 116.4 & 4.06E-03 \\
\hline NS31-6 & 1.7873 & 1100 & 102 & 0.5432 & $4.53 \mathrm{E}-02$ & 2219.7 & 7.69E-02 & 989.4 & 3.43E-02 & 263.5 & $9.13 \mathrm{E}-03$ \\
\hline NB31-3 & 1.6750 & 800 & 405 & 0.0012 & $1.00 \mathrm{E}-04$ & 2.61 & $9.12 \mathrm{E}-05$ & $*$ & * & * & * \\
\hline NB31-8 & 1.5024 & 800 & 407 & 0.0015 & $1.25 \mathrm{E}-04$ & 3.52 & $1.22 \mathrm{E}-04$ & 2.58 & 8.94E-05 & 0.22 & $7.62 \mathrm{E}-06$ \\
\hline NB31-4 & 1.7983 & 900 & 344 & 0.0347 & 2.89E-03 & 118.5 & 4.17E-03 & $*$ & $*$ & $*$ & * \\
\hline NB31-7 & 1.2774 & 900 & 347 & 0.0357 & $2.98 \mathrm{E}-03$ & 117.2 & $4.06 \mathrm{E}-03$ & 52.6 & $1.82 \mathrm{E}-03$ & 21.3 & $7.38 \mathrm{E}-04$ \\
\hline NB31-6 & 1.1711 & 1000 & 225 & 0.2875 & $2.40 \mathrm{E}-02$ & 1034.1 & $3.61 \mathrm{E}-02$ & 379.7 & $1.33 \mathrm{E}-02$ & 254.6 & $8.90 \mathrm{E}-03$ \\
\hline NB31-5 & 1.4290 & 1100 & 104 & 0.7864 & $6.55 \mathrm{E}-02$ & 3560.1 & $1.25 \mathrm{E}-01$ & 1457.8 & $5.13 \mathrm{E}-02$ & 605.8 & 2.13E-02 \\
\hline
\end{tabular}

*: Electronic background noise prevented accurate $\mathrm{CO}_{2}$ and $\mathrm{CO}$ data.

Following each experiment the carbon fiber composite samples and platinum wire harness were retrieved from the reaction chamber and then inspected and weighed. In general, there was no visible change in the appearance of the sample material tested at the lower temperatures. However following the $1100^{\circ} \mathrm{C}$ experiments the samples appeared to be slightly smaller as demonstrated by their loose fit in the platinum wire harnesses. 
As indicated previously by Eqs. 1a-1c, steam interactions with hot carbon can produce significant quantities of hydrogen. In order for the law of conservation of mass to be valid in these reactions the moles of carbon consumed must equal the moles of $\mathrm{CO}$ generated plus the moles of $\mathrm{CO}_{2}$ generated as given by Eq. (10).

$$
\text { Eq. (10) } \mathrm{C}_{\text {Consumed }}(\text { moles })=\mathrm{CO} \text { (moles) }+\mathrm{CO}_{2} \text { (moles) }
$$

A summary of the moles of carbon consumed and the moles of $\mathrm{CO}$ and $\mathrm{CO}_{2}$ generated is given in Table 5. As shown in the first three columns of the table, each experiment is identified with a sample ID, a unique sample mass, and the test temperature for that sample. The fourth column lists the moles of carbon consumed as derived from the weight loss data. Columns 5 and 6 lists the moles of $\mathrm{CO}_{2}$ and $\mathrm{CO}$ generated as derived from the mass spectrometer data. Column 7 lists the total moles of $\mathrm{CO}_{2}$ and $\mathrm{CO}$ generated during each experiment. The ratio of moles of carbon consumed to the total moles of $\mathrm{CO}_{2}$ and $\mathrm{CO}$ generated is listed in column 8.

Table 5. Comparison of the moles of carbon consumed to the moles of $\mathrm{CO}_{2}$ and $\mathrm{CO}$ generated.

\begin{tabular}{|c|c|c|c|c|c|c|c|}
\hline \multirow{2}{*}{$\begin{array}{c}\text { Sample } \\
\text { ID }\end{array}$} & \multirow{2}{*}{$\begin{array}{c}\text { Mass } \\
\text { (g) }\end{array}$} & \multirow{2}{*}{$\begin{array}{c}\text { Steam } \\
\text { Exposure } \\
\left({ }^{\circ} \mathrm{C}\right)\end{array}$} & \multirow{2}{*}{$\begin{array}{c}\text { Carbon } \\
\text { Consumed } \\
\text { (moles) }\end{array}$} & \multicolumn{3}{|c|}{ Gas Generated } & \multirow{2}{*}{$\begin{array}{c}\text { Ratio } \\
\mathrm{C} /\left(\mathrm{CO}_{2}+\mathrm{CO}\right)\end{array}$} \\
\hline & & & & $\begin{array}{c}\mathrm{CO}_{2} \\
\text { (moles) }\end{array}$ & $\begin{array}{c}\text { CO } \\
\text { (moles) }\end{array}$ & $\begin{array}{c}\mathrm{CO}_{2}+\mathrm{CO} \\
\text { (moles) }\end{array}$ & \\
\hline NS31-9 & 0.9854 & 800 & $2.42 \mathrm{E}-04$ & 2.09E-04 & $2.35 \mathrm{E}-05$ & 2.32E-04 & 1.04 \\
\hline NS31-8 & 1.2436 & 900 & $2.38 \mathrm{E}-03$ & $1.73 \mathrm{E}-03$ & $4.01 \mathrm{E}-04$ & $2.13 \mathrm{E}-03$ & 1.11 \\
\hline NS31-5 & 1.2892 & 1000 & $1.31 \mathrm{E}-02$ & $7.74 \mathrm{E}-03$ & $4.06 \mathrm{E}-03$ & $1.18 \mathrm{E}-02$ & 1.11 \\
\hline NS31-6 & 1.7873 & 1100 & $4.53 \mathrm{E}-02$ & $3.43 \mathrm{E}-02$ & $9.13 \mathrm{E}-03$ & 4.34E-02 & 1.04 \\
\hline NB31-8 & 1.5024 & 800 & $1.25 \mathrm{E}-04$ & 8.94E-05 & 7.62E-06 & $9.70 \mathrm{E}-05$ & 1.29 \\
\hline NB31-7 & 1.2774 & 900 & $2.98 \mathrm{E}-03$ & $1.82 \mathrm{E}-03$ & $7.38 \mathrm{E}-04$ & $2.56 \mathrm{E}-03$ & 1.16 \\
\hline NB31-6 & 1.1711 & 1000 & $2.40 \mathrm{E}-02$ & $1.33 \mathrm{E}-02$ & $8.90 \mathrm{E}-03$ & $2.22 \mathrm{E}-02$ & 1.08 \\
\hline NB31-5 & 1.4290 & 1100 & $6.55 \mathrm{E}-02$ & $5.13 \mathrm{E}-02$ & $2.13 \mathrm{E}-02$ & $7.26 \mathrm{E}-02$ & 0.90 \\
\hline
\end{tabular}

In general the agreement is quite good between the moles of carbon consumed and the total moles of $\mathrm{CO}_{2}$ and $\mathrm{CO}$ generated, as indicated by the ratio $\mathrm{C} /\left(\mathrm{CO}_{2}+\mathrm{CO}\right)$ of weightloss data to mass-spectrometer data in column eight of the table. The reasons for the discrepancies between the weight-loss and mass-spectrometer data are threefold: (1) inaccuracies associated with measuring very small mass differences with the precision balance, (2) inaccuracies associated with the $\mathrm{CO}_{2}$ and $\mathrm{CO}$ calibration of the massspectrometer, and (3) possible inaccuracies associated with a determination of the massspectrometer background. Uncertainty in the mass measurements is approximately $+/-0.1 \mathrm{mg}$. We believe that the moles of carbon consumed derived from the weight-loss data is generally more accurate than the moles of $\mathrm{CO}_{2}$ and $\mathrm{CO}$ derived from the massspectrometer data. The fact that the $\mathrm{C} /\left(\mathrm{CO}_{2}+\mathrm{CO}\right)$ ratios are near 1.0 indicates that the 
inaccuracies associated with our two point calibration curves for $\mathrm{CO}_{2}$ and $\mathrm{CO}$ and massspectrometer background issues are about $15 \%$ or less.

Equation (11) relates the moles of $\mathrm{H}_{2}$ generated in the carbon steam chemical reaction to the moles of $\mathrm{CO}$ and $\mathrm{CO}_{2}$ generated.

$$
\text { Eq. (11) } \mathrm{H}_{2} \text { (moles) }=\mathrm{CO} \text { (moles) }+2\left(\mathrm{CO}_{2}\right) \text { (moles) }
$$

A summary of the moles of $\mathrm{H}_{2}, \mathrm{CO}$, and $\mathrm{CO}_{2}$ generated in the steam chemical reactivity experiments is given in Table 6. As shown in the first three columns of the table, each experiment is identified with a sample ID, a unique sample mass, and the test temperature for that sample. Columns 4, 5 and 6 list the moles of $\mathrm{H}_{2}, \mathrm{CO}_{2}$, and $\mathrm{CO}$ generated as derived from the mass spectrometer data. Column 7 lists the total moles of $\left(2 \mathrm{CO}_{2}+\mathrm{CO}\right)$ generated during each experiment. The ratio of moles of $\mathrm{H}_{2}$ to the total moles of $\left(2 \mathrm{CO}_{2}+\mathrm{CO}\right)$ generated is listed in column 8 .

Table 6. Comparison of the moles of $\mathrm{H}_{2}, \mathrm{CO}_{2}$ and $\mathrm{CO}$ generated.

\begin{tabular}{|c|c|c|c|c|c|c|c|}
\hline \multirow{2}{*}{$\begin{array}{c}\text { Sample } \\
\text { ID }\end{array}$} & \multirow{2}{*}{$\begin{array}{l}\text { Mass } \\
\text { (g) }\end{array}$} & \multirow{2}{*}{$\begin{array}{c}\text { Steam } \\
\text { Exposure } \\
\left({ }^{\circ} \mathrm{C}\right)\end{array}$} & \multicolumn{3}{|c|}{ Gas Generated } & \multirow[b]{2}{*}{$\begin{array}{c}2 \mathrm{CO}_{2}+\mathrm{CO} \\
\text { (moles) }\end{array}$} & \multirow{2}{*}{$\begin{array}{c}\text { Ratio } \\
\mathrm{H}_{2} /\left(2 \mathrm{CO}_{2}+\mathrm{CO}\right)\end{array}$} \\
\hline & & & $\begin{array}{c}\mathbf{H}_{2} \\
\text { (moles) }\end{array}$ & $\begin{array}{c}\mathrm{CO}_{2} \\
\text { (moles) }\end{array}$ & $\begin{array}{c}\text { CO } \\
\text { (moles) }\end{array}$ & & \\
\hline NS31-9 & 0.9854 & 800 & $3.26 \mathrm{E}-04$ & 2.09E-04 & $2.35 \mathrm{E}-05$ & $4.41 \mathrm{E}-04$ & 0.74 \\
\hline NS31-8 & 1.2436 & 900 & $3.52 \mathrm{E}-03$ & $1.73 \mathrm{E}-03$ & $4.01 \mathrm{E}-04$ & $3.87 \mathrm{E}-03$ & 0.91 \\
\hline NS31-5 & 1.2892 & 1000 & $1.83 \mathrm{E}-02$ & 7.74E-03 & $4.06 \mathrm{E}-03$ & $1.96 \mathrm{E}-02$ & 0.94 \\
\hline NS31-6 & 1.7873 & 1100 & 7.69E-02 & $3.43 \mathrm{E}-02$ & $9.13 \mathrm{E}-03$ & 7.77E-02 & 0.99 \\
\hline NB31-8 & 1.5024 & 800 & $1.22 \mathrm{E}-04$ & $8.94 \mathrm{E}-05$ & 7.62E-06 & 1.86E-04 & 0.65 \\
\hline NB31-7 & 1.2774 & 900 & $4.06 \mathrm{E}-03$ & $1.82 \mathrm{E}-03$ & 7.38E-04 & 4.38E-03 & 0.93 \\
\hline NB31-6 & 1.1711 & 1000 & $3.61 \mathrm{E}-02$ & $1.33 \mathrm{E}-02$ & 8.90E-03 & $3.54 \mathrm{E}-02$ & 1.02 \\
\hline NB31-5 & 1.4290 & 1100 & $1.25 \mathrm{E}-01$ & 5.13E-02 & $2.13 \mathrm{E}-02$ & $1.24 \mathrm{E}-01$ & 1.01 \\
\hline
\end{tabular}

At the higher test temperatures (above $800^{\circ} \mathrm{C}$ ) the agreement is quite good between the moles of $\mathrm{H}_{2}$ generated and the total moles of $2 \mathrm{CO}_{2}+\mathrm{CO}$ generated, as indicated by the ratio $\mathrm{H}_{2} /\left(2 \mathrm{CO}_{2}+\mathrm{CO}\right)$ in column eight of the table. Discrepancies between the $\mathrm{H}_{2}$ and $\left(2 \mathrm{CO}_{2}+\mathrm{CO}\right)$ mass-spectrometer data are greatest at the lower test temperatures and smallest at the higher temperatures. The reasons for the discrepancies are twofold: (1) inaccuracies associated with the $\mathrm{H}_{2}, \mathrm{CO}_{2}$, and $\mathrm{CO}$ calibration of the mass-spectrometer, and (2) possible inaccuracies associated with a determination of the mass-spectrometer background. Since a number of $\mathrm{Ar}-\mathrm{H}_{2}$ primary calibration standards were used to calibrate the QMS/sampling valve for $\mathrm{H}_{2}$ and only one calibration standard was used to calibrate the QMS/sampling valve for $\mathrm{CO}$ and $\mathrm{CO}_{2}$, we believe that the calibration of the QMS/sampling valve for $\mathrm{H}_{2}$ is more accurate than it is for $\mathrm{CO}$ and $\mathrm{CO}_{2}$. The fact that the $\mathrm{H}_{2} /\left(2 \mathrm{CO}_{2}+\mathrm{CO}\right)$ ratios are near 1.0 at the higher temperatures indicates that the discrepancies at the lower test temperatures are most likely due to inaccuracies associated with a determination of the mass-spectrometer background. 
Graphical presentations of the $\mathrm{H}_{2}, \mathrm{CO}_{2}$, and $\mathrm{CO}$ generation data that were derived from measurements with the on-line mass-spectrometer are given in Figures 2 to 29. Each figure is identified by a title that contains the sample type, a unique sample mass, and the test temperature for that sample. For each experiment the $\mathrm{H}_{2}$ generation data is presented first, followed by the $\mathrm{CO}_{2}$ and $\mathrm{CO}$ generation data. The figures are comprised of two parts, an upper graph labeled (a), and a lower graph labeled (b). Part (a) displays either the $\mathrm{H}_{2}, \mathrm{CO}_{2}$, or $\mathrm{CO}$ concentration in the process stream as a function of elapsed time both in terms of peak-height ratios relative to mass 40 and in ppm. Part (b) of each figure displays either the observed $\mathrm{H}_{2}, \mathrm{CO}_{2}$, or $\mathrm{CO}$ generation data as generation rates in units of sccm (standard cc/minute) and as cumulative quantities in units of std cc (standard cc), both plotted as a function of elapsed time, where time zero corresponds to the time that the steam exposure was initiated. Termination of the steam exposure corresponds approximately to the time when the $\mathrm{H}_{2}, \mathrm{CO}_{2}$, or $\mathrm{CO}$ signal rises slightly and then begins to drop off more rapidly. It should be noted that the derived results that are plotted as $\mathrm{H}_{2}$, $\mathrm{CO}_{2}$, or $\mathrm{CO}$ generation rates in part (b) of the figures can be interpreted only in an approximate sense as "generation rates". This interpretation is approximate because the experimental system has an intrinsic time response that depends on the system internal volume, the carrier gas flow rate and the $\mathrm{H}_{2}, \mathrm{CO}_{2}$, and $\mathrm{CO}$ generation rates. If the actual $\mathrm{H}_{2}, \mathrm{CO}_{2}$, and $\mathrm{CO}$ generation rates are much less than the carrier-gas flow rate, usually the case for the lower temperature experiments, then the derived values do provide a reasonable kinetic picture of the steam-metal chemical reaction rate. However, if the actual $\mathrm{H}_{2}, \mathrm{CO}_{2}$, and $\mathrm{CO}$ generation rates are comparable to the carrier gas flow rate, as is the case for the $\mathrm{NB} 31$ at $1100^{\circ} \mathrm{C}$ test, then the derived $\mathrm{H}_{2}, \mathrm{CO}_{2}$, and $\mathrm{CO}$ generation values do not represent an accurate kinetic picture of the carbon steam reaction. These latter data can, however, be translated into an accurate kinetic picture by unfolding the time response of the system. This was not done for the results presented here. In general though, computation of the cumulative $\mathrm{H}_{2}, \mathrm{CO}_{2}$, and $\mathrm{CO}$ quantities by integration of the mass-spectrometer generation data provides an accurate means to obtain the total quantities of $\mathrm{H}_{2}, \mathrm{CO}_{2}$, and $\mathrm{CO}$ generated in a carbon steam chemical reactivity experiment.

Figures 2-15 present the mass-spectrometer results for the NS31 carbon fiber composite samples tested from $800^{\circ} \mathrm{C}$ to $1100^{\circ} \mathrm{C}$. A small amount of electronic background noise was present in most of the experiments conducted on the NS31 carbon fiber composite samples. The electronic background noise primarily affected the mass 40 and mass 44 peaks and its overall effect on the mass spectrometer data was minimized utilizing a 5-point average smoothing technique. We believe that the electronic background rate had little effect on the large $\mathrm{H}_{2}, \mathrm{CO}_{2}$, and $\mathrm{CO}$ generation rates measured at the $1000^{\circ} \mathrm{C}$ (Figures 10-12) and $1100^{\circ} \mathrm{C}$ (Figures 13-15) test temperatures. Only at the lowest test temperature experiments of $800^{\circ} \mathrm{C}$ (Figure 2) and $900^{\circ} \mathrm{C}$ (Figure 6), where the $\mathrm{CO}_{2}$ and $\mathrm{CO}$ generation rates were small, did the electronic background noise prevent accurate $\mathrm{CO}_{2}$ and $\mathrm{CO}$ mass spectrometer data from being obtained. Eventually the electronic background noise was traced to a corrupted output of a power conditioner and the $800^{\circ} \mathrm{C}$ and $900^{\circ} \mathrm{C}$ experiments were repeated. Figures 3-5 and Figures 7-9 present the massspectrometer analysis for the second $800^{\circ} \mathrm{C}$ and $900^{\circ} \mathrm{C}$ experiments respectively. 
The $800^{\circ}$ to $1100^{\circ} \mathrm{C}$ steam chemical reactivity experiments on the NS31 carbon fiber composite samples show $\mathrm{H}_{2}, \mathrm{CO}_{2}$, and $\mathrm{CO}$ generation rates that are primarily dependent on the test temperature. At a test temperature of $800^{\circ} \mathrm{C}$, the $\mathrm{H}_{2}$ and $\mathrm{CO}_{2}$ generation rates appear to increase slowly with cumulative steam exposure time. For 900 and $1000^{\circ} \mathrm{C}$, the $\mathrm{H}_{2}$ and $\mathrm{CO}_{2}$ generation rates increase to relatively constant values that continue until steam exposure is terminated. For 800 to $1000^{\circ} \mathrm{C}$, the $\mathrm{CO}$ generation rates increase with steam exposure time and do not reduce in value until steam exposure is terminated. For the NS31 sample tested at $1100^{\circ} \mathrm{C}$, (Figures 13-14) the $\mathrm{H}_{2}$ and $\mathrm{CO}_{2}$ generation rates rise to relatively constant values before they fall off as the sample mass and surface area decrease because of sample consumption. Approximately $30 \%$ of the sample by mass was consumed in this test and $12 \%$ of the sample was consumed in the test at $1000^{\circ} \mathrm{C}$. For the test at $1100^{\circ} \mathrm{C}$, the $\mathrm{CO}$ generation rates increase with exposure time and experience a fall off as the sample is consumed.

Figures 16-29 present the mass-spectrometer results for the NB31 carbon fiber composite samples tested from $800^{\circ} \mathrm{C}$ to $1100^{\circ} \mathrm{C}$. Again, electronic background noise was present in most of the experiments conducted on the NB31 carbon fiber composite samples. As before, the electronic background noise primarily affected the mass 40 and mass 44 peaks and its overall effect on the mass spectrometer data was minimized utilizing a 5-point average smoothing technique. The electronic background rate had little effect on the large $\mathrm{H}_{2}, \mathrm{CO}_{2}$, and $\mathrm{CO}$ generation rates measured at the $1000^{\circ} \mathrm{C}$ (Figures $24-26$ ) and $1100^{\circ} \mathrm{C}$ (Figures $27-29$ ) test temperatures. Only at the lowest test temperatures of $800^{\circ} \mathrm{C}$ (Figure 16) and $900^{\circ} \mathrm{C}$ (Figure 20), where the $\mathrm{CO}_{2}$ and $\mathrm{CO}$ generation rates were small, did the electronic background noise prevent accurate $\mathrm{CO}_{2}$ and $\mathrm{CO}$ mass spectrometer data from being obtained. Eventually the electronic background noise was eliminated and the $800^{\circ} \mathrm{C}$ and $900^{\circ} \mathrm{C}$ experiments were repeated. Figures 17-19 and Figures 21-23 present the mass-spectrometer analysis for the second $800^{\circ} \mathrm{C}$ and $900^{\circ} \mathrm{C}$ experiments respectively.

The $800^{\circ}$ to $1100^{\circ} \mathrm{C}$ steam chemical reactivity experiments on the NB31 carbon fiber composite samples show $\mathrm{H}_{2}, \mathrm{CO}_{2}$, and $\mathrm{CO}$ generation rates that are primarily dependent on the test temperature. The $\mathrm{H}_{2}$ and $\mathrm{CO}_{2}$ generation rate curves for NB31 at 800 to $1000^{\circ} \mathrm{C}$ were slightly different from those for NS31 at these temperatures. At $800^{\circ} \mathrm{C}$, the $\mathrm{H}_{2}$ and $\mathrm{CO}_{2}$ generation rates were low, with very small increases in values as the steam exposure increased. For $900^{\circ} \mathrm{C}$, the $\mathrm{H}_{2}$ and $\mathrm{CO}_{2}$ generation rates increased steadily throughout the steam exposure time and fell off after termination of steam exposure. $\mathrm{H}_{2}$ and $\mathrm{CO}_{2}$ generation rate profiles for $\mathrm{NB} 31$ at 1000 and $1100^{\circ} \mathrm{C}$ test temperatures were similar to those for NS31 at these temperatures. CO generation rate profiles for NB31 exposed to steam at 900 to $1100^{\circ} \mathrm{C}$ were similar to those for NS31. Approximately $55 \%$ of the NB31 sample was consumed at $1100^{\circ} \mathrm{C}$ and $24 \%$ was consumed in the $1000^{\circ} \mathrm{C}$ test. 

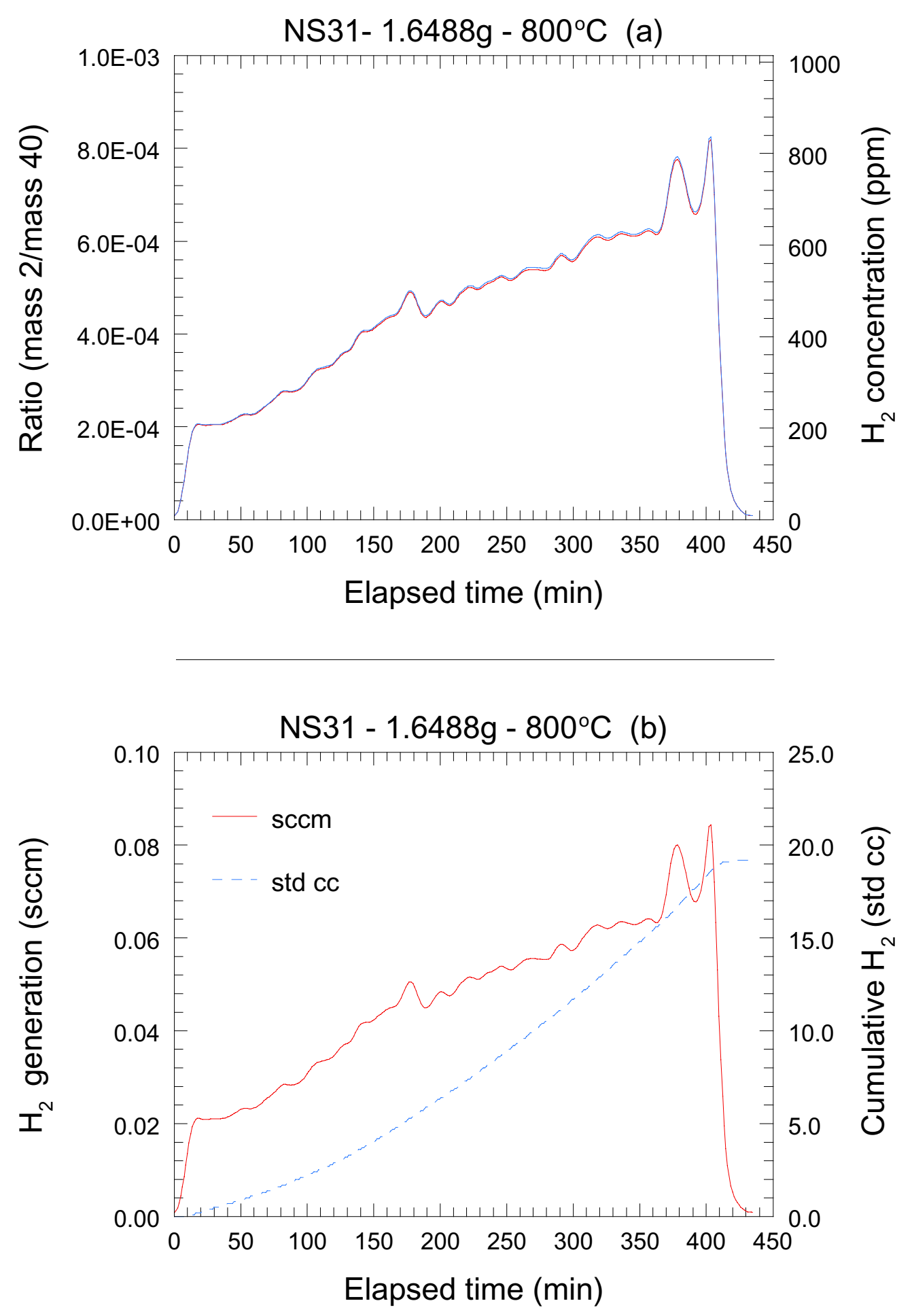

Figure 2. Results of mass-spectrometer analysis for $\mathrm{H}_{2}$ generation from NS31-3 exposed to steam at $800^{\circ} \mathrm{C}$. Electronic background noise prevented accurate $\mathrm{CO}_{2}$ and $\mathrm{CO}$ massspectrometer data from being obtained from this experiment. 

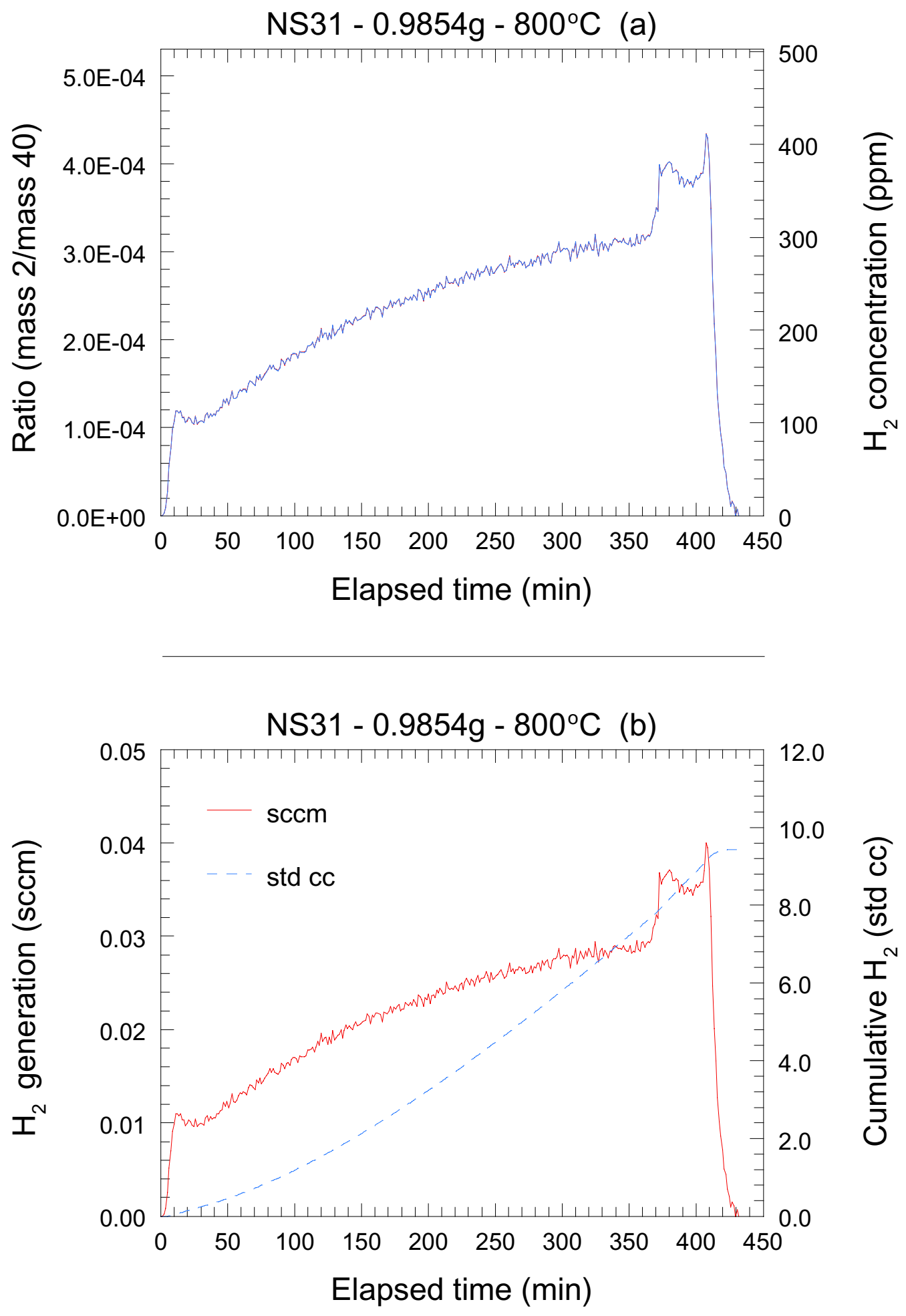

Figure 3. Results of mass-spectrometer analysis for $\mathrm{H}_{2}$ generation from NS31-9 exposed to steam at $800^{\circ} \mathrm{C}$. 

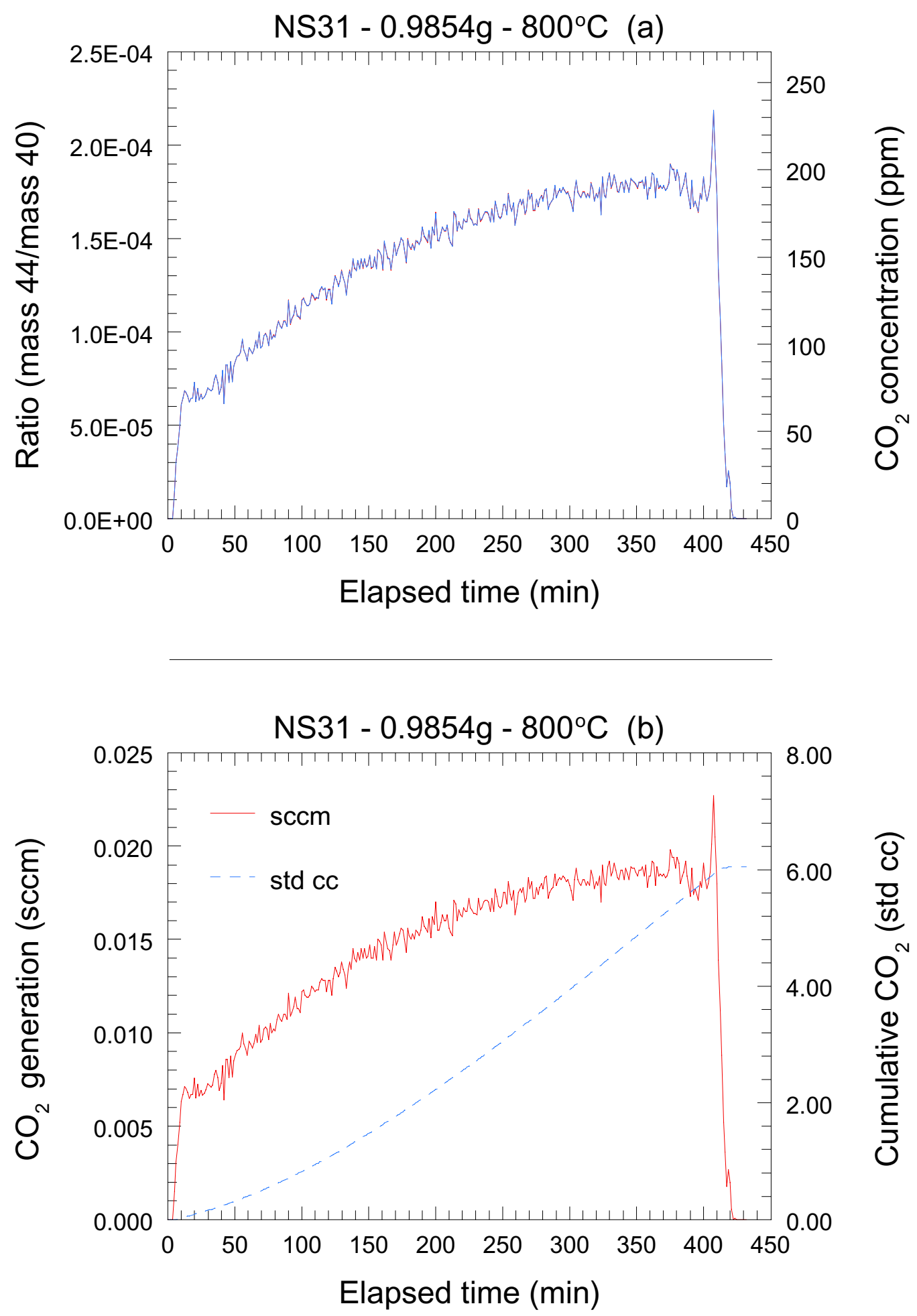

Figure 4. Results of mass-spectrometer analysis for $\mathrm{CO}_{2}$ generation from NS31-9 exposed to steam at $800^{\circ} \mathrm{C}$. 

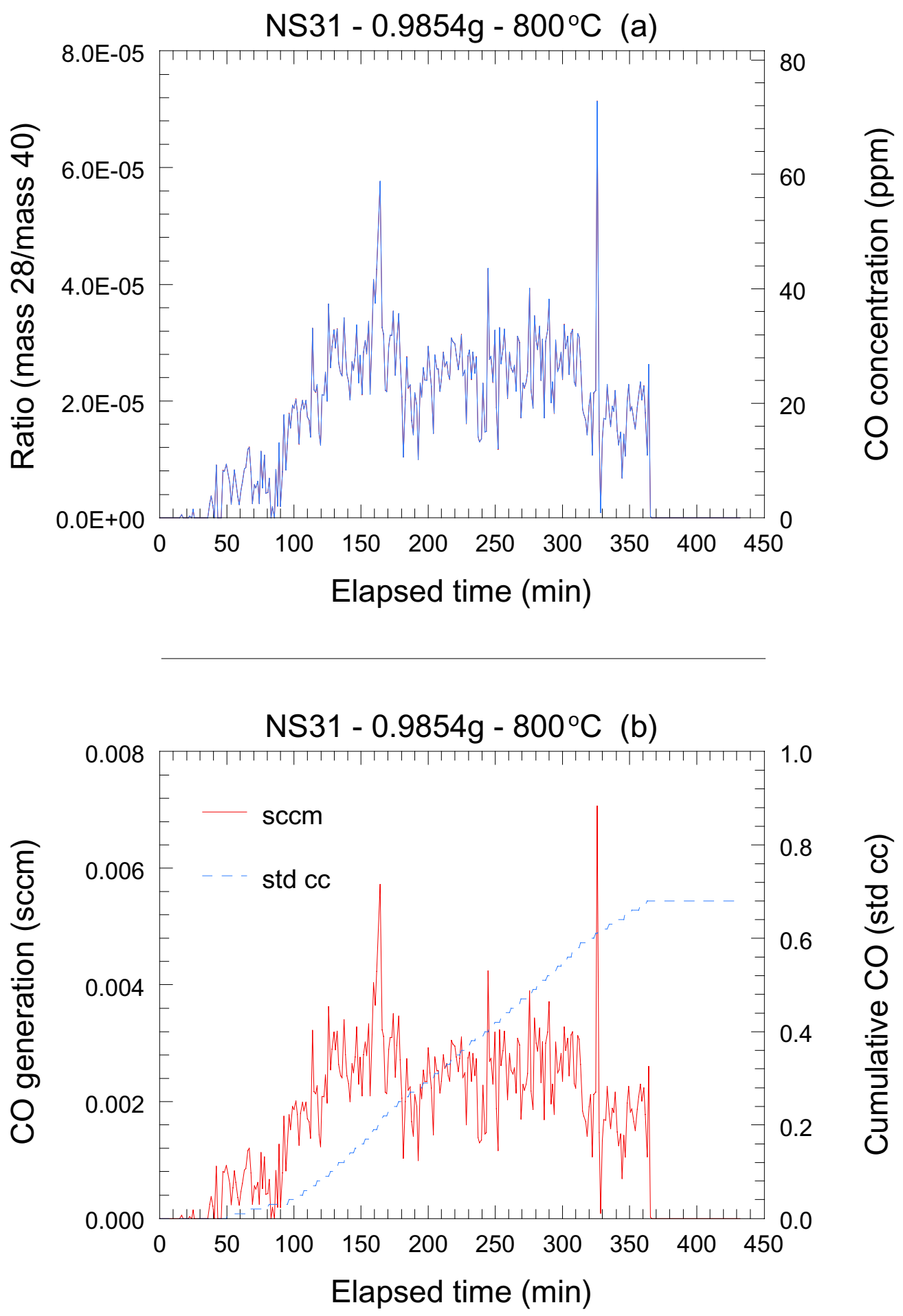

Figure 5. Results of mass-spectrometer analysis for CO generation from NS31-9 exposed to steam at $800^{\circ} \mathrm{C}$. 

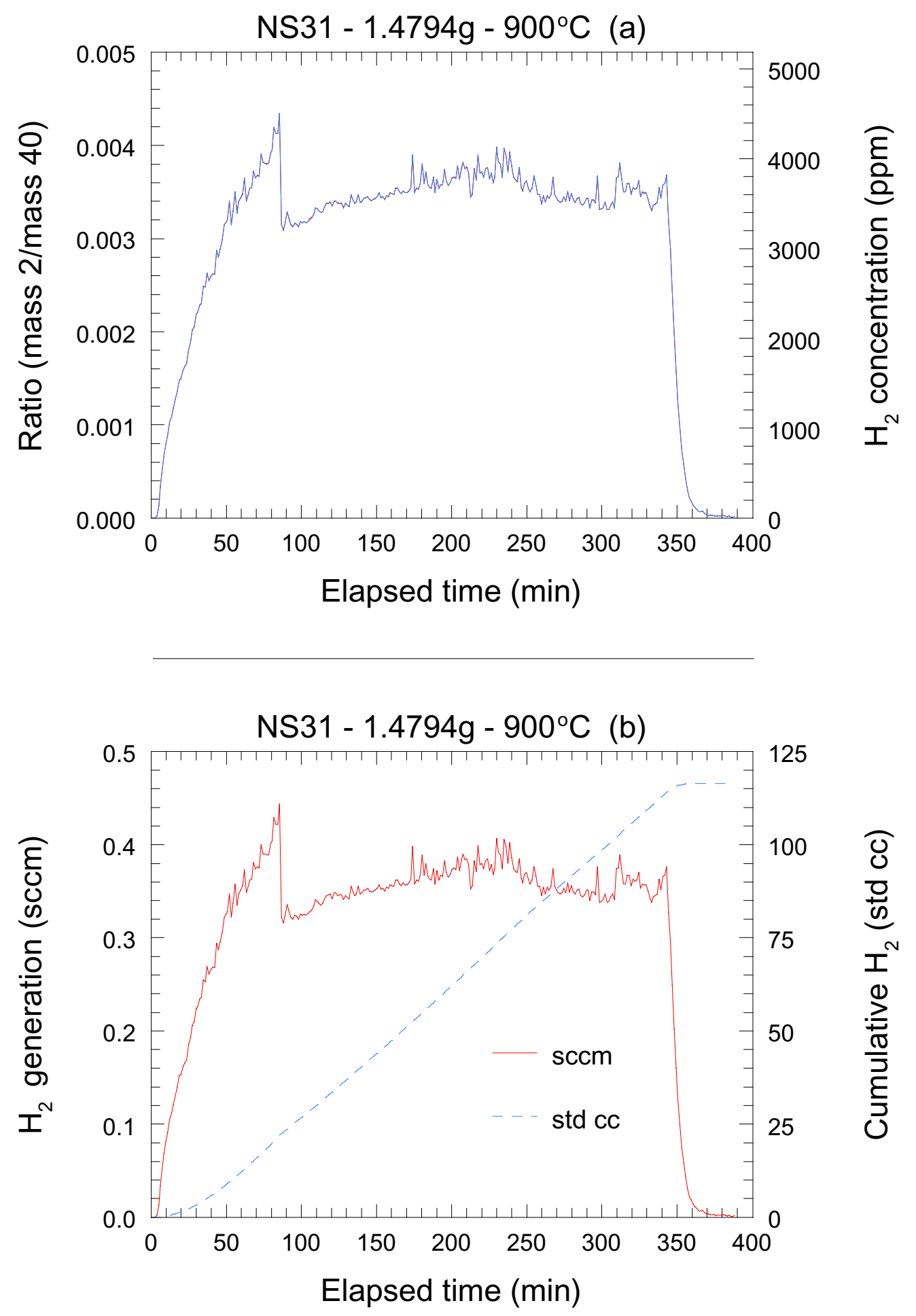

Figure 6. Results of mass-spectrometer analysis for $\mathrm{H}_{2}$ generation from NS31-4 exposed to steam at $900^{\circ} \mathrm{C}$. The spike is the result of a temporary decrease in the mass 40 signal. Electronic background noise prevented accurate $\mathrm{CO}_{2}$ and $\mathrm{CO}$ mass-spectrometer data from being obtained from this experiment. 

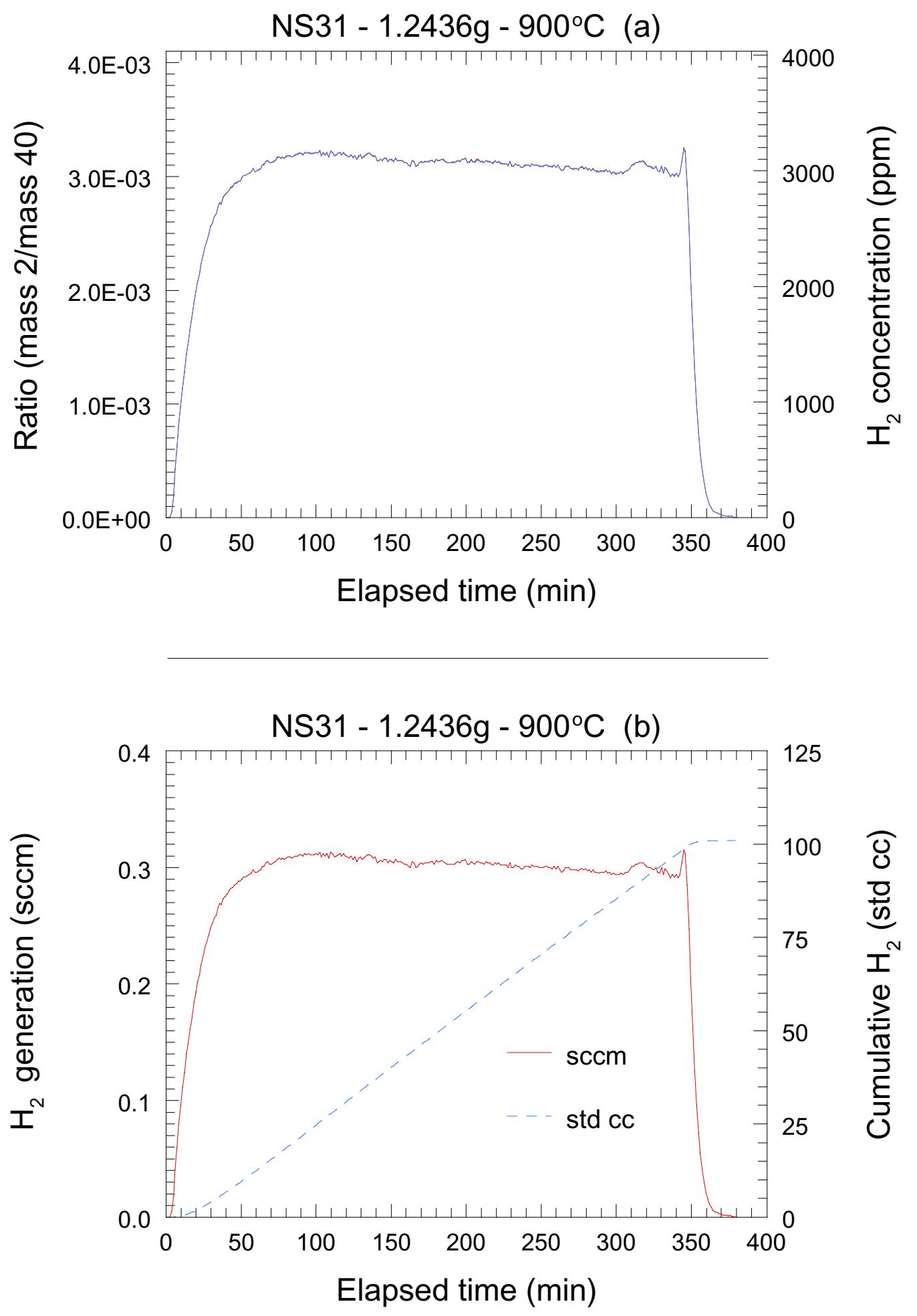

Figure 7. Results of mass-spectrometer analysis for $\mathrm{H}_{2}$ generation from NS31-8 exposed to steam at $900^{\circ} \mathrm{C}$. 

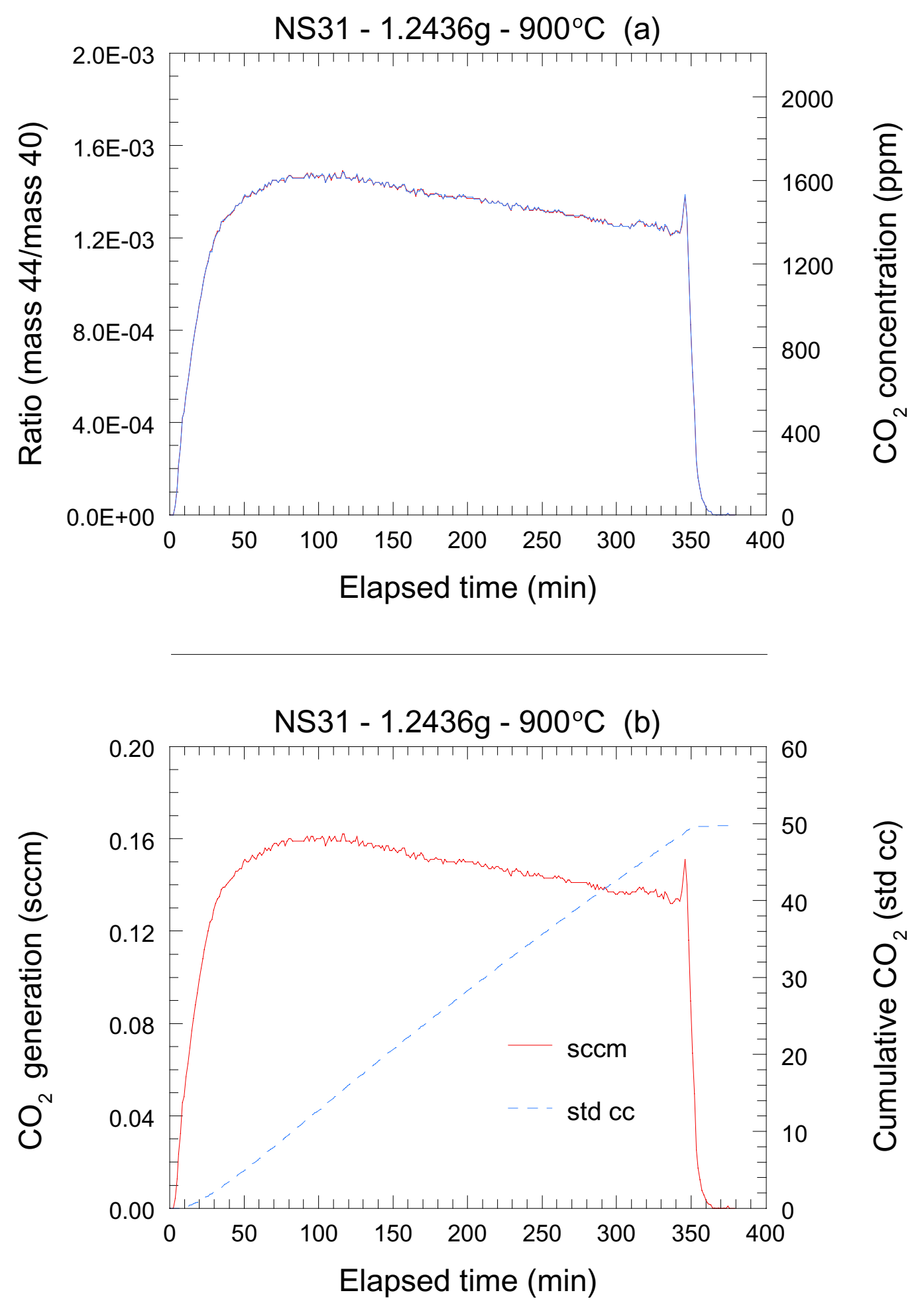

Figure 8. Results of mass-spectrometer analysis for $\mathrm{CO}_{2}$ generation from NS31-8 exposed to steam at $900^{\circ} \mathrm{C}$. 

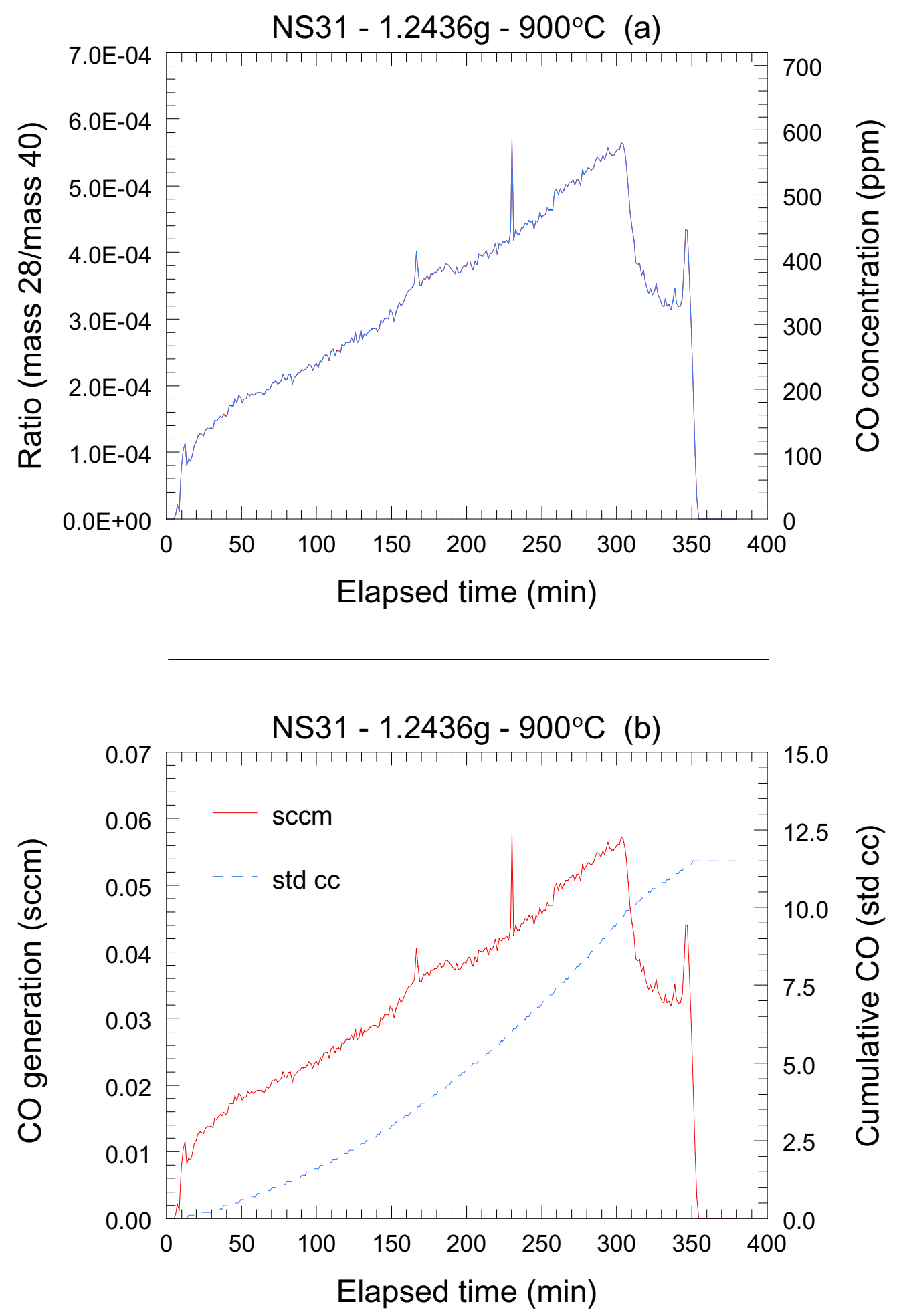

Figure 9. Results of mass-spectrometer analysis for CO generation from NS31-8 exposed to steam at $900^{\circ} \mathrm{C}$. 

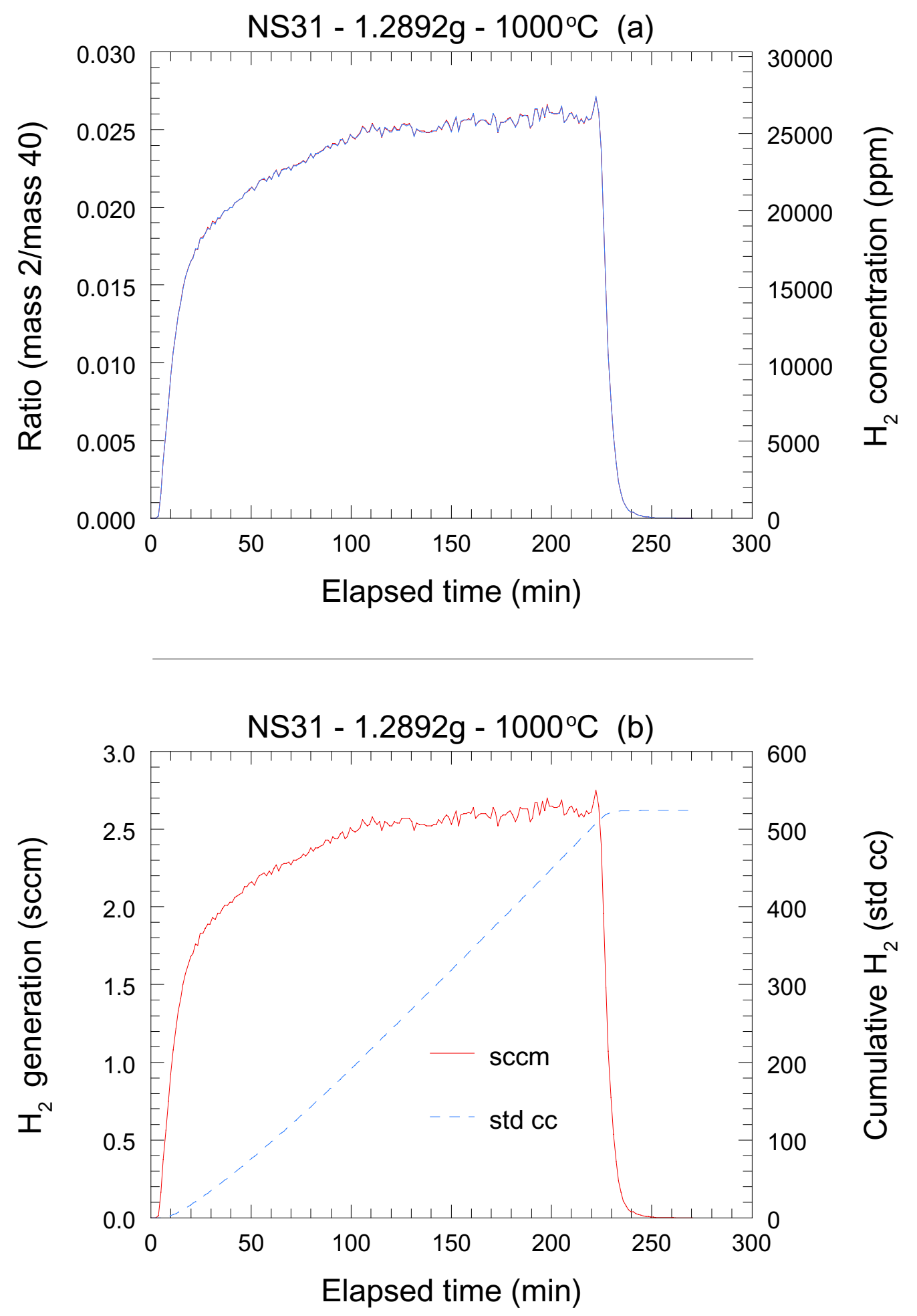

Figure 10. Results of mass-spectrometer analysis for $\mathrm{H}_{2}$ generation from NS31-5 exposed to steam at $1000^{\circ} \mathrm{C}$. 

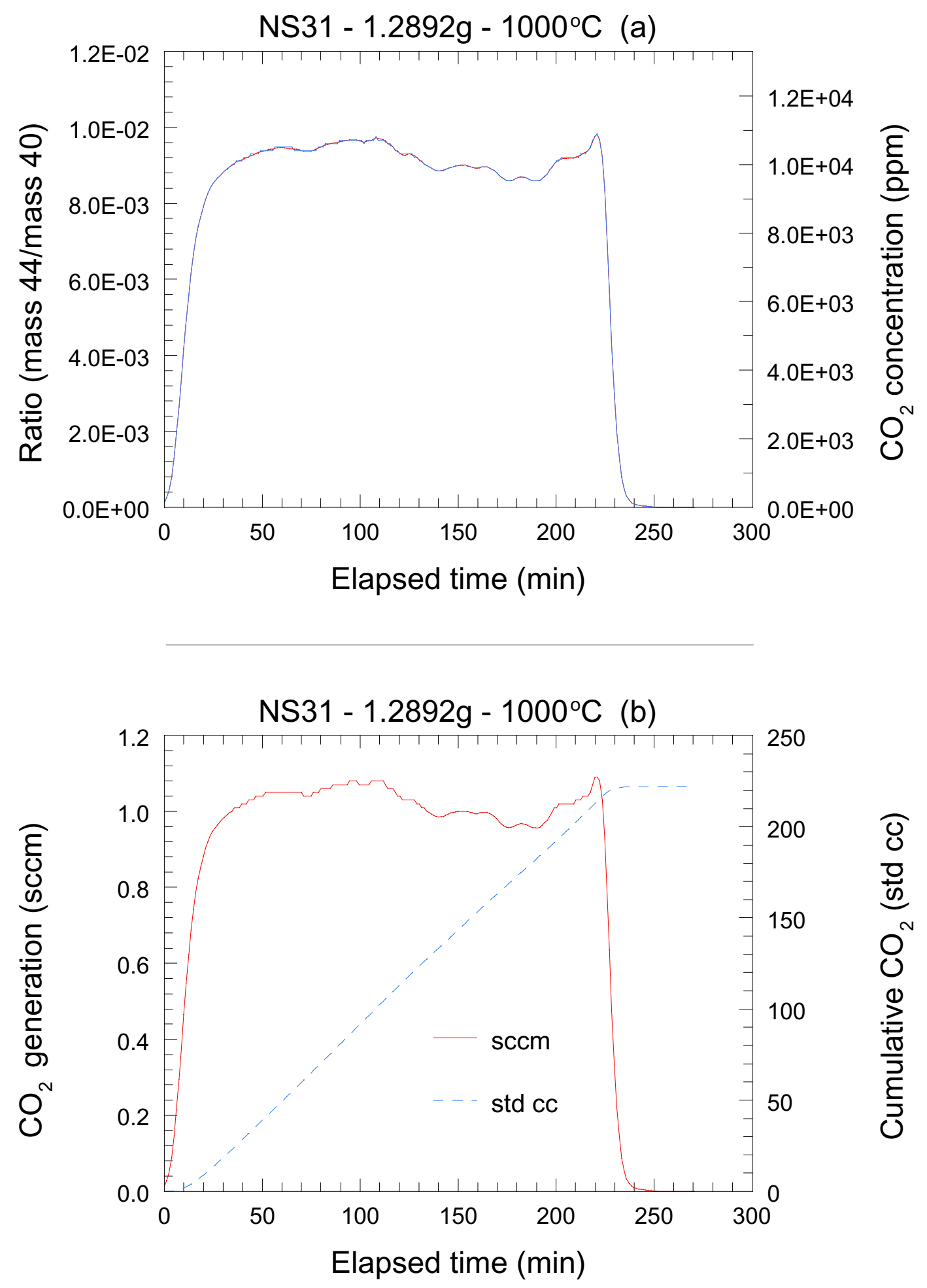

Figure 11. Results of mass-spectrometer analysis for $\mathrm{CO}_{2}$ generation from NS31-5 exposure to steam at $1000^{\circ} \mathrm{C}$. 

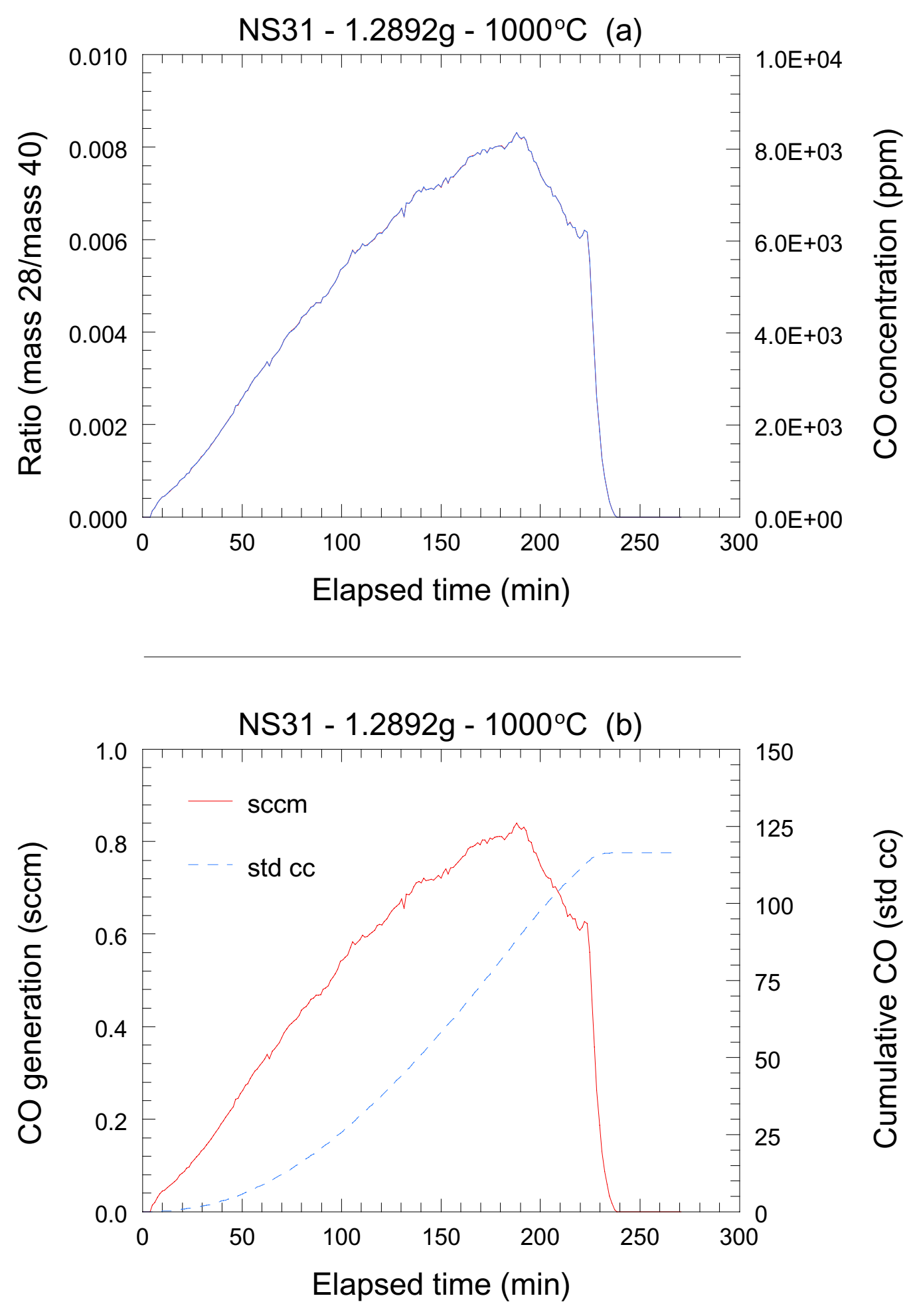

Figure 12. Results of mass-spectrometer analysis for CO generation from NS31-5 exposed to steam at $1000^{\circ} \mathrm{C}$. 

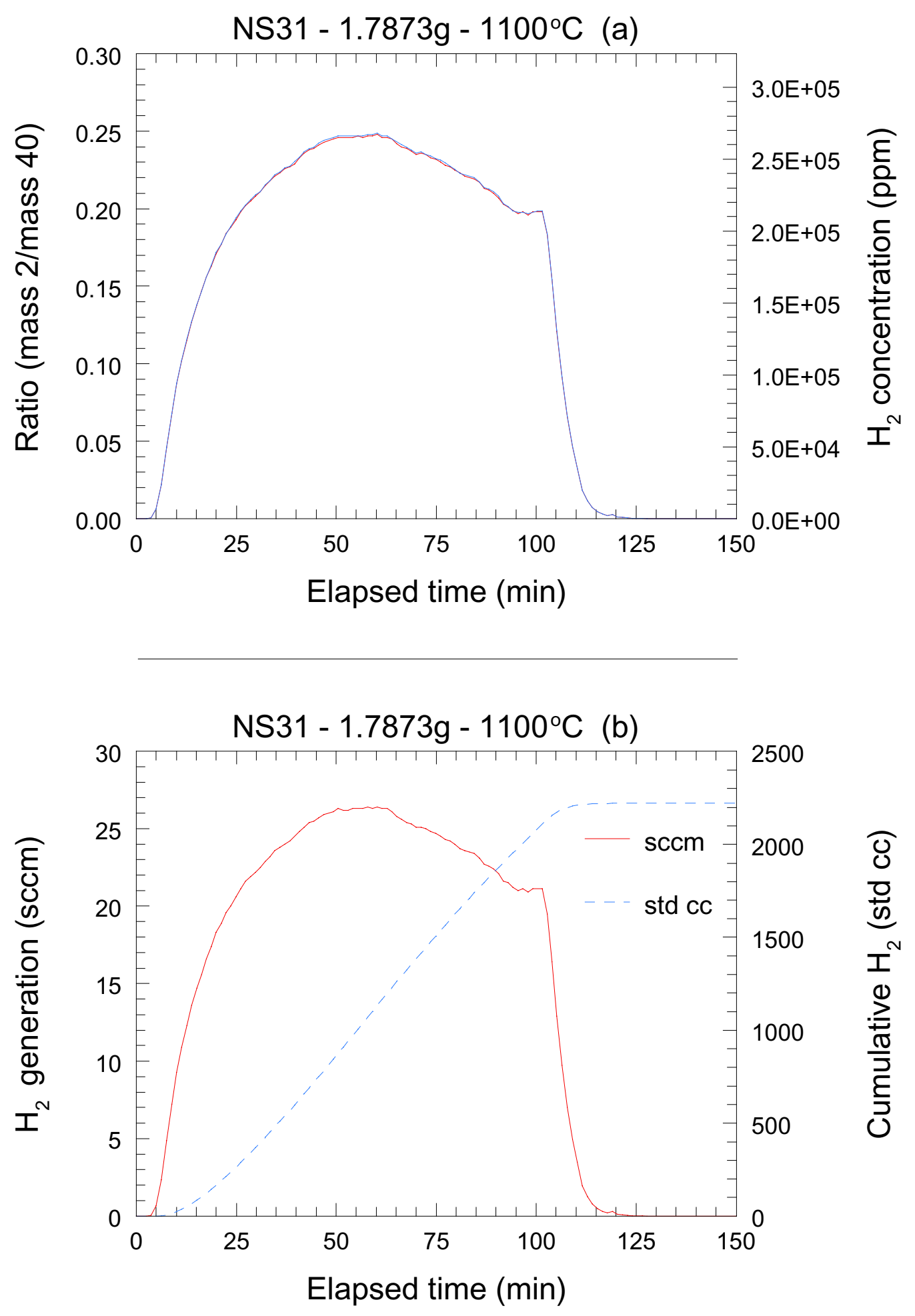

Figure 13. Results of mass-spectrometer analysis for $\mathrm{H}_{2}$ generation from NS31-6 exposed to steam at $1100^{\circ} \mathrm{C}$. 

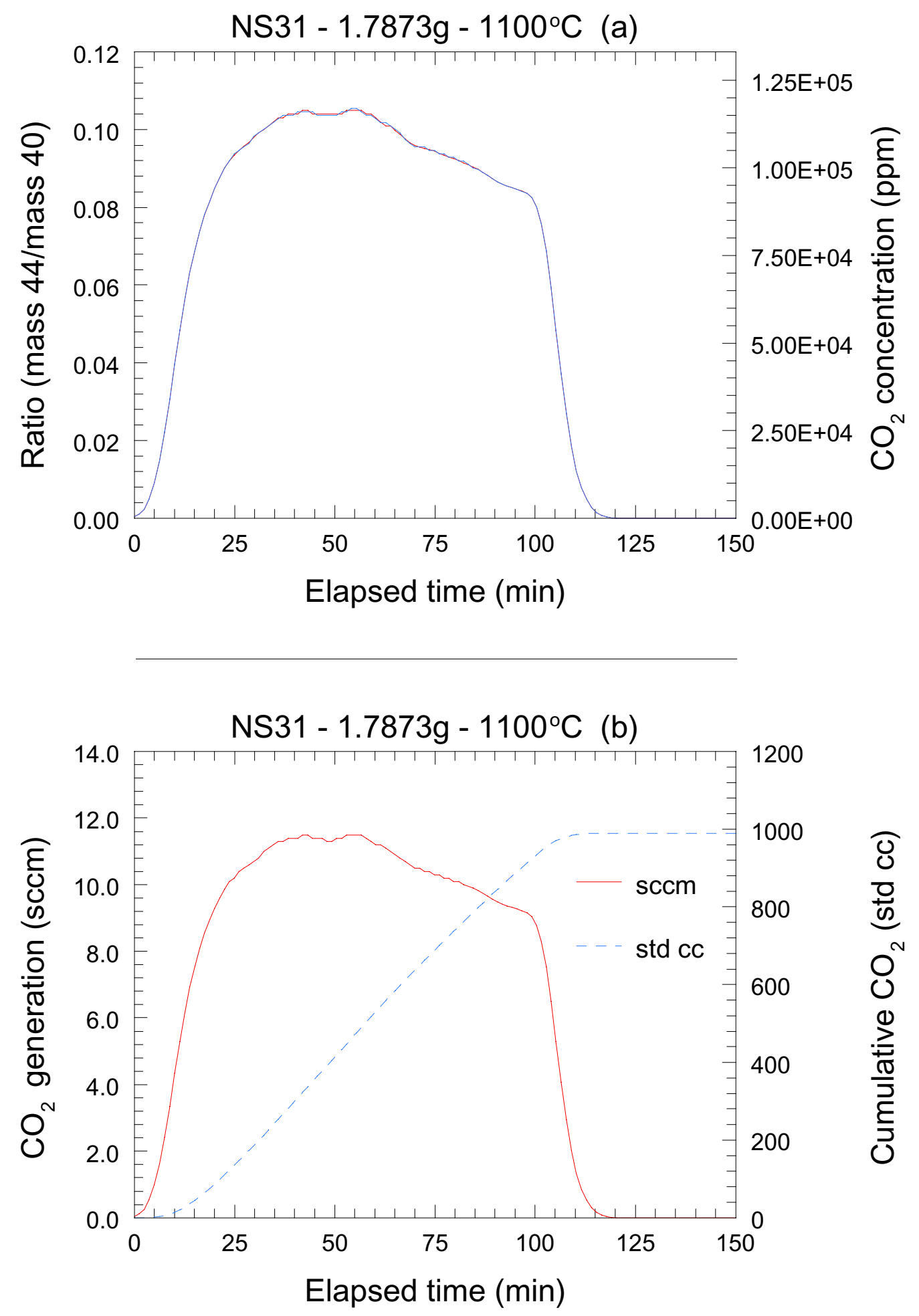

Figure 14. Results of mass-spectrometer analysis for $\mathrm{CO}_{2}$ generation from NS31-6 exposed to steam at $1100^{\circ} \mathrm{C}$. 

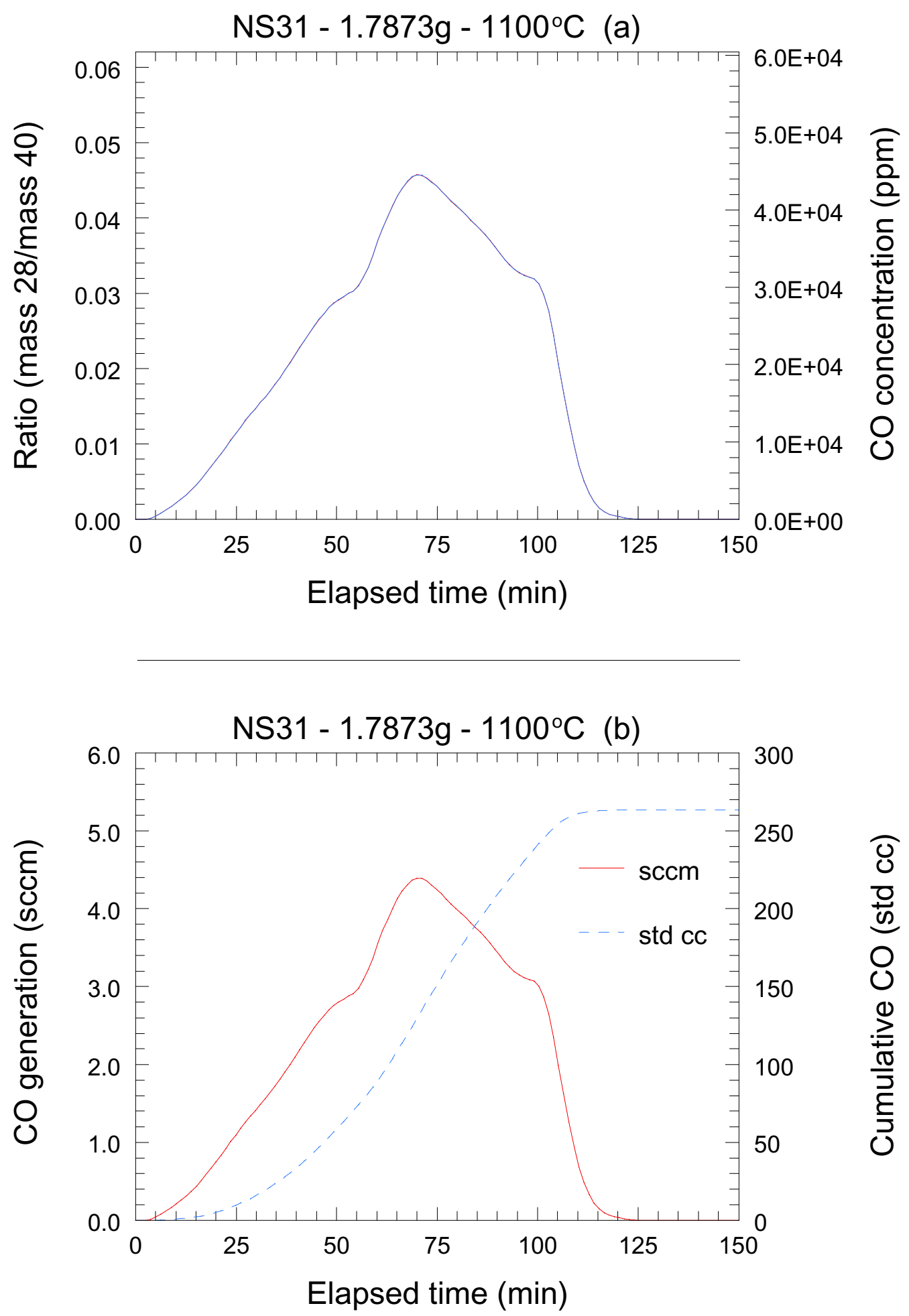

Figure 15. Results of mass-spectrometer analysis for CO generation from NS31-6 exposed to steam at $1100^{\circ} \mathrm{C}$. 

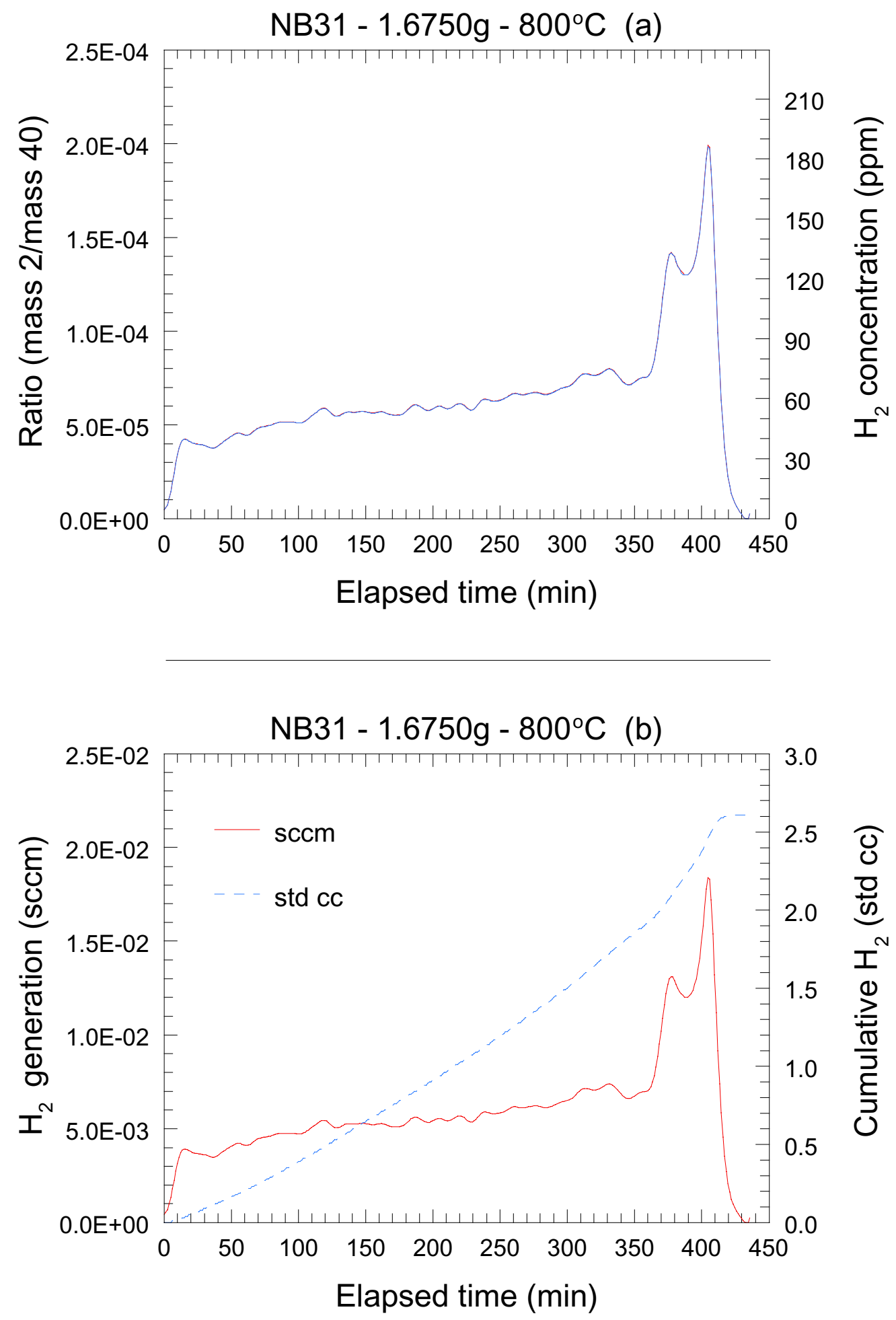

Figure 16. Results of mass-spectrometer analysis for $\mathrm{H}_{2}$ generation from NB31-3 exposed to steam at $800^{\circ} \mathrm{C}$. Electronic background noise prevented accurate $\mathrm{CO}_{2}$ and $\mathrm{CO}$ mass-spectrometer data from being obtained from this experiment. 

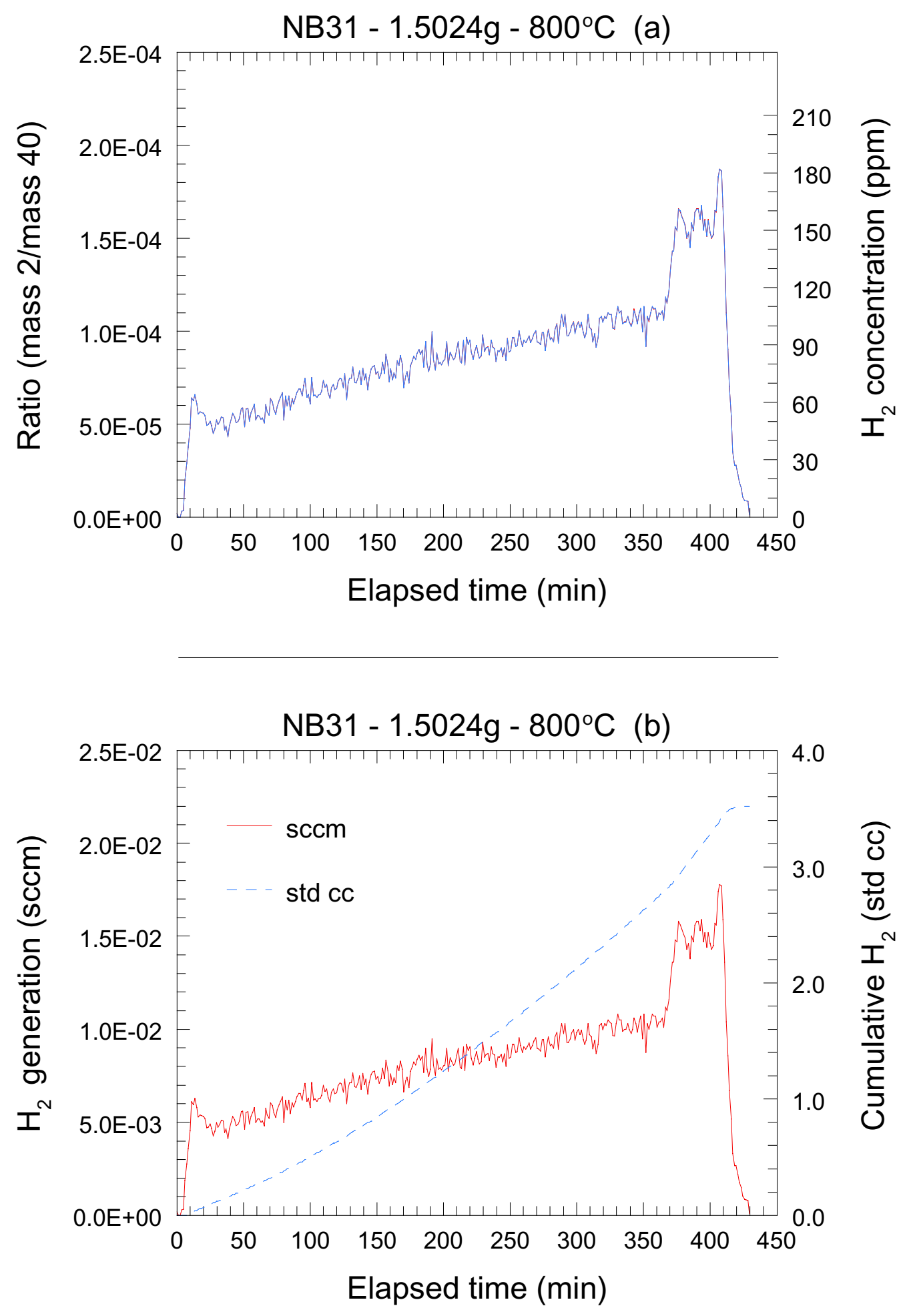

Figure 17. Results of mass-spectrometer analysis for $\mathrm{H}_{2}$ generation from NB31-8 exposed to steam at $800^{\circ} \mathrm{C}$. 

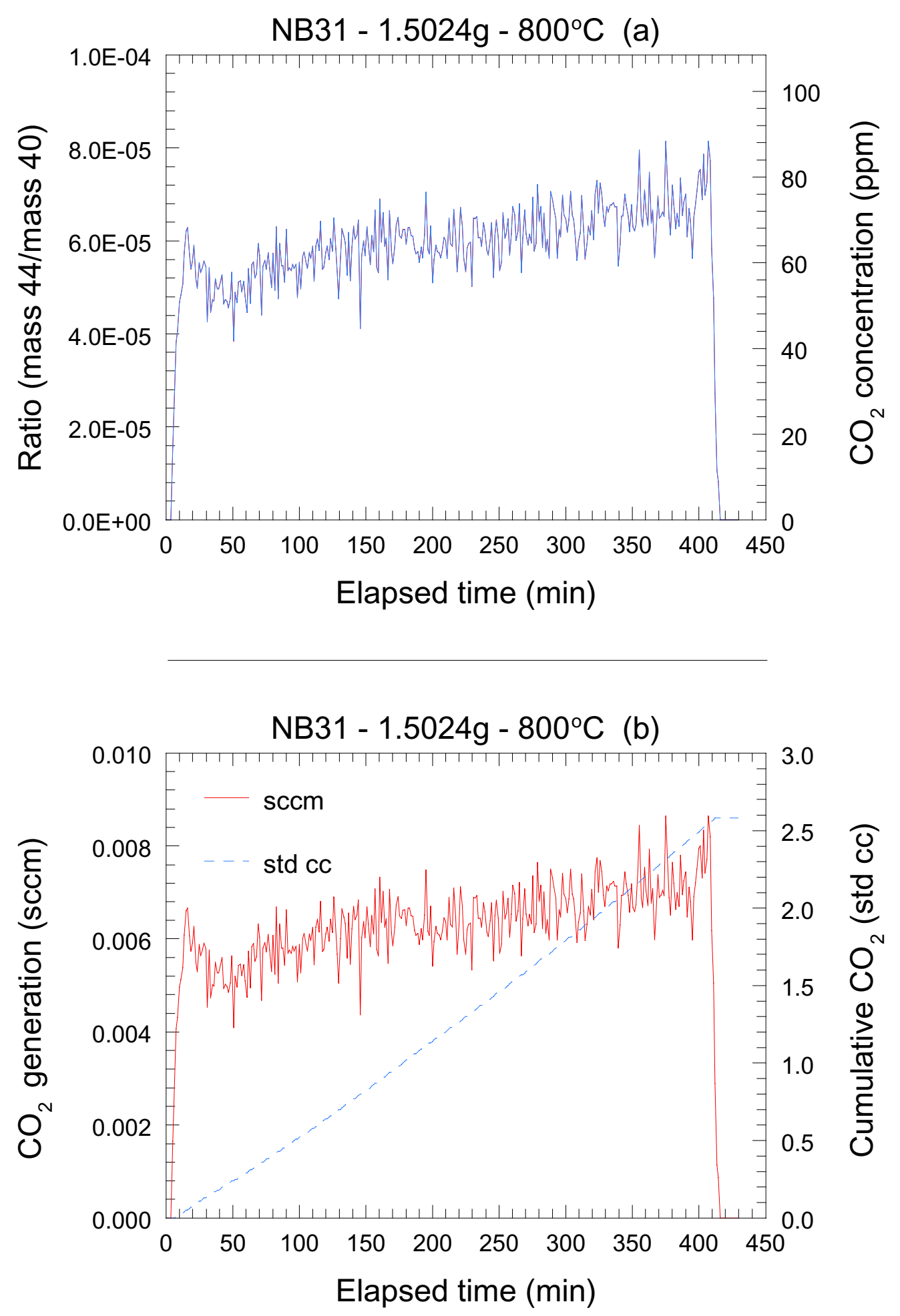

Figure 18. Results of mass-spectrometer analysis for $\mathrm{CO}_{2}$ generation from NB31-8 exposed to steam at $800^{\circ} \mathrm{C}$. 

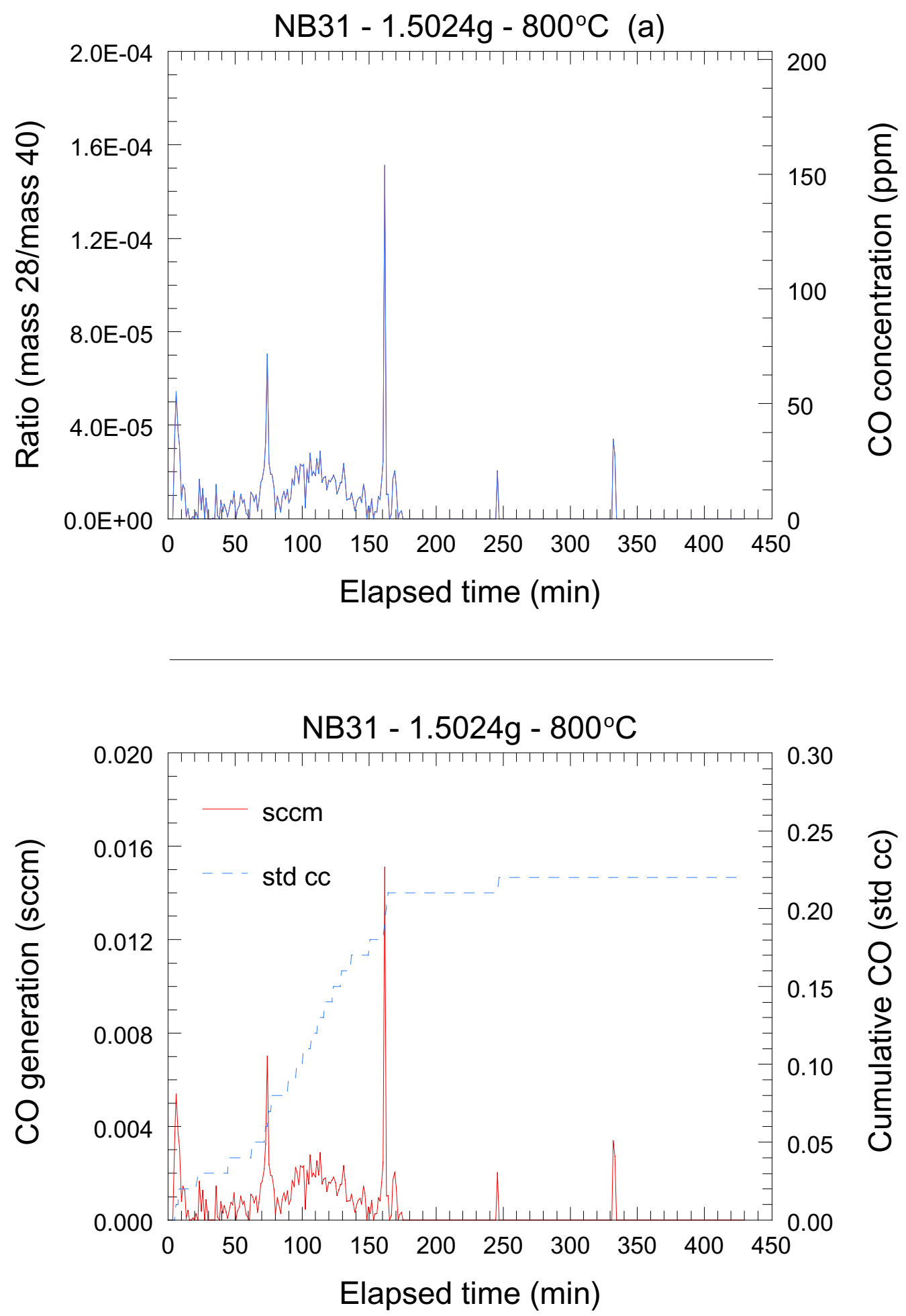

Figure 19. Results of mass-spectrometer analysis for $\mathrm{CO}$ generation from NB31-8 exposed to steam at $800^{\circ} \mathrm{C}$. 

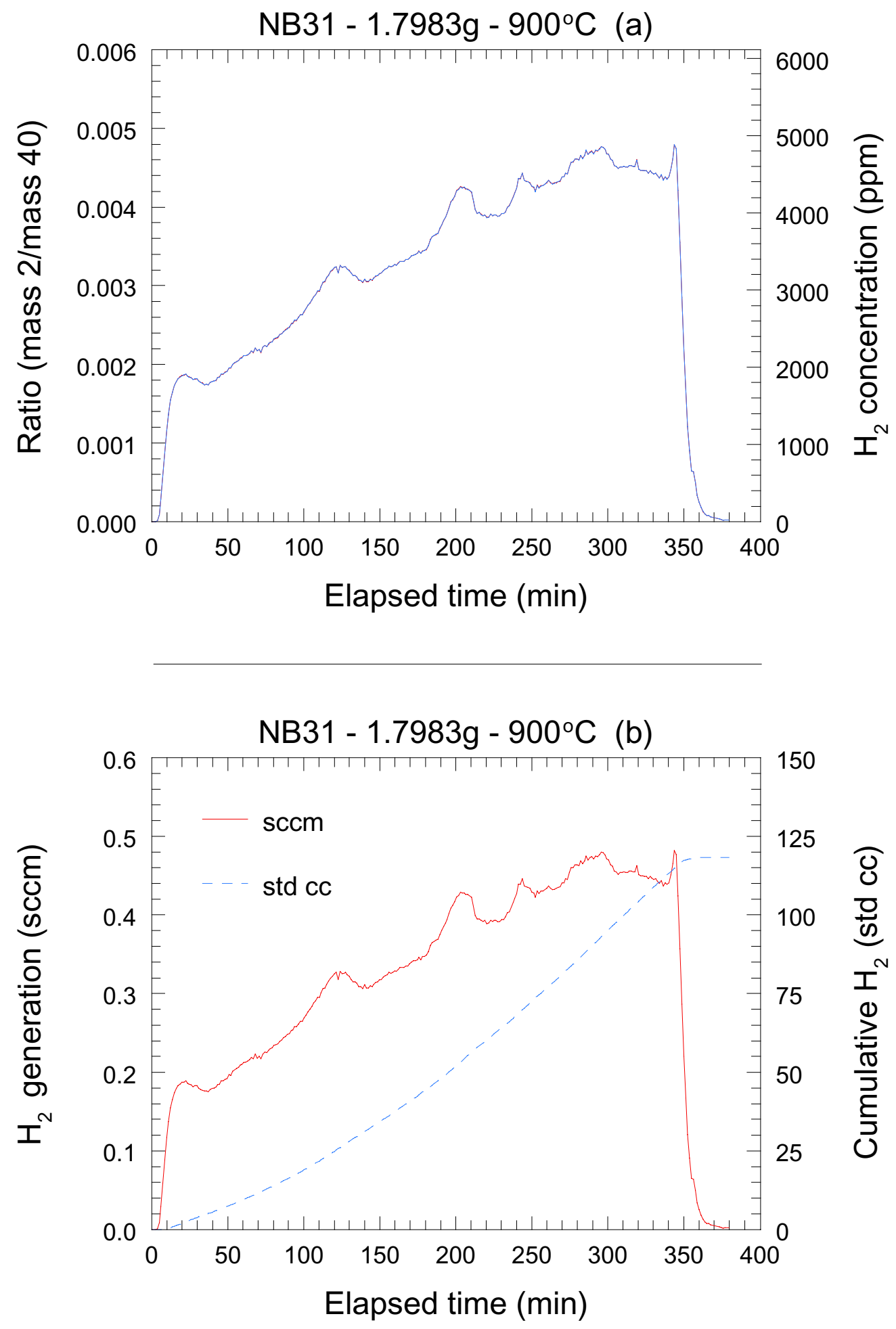

Figure 20. Results of mass-spectrometer analysis for $\mathrm{H}_{2}$ generation from NB31-4 exposed to steam at $900^{\circ} \mathrm{C}$. The bumps are due to electronic noise in the mass 40 signal. Electronic background noise also prevented accurate $\mathrm{CO}_{2}$ and $\mathrm{CO}$ mass-spectrometer data from being obtained from this experiment. 

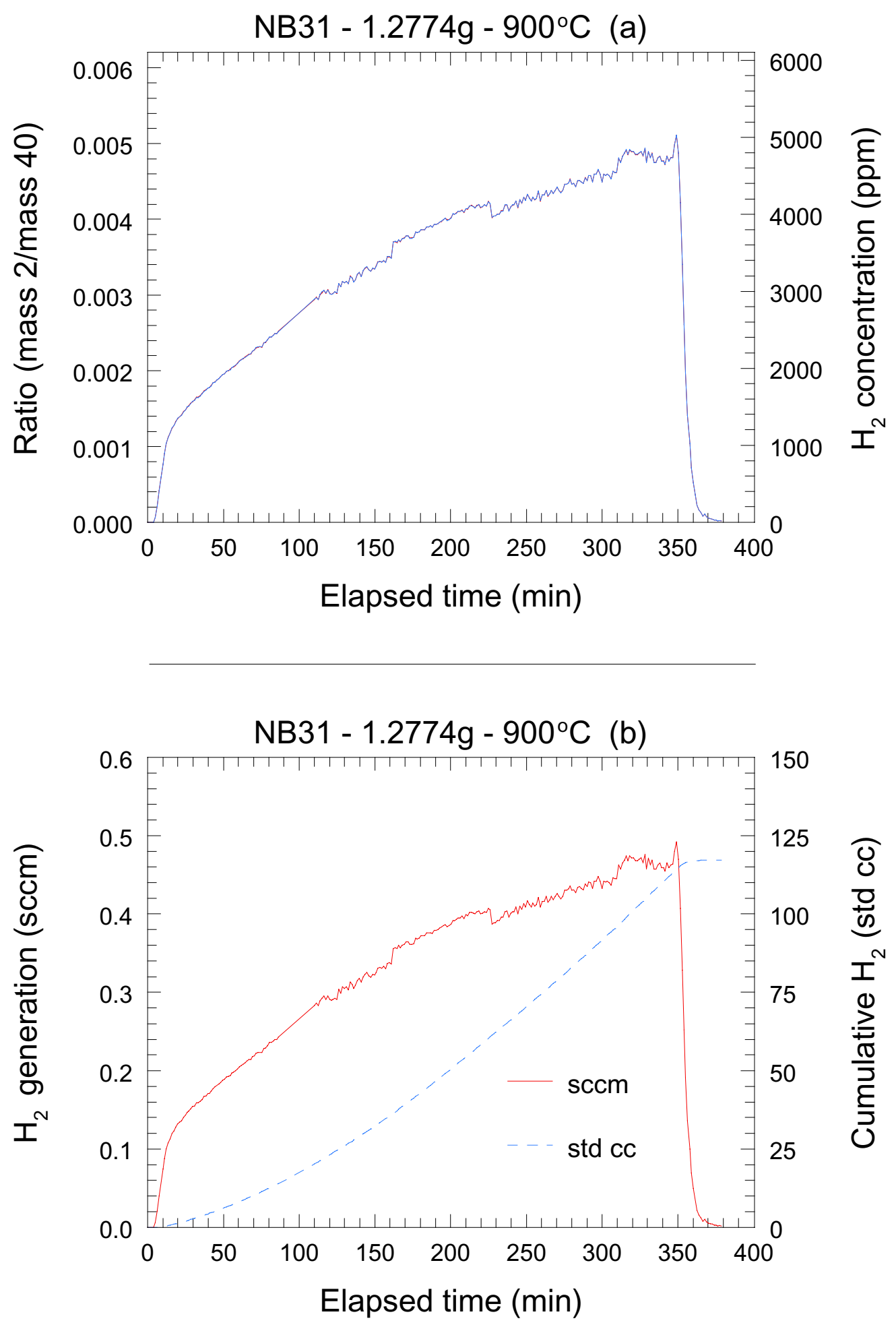

Figure 21. Results of mass-spectrometer analysis for $\mathrm{H}_{2}$ generation from NB31-7 exposed to steam at $900^{\circ} \mathrm{C}$. 

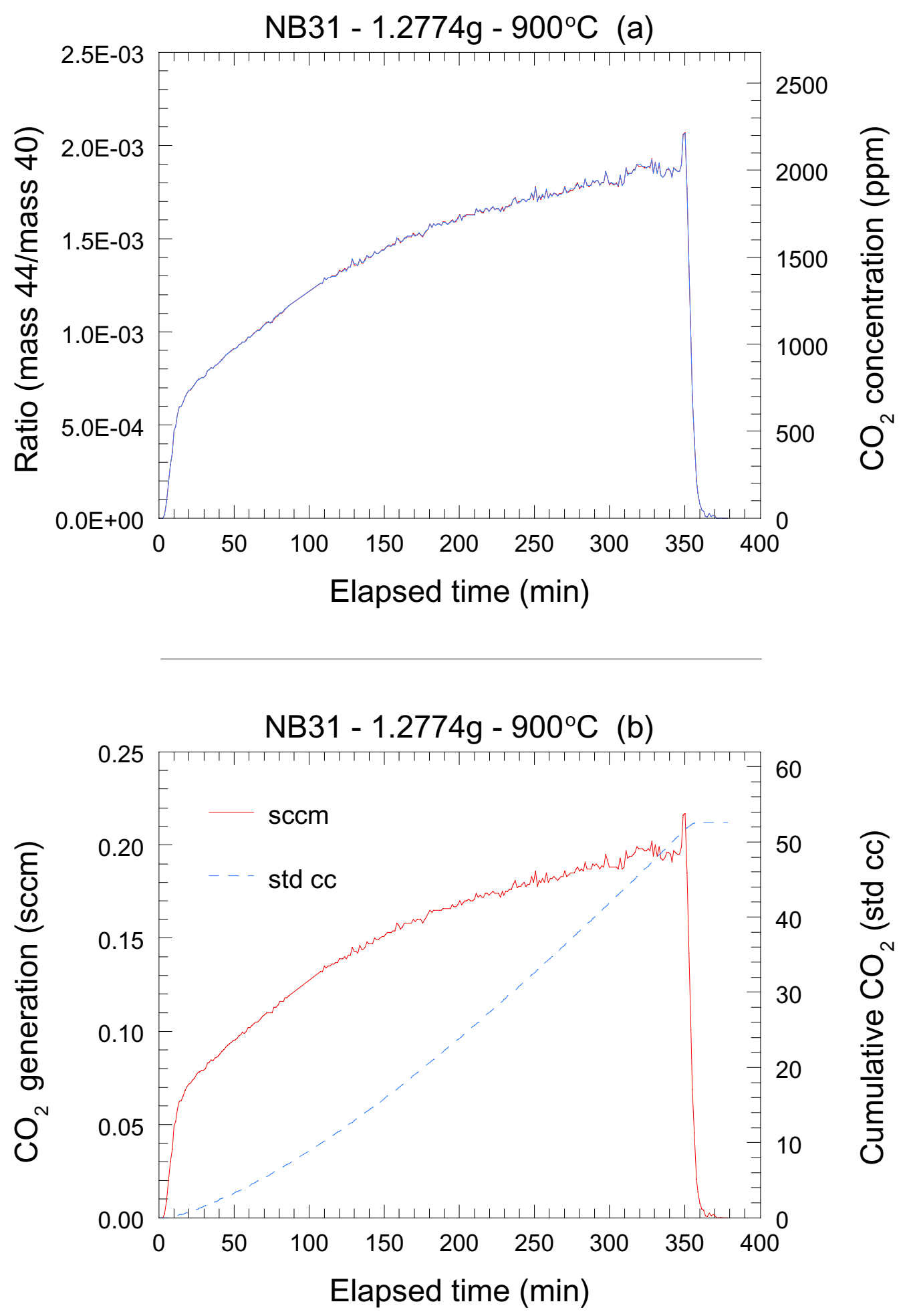

Figure 22. Results of mass-spectrometer analysis for $\mathrm{CO}_{2}$ generation from NB31-7 exposed to steam at $900^{\circ} \mathrm{C}$. 

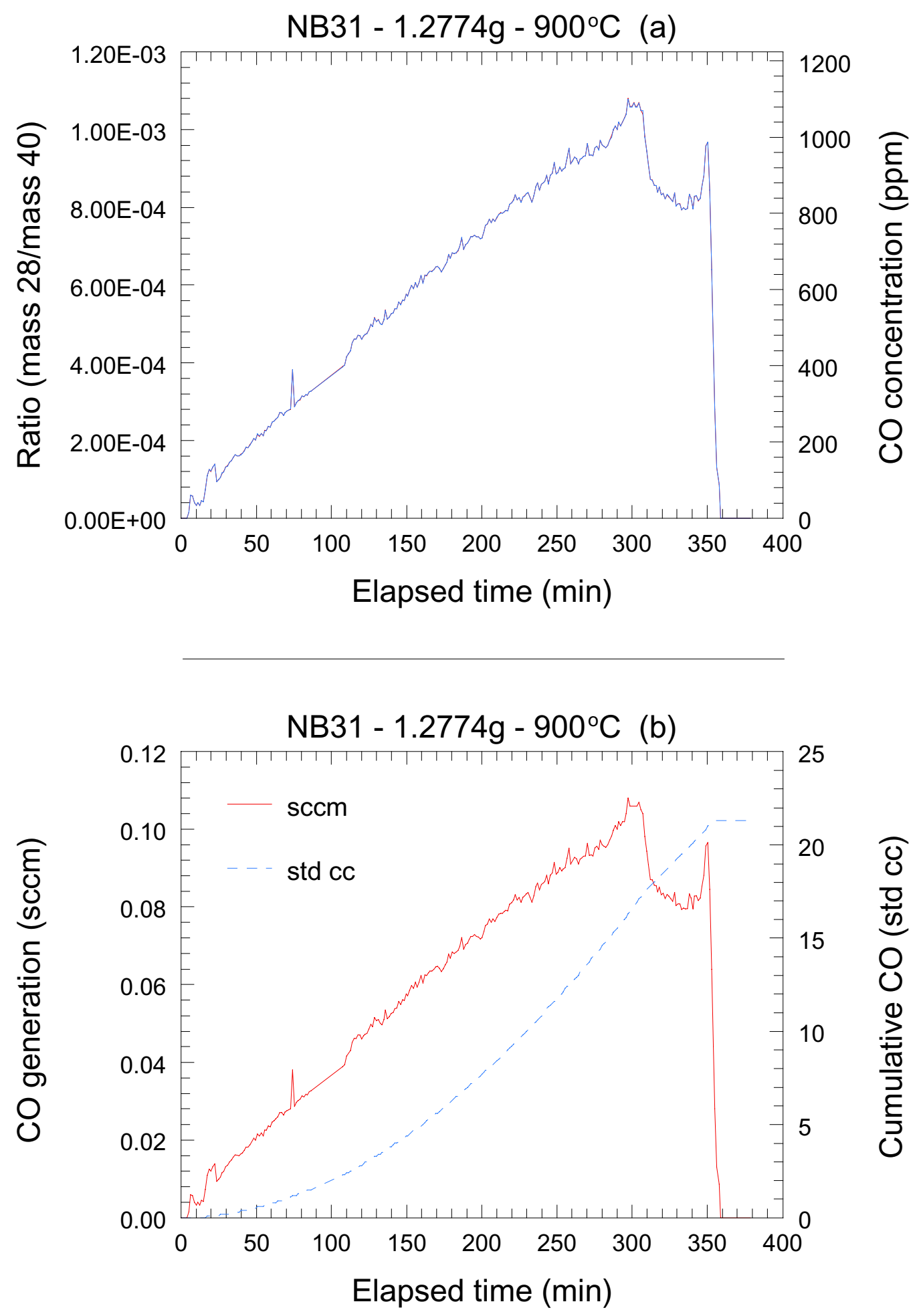

Figure 23. Results of mass-spectrometer analysis for $\mathrm{CO}$ generation from NB31-7 exposed to steam at $900^{\circ} \mathrm{C}$. 

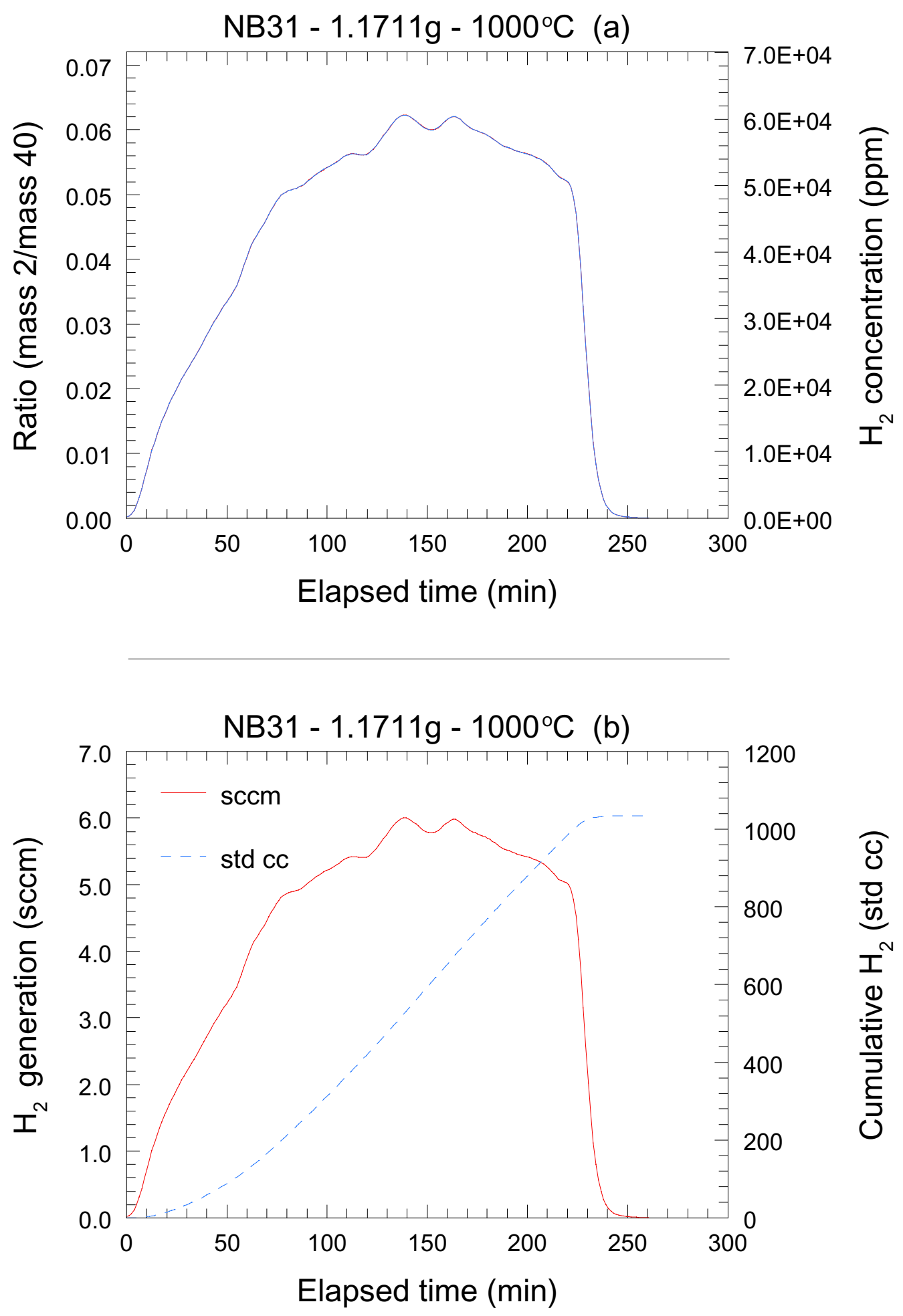

Figure 24. Results of mass-spectrometer analysis for $\mathrm{H}_{2}$ generation from NB31-6 exposed to steam at $1000^{\circ} \mathrm{C}$. 

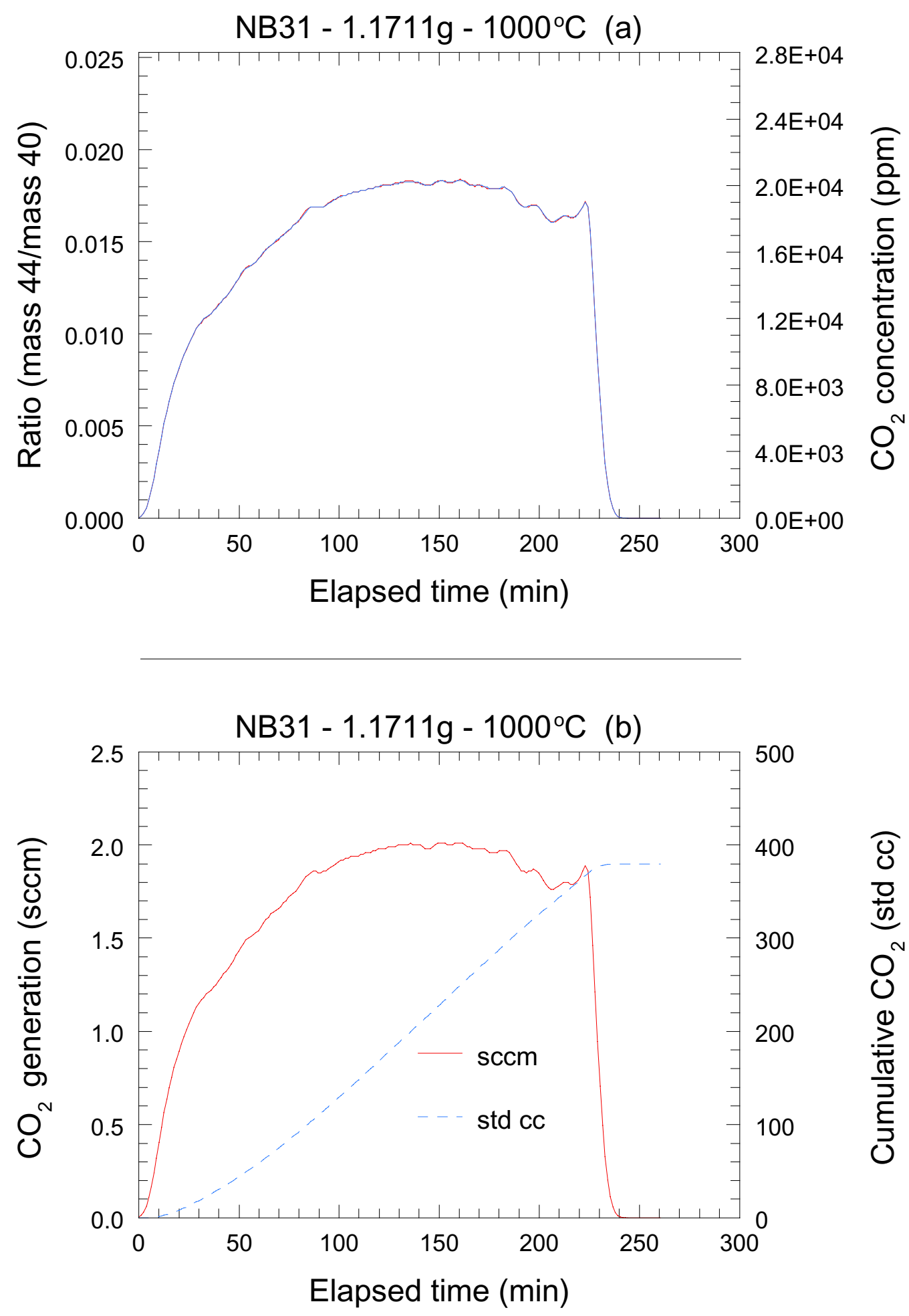

Figure 25. Results of mass-spectrometer analysis for $\mathrm{CO}_{2}$ generation from NB31-6 exposed to steam at $1000^{\circ} \mathrm{C}$. 

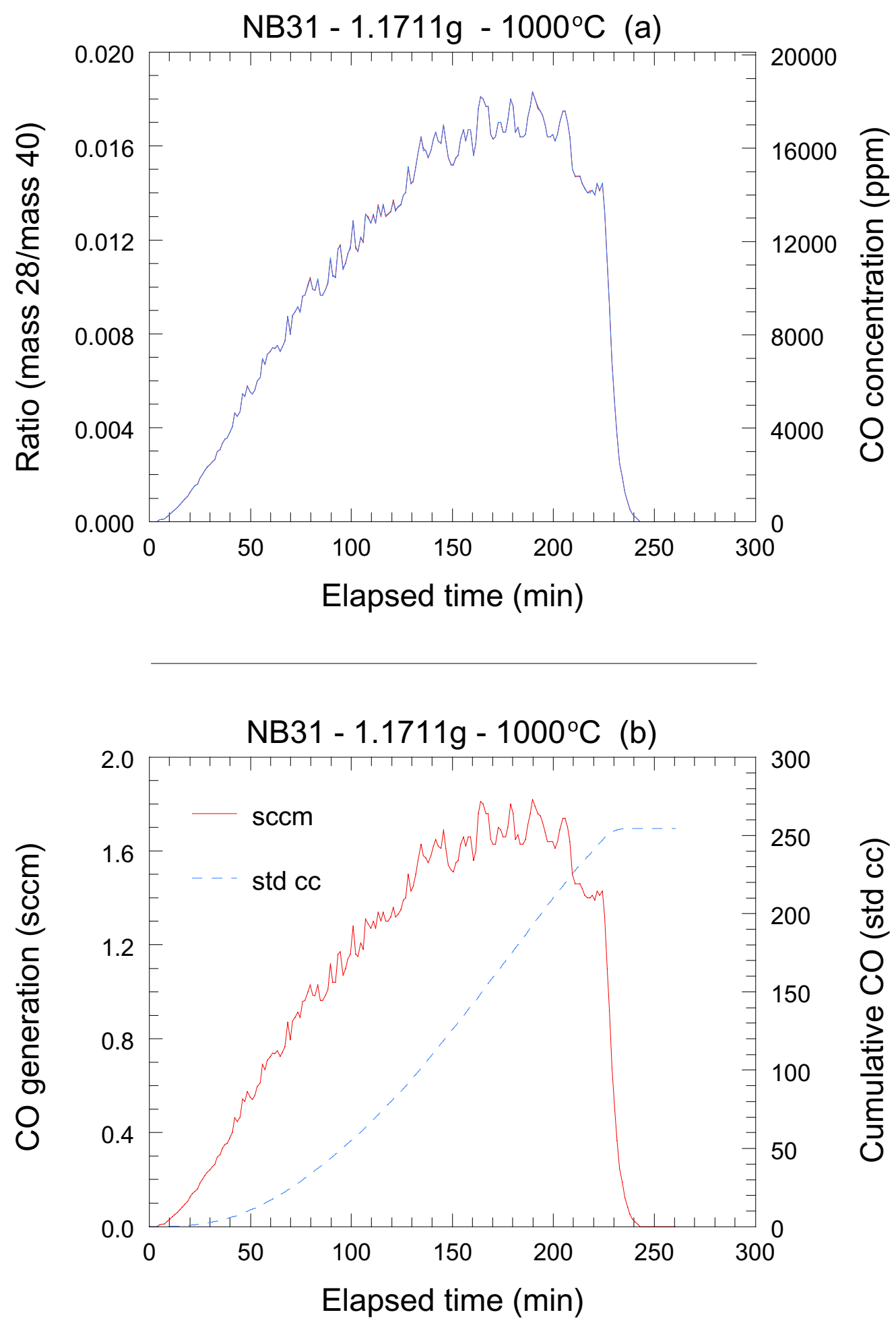

Figure 26. Results of mass-spectrometer analysis for CO generation from NB31-6 exposed to steam at $1000^{\circ} \mathrm{C}$. 


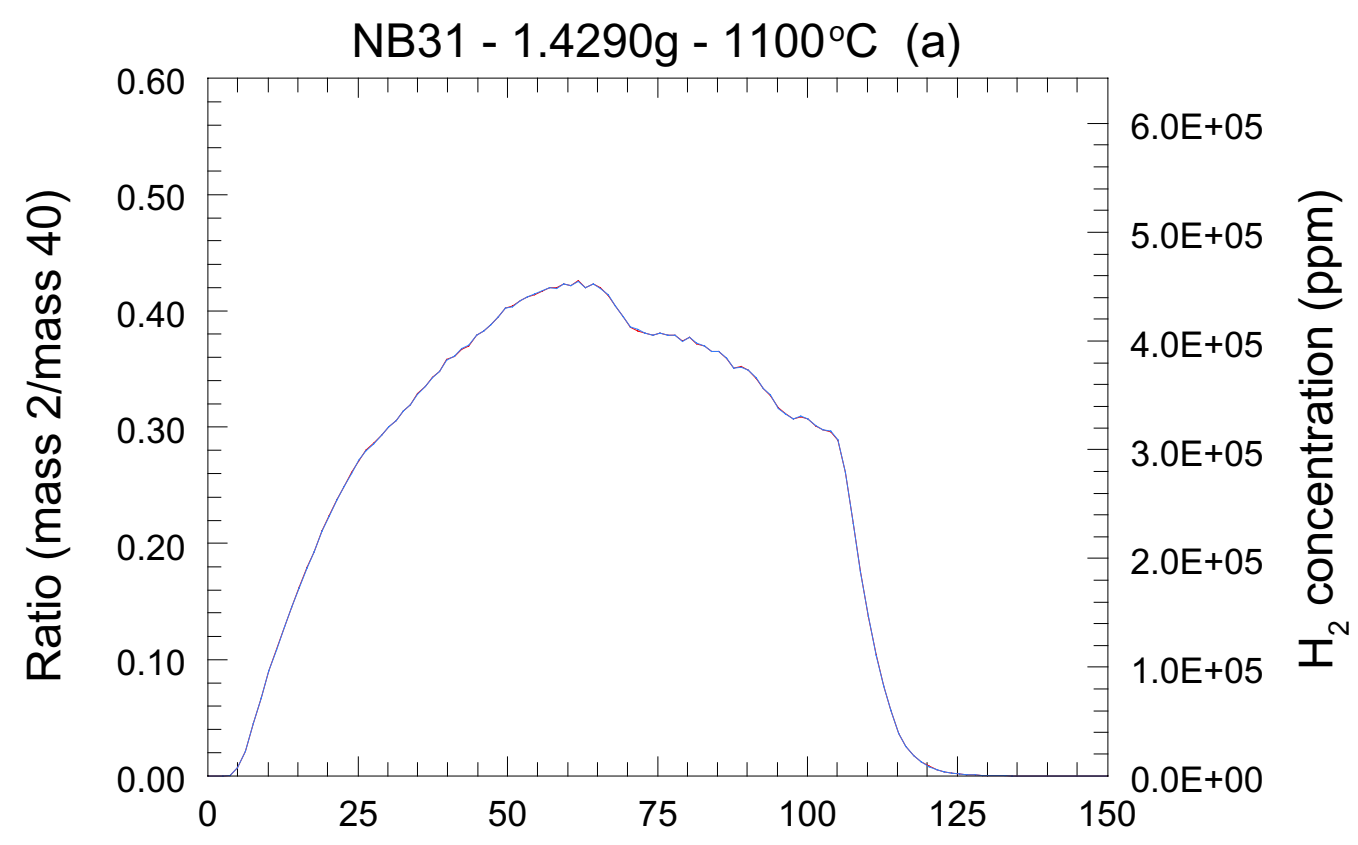

Elapsed time ( $\mathrm{min})$

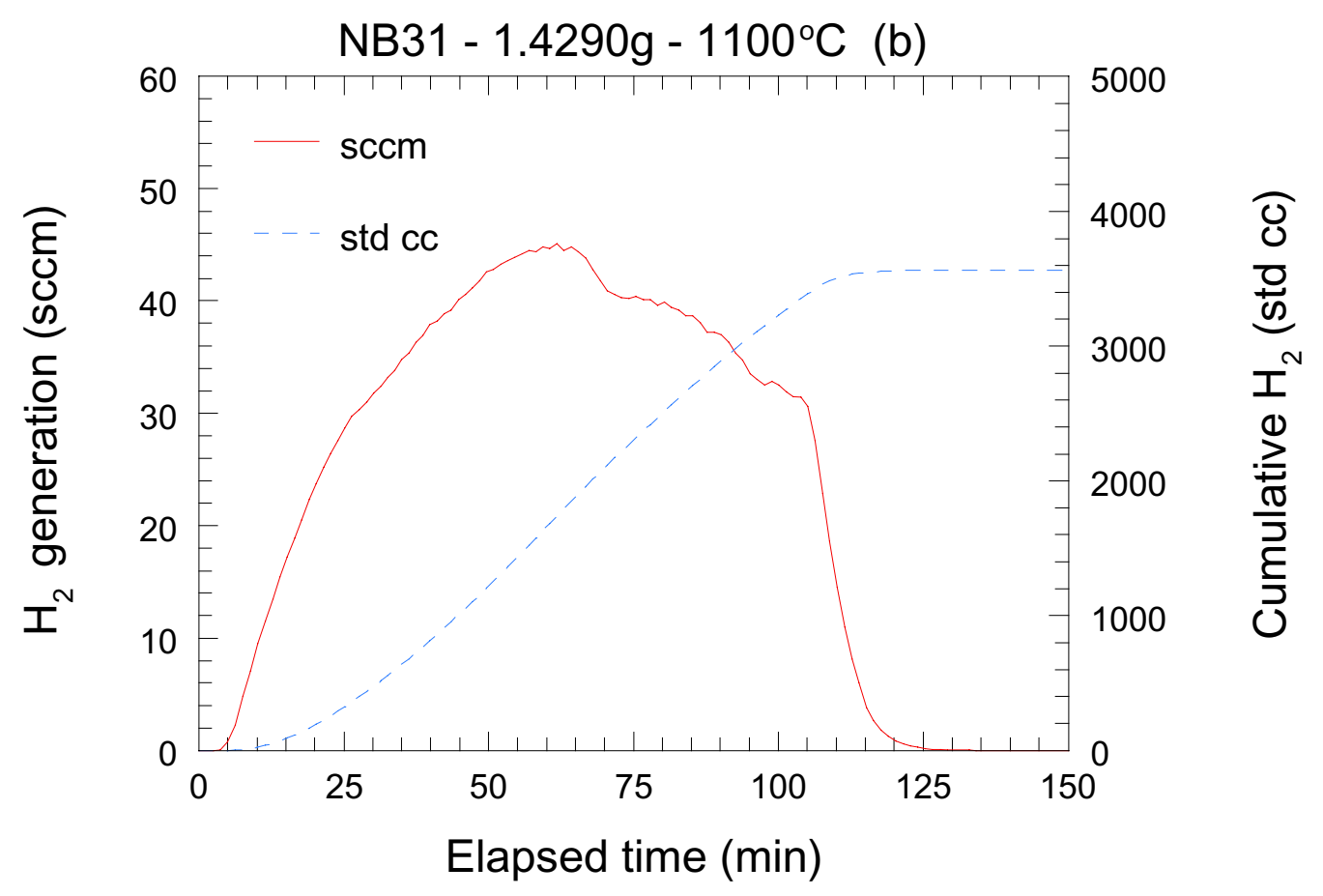

Figure 27. Results of mass-spectrometer analysis for $\mathrm{H}_{2}$ generation from NB31-5 exposed to steam at $1100^{\circ} \mathrm{C}$. 

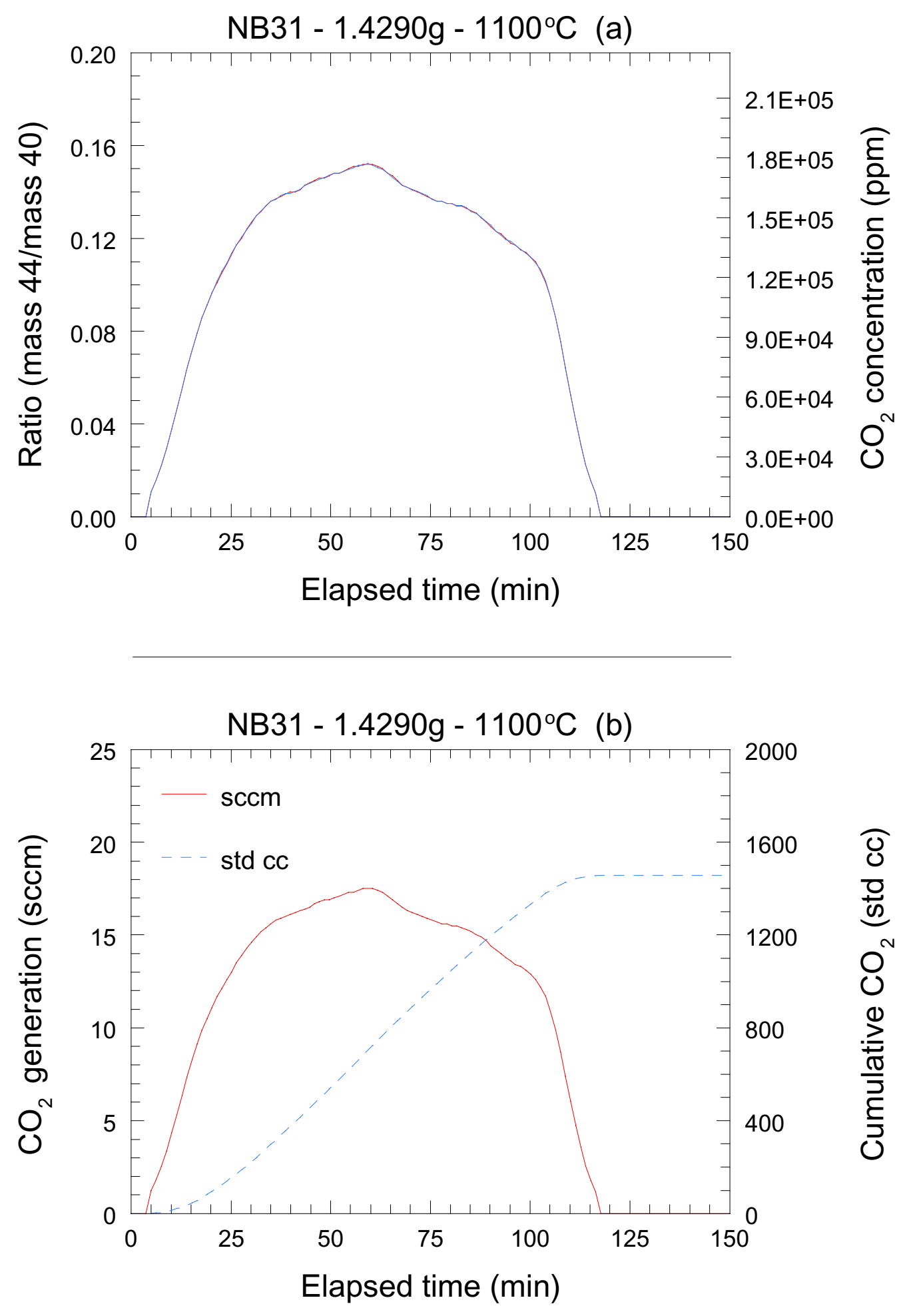

Figure 28. Results of mass-spectrometer analysis for $\mathrm{CO}_{2}$ generation from NB31-5 exposed to steam at $1100^{\circ} \mathrm{C}$. 

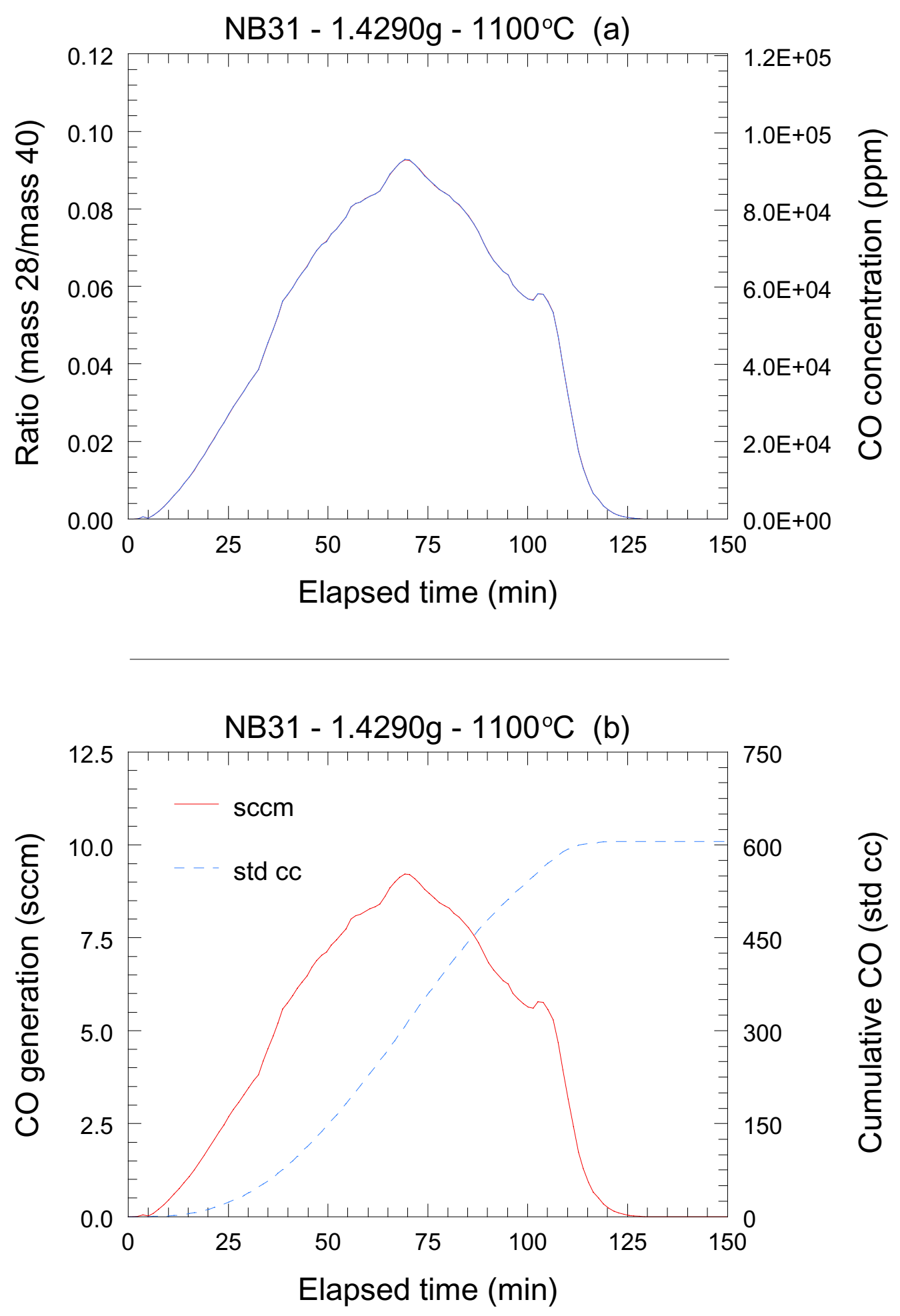

Figure 29. Results of mass-spectrometer analysis for $\mathrm{CO}$ generation from NB31-5 exposed to steam at $1100^{\circ} \mathrm{C}$. 


\subsection{Hydrogen Generation Rates}

Average hydrogen generation rates over the steam exposure time were derived from the steam-reactivity data detailed in Table 4 using both the geometric surface areas and the BET specific surface areas. This approach computes an average generation rate as the total quantity of hydrogen generated (based upon the valued obtained from the massspectrometer measurements), divided by the initial specimen surface area and by the steam exposure or reaction time. By using the geometric surface area, this approach is consistent with previous chemical steam reaction studies $[3,4]$ conducted at the INEEL on other carbon fiber composites.

A summary of the average $\mathrm{H}_{2}$ generation rate analyses is given in Table 7 . Values for the average hydrogen generation rates are presented using both the geometric surface area and the BET specific surface area. As shown in the first three columns of the table, each experiment is identified with a sample ID, a unique sample mass, and the test temperature for that sample. The fourth column lists the inverse temperature defined as 10,000 divided by test temperature in degrees Kelvin. The fifth column lists the steam exposure times for each experiment. Column 6 lists the measured geometric surface area for each sample followed by the average $\mathrm{H}_{2}$ generation rate based on geometric surface area in column 7. In column 8 we list values of the carbon reaction rates as derived from the weight-loss data and the geometric surface areas. Column 9 lists the average BET specific surface area for the NS31 and NB31 samples as detailed in Section 2.2. The average $\mathrm{H}_{2}$ generation rates based on BET specific surface are listed in column 10. In column 11 we list values of the carbon reaction rates as derived from the weight-loss data and the BET specific surface areas.

Table 7. Summary of average hydrogen generation and carbon reaction rates for CFC samples based on the geometric surface areas and the BET specific surface areas.

\begin{tabular}{|c|c|c|c|c|c|c|c|c|c|c|}
\hline \multirow[b]{2}{*}{$\begin{array}{c}\text { Sample } \\
\text { ID }\end{array}$} & \multirow[b]{2}{*}{$\begin{array}{c}\text { Mass } \\
\text { (g) }\end{array}$} & \multicolumn{3}{|c|}{ Steam Exposure } & \multicolumn{3}{|c|}{ Geometric Surface Area Rates } & \multicolumn{3}{|c|}{ BET Surface Area Rates } \\
\hline & & $\begin{array}{l}\text { Temp. } \\
\left({ }^{\circ} \mathrm{C}\right)\end{array}$ & $\begin{array}{l}\text { Inv. Temp. } \\
(10,000 / K)\end{array}$ & $\begin{array}{l}\text { Time } \\
\text { (min) }\end{array}$ & $\begin{array}{c}\text { SA } \\
\left(\mathrm{cm}^{2}\right)\end{array}$ & $\begin{array}{c}\mathrm{H}_{2} \text { Rate } \\
\left(\mathrm{l} / \mathrm{m}^{2}-\mathrm{s}\right)\end{array}$ & $\begin{array}{c}\text { C Reaction } \\
\begin{array}{c}\text { Rate } \\
\left(\mathrm{g} / \mathrm{m}^{2}-\mathrm{s}\right)\end{array} \\
\end{array}$ & $\begin{array}{c}\text { SSA } \\
\left(\mathrm{m}^{2} / \mathrm{g}\right)\end{array}$ & \begin{tabular}{|c}
$\mathrm{H}_{2}$ Rate \\
$\left(\mathrm{l} / \mathrm{m}^{2}-\mathrm{s}\right)$
\end{tabular} & $\begin{array}{c}\text { C } \\
\text { Reaction } \\
\text { Rate } \\
\left(\mathbf{g} / \mathbf{m}^{2}-\mathbf{s}\right) \\
\end{array}$ \\
\hline NS31-3 & 1.6488 & 800 & 9.32 & 402 & 6.545 & $1.22 \mathrm{E}-03$ & $2.53 \mathrm{E}-04$ & 0.1465 & $3.30 \mathrm{E}-06$ & $6.87 \mathrm{E}-07$ \\
\hline NS31-9 & 0.9854 & 800 & 9.32 & 408 & 5.446 & 7.07E-04 & $2.18 \mathrm{E}-04$ & 0.1465 & $2.67 \mathrm{E}-06$ & 8.21E-07 \\
\hline NS31-4 & 1.4794 & 900 & 8.53 & 342 & 6.275 & $9.05 \mathrm{E}-03$ & $2.35 \mathrm{E}-03$ & 0.1465 & 2.62E-05 & 6.79E-06 \\
\hline NS31-8 & 1.2436 & 900 & 8.53 & 345 & 5.921 & $8.24 \mathrm{E}-03$ & $2.33 \mathrm{E}-03$ & 0.1465 & $2.68 \mathrm{E}-05$ & $7.56 \mathrm{E}-06$ \\
\hline NS31-5 & 1.2892 & 1000 & 7.86 & 222 & 5.974 & $6.59 \mathrm{E}-02$ & $1.98 \mathrm{E}-02$ & 0.1465 & $2.08 \mathrm{E}-04$ & $6.26 \mathrm{E}-05$ \\
\hline NS31-6 & 1.7873 & 1100 & 7.28 & 102 & 6.790 & $5.34 \mathrm{E}-01$ & $1.31 \mathrm{E}-01$ & 0.1465 & $1.39 \mathrm{E}-03$ & $3.39 \mathrm{E}-04$ \\
\hline NB31-3 & 1.6750 & 800 & 9.32 & 405 & 6.916 & $1.55 \mathrm{E}-04$ & 7.14E-05 & 0.1463 & 4.38E-07 & $2.02 \mathrm{E}-07$ \\
\hline NB31-8 & 1.5024 & 800 & 9.32 & 407 & 6.514 & $2.21 \mathrm{E}-04$ & $9.43 \mathrm{E}-05$ & 0.1463 & $6.56 \mathrm{E}-07$ & $2.79 \mathrm{E}-07$ \\
\hline NB31-4 & 1.7983 & 900 & 8.53 & 344 & 7.089 & $8.10 \mathrm{E}-03$ & 2.37E-03 & 0.1463 & $2.18 \mathrm{E}-05$ & $6.39 \mathrm{E}-06$ \\
\hline NB31-7 & 1.2774 & 900 & 8.53 & 347 & 6.094 & $9.24 \mathrm{E}-03$ & $2.81 \mathrm{E}-03$ & 0.1463 & $3.01 \mathrm{E}-05$ & $9.18 \mathrm{E}-06$ \\
\hline NB31-6 & 1.1711 & 1000 & 7.86 & 225 & 5.940 & $1.29 \mathrm{E}-01$ & $3.59 \mathrm{E}-02$ & 0.1463 & 4.47E-04 & $1.24 \mathrm{E}-04$ \\
\hline NB31-5 & 1.4290 & 1100 & 7.28 & 104 & 6.420 & 8.89E-01 & $1.96 \mathrm{E}-01$ & 0.1463 & $2.73 \mathrm{E}-03$ & $6.03 \mathrm{E}-04$ \\
\hline
\end{tabular}


A graphical presentation of the average $\mathrm{H}_{2}$ generation rates that were derived using both the geometric surface area and the BET specific surface area is given in Figure 30. As detailed in Section 2.0, the measured BET specific surface areas are $0.15 \mathrm{~m}^{2} / \mathrm{g}(+/-14 \%)$ for the NS31 material and $0.15 \mathrm{~m}^{2} / \mathrm{g}(+/-7 \%)$ for the NB31 material. These values are approximately a factor of 330 greater than the geometric surface areas. Consequently the average $\mathrm{H}_{2}$ generation rate values derived from the geometric surface areas are approximately 330 times greater than the values derived from the BET specific surface areas.

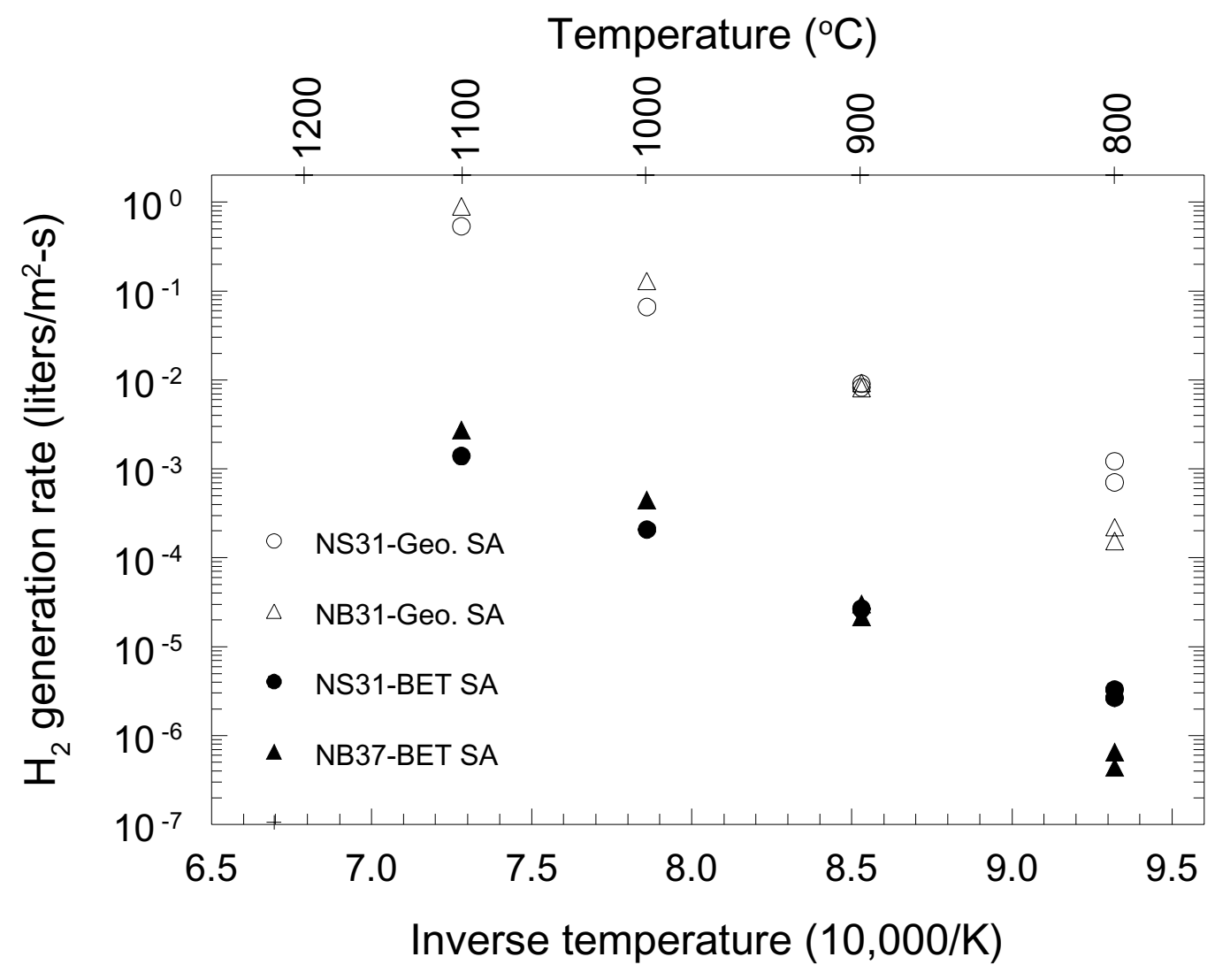

Figure 30. Average $\mathrm{H}_{2}$ generation rates for carbon fiber composite samples based on the geometric surface areas and the BET specific surface areas.

\subsection{DISCUSSION}

In this work we have conducted measurements and analyses to assess the chemical reactivity of NS31 and NB31 carbon fiber carbon samples exposed to steam at elevated temperatures. The work entailed physical characterization of the carbon fiber composite types that included measurements of the geometric surface area, BET specific surface area and immersion density. Chemical reactivity experiments were conducted at temperatures from $800^{\circ} \mathrm{C}$ to $1100^{\circ} \mathrm{C}$. Average $\mathrm{H}_{2}$ generation rates were derived for each 
chemical reactivity experiment using both the geometric surface area and the BET specific surface area. In addition, average carbon reaction rates were derived for each experiment using the weight-loss data and both the geometric surface area and the BET specific surface area. In the following paragraphs, we discuss these results and compare them to previous studies $[3,4]$ on carbon fiber composites.

Density measurements were made by two methods, mass and dimensional measurements and immersion-density measurements. Densities derived from mass and dimensional measurements were $2.13 \mathrm{~g} / \mathrm{cc}+/-2 \%$ for NS31 and $1.96 \mathrm{~g} / \mathrm{cc}+/-1 \%$ for NB31. Based on immersion density measurements, we obtained $2.13 \mathrm{~g} / \mathrm{cc}+/-0.7 \%$ for NS31 and $1.95 \mathrm{~g} / \mathrm{cc}$ $+/-0.6 \%$ for NB31, results that are in excellent agreement with those obtained from the mass and dimensional measurements. These results are in good agreement with the values of $2.09 \mathrm{~g} / \mathrm{cc}$ for NS31 and $1.91 \mathrm{~g} / \mathrm{cc}$ for NB31 that were provided with the sample material. The increased density for NS31 can be accounted for by Si-filling of the pores in the composite matrix. The NS31 and NB31 CFC materials are typically more dense than previously-tested samples of DUNLOP, FMI HDFG and FMI 4D carbon fiber composites that had measured densities of $1.73 \mathrm{~g} / \mathrm{cc}, 1.72 \mathrm{~g} / \mathrm{cc}$ and $1.93 \mathrm{~g} / \mathrm{cc}$, respectively $[3,4]$.

Based on our immersion density measurements, we obtained open porosity values of $1.8 \%$ for NS31 and $6.2 \%$ for NB31 sample materials. The result for NS31 is somewhat larger than the $1 \%$ that was identified [5] for the NS31 material.

From an analysis of several samples of each CFC material type we obtained average BET specific surface areas of $0.15 \mathrm{~m}^{2} / \mathrm{g}+/-15 \%$ for NS31 and $0.15 \mathrm{~m}^{2} / \mathrm{g}+/-7 \%$ for NB31. The percent uncertainty in these values represents the standard deviation in the measurements made for each sample type and does not include a uncertainty of $6 \%$ associated with the calibration standard. This result, comparable BET specific surface areas for the CFC materials, is surprising, especially with the observed differences in density and porosity. However, based on the micro-structural characterization measurements summarized in Appendix A, there may be a basis for similar BET specific surface areas. As we noted in Appendix A, the material microstructure was quite similar for the two CFC types, with one major difference. Voids and substantial porosity were observed in NB37, whereas, this porosity was filled to a high degree in NS37 by the Si infiltration. However, both materials showed micro-cracking or separation along different material interfaces, probably because of thermal cycling and the influence of different thermal expansion coefficients for the different material layers. Such microcracking would provide gas access to the porosity network in each material resulting in gas adsorption on nearly equivalent internal surface areas. These measurements indicate that the NS31 and NB31 materials have specific surface areas that are less than those measured [7] for some bulk graphites $\left(0.75 \mathrm{~m}^{2} / \mathrm{g}\right.$ for H451, $0.69 \mathrm{~m}^{2} / \mathrm{g}$ for GRAPHNOL $\mathrm{N} 3 \mathrm{M}, 0.34 \mathrm{~m}^{2} / \mathrm{g}$ for POCO AXF-5Q) but greater than that measured for pyrolytic graphite $\left(0.04 \mathrm{~m}^{2} / \mathrm{g}\right)$.

In general, the steam reactivity results for NS31 and NB31 CFC samples were similar, however we did observe some differences that may be due to differences in the physical 
properties, material chemical composition and material microstructure. From the kinetic behavior perspective we observe the following. For steam exposure at $800^{\circ}$, the $\mathrm{H}_{2}$ generation rate for NS31 (Fig. 4) appears to increase more rapidly during the steam exposure time than that for NB31 (Fig. 17). For the test at $900^{\circ}$, the $\mathrm{H}_{2}$ generation rate for NS31 (Fig. 7) rises rapidly to a relatively constant value for the duration of the experiment, whereas, the rate for NB31 (Fig. 21) increases continuously throughout the steam exposure time. For the steam exposure experiments at $1000^{\circ} \mathrm{C}$ and $1100^{\circ}$, the $\mathrm{H}_{2}$ generation kinetic behavior was very similar for NS31 and NB31. When we compare the $\mathrm{CO}_{2}$ and $\mathrm{CO}$ generation kinetic data to that for $\mathrm{H}_{2}$, we note that the curves for $\mathrm{H}_{2}$ and $\mathrm{CO}_{2}$ are very similar for both materials, whereas, the curves for $\mathrm{CO}$ show that its generation rate steadily increases during the steam exposure time for all test temperatures. As discussed by Clark et al., [1], $\mathrm{CO}_{2}$ is most likely produced via $\mathrm{CO} /$ steam interactions in the hot zone of the furnace. Consequently, the kinetic behavior for the $\mathrm{CO}$ and $\mathrm{CO}_{2}$ observed signals is probably related to both the $\mathrm{CFC} /$ steam reaction and to the $\mathrm{CO} /$ steam reaction, with both the residence time and furnace temperatures being important parameters. These factors could contribute to the observed differences in kinetic behavior for the gases.

A comparison of the average $\mathrm{H}_{2}$ generation rates and carbon reaction rates for NS31 and NB31, as detailed in Table 7, indicates the following. For $800^{\circ} \mathrm{C}$, the $\mathrm{H}_{2}$ and carbon rates are factors of 5 and 3 higher, respectively, for NS31 than for NB31. However, at $900^{\circ} \mathrm{C}$, the rates are comparable for the two material types. At test temperatures of 1000 and $1100^{\circ} \mathrm{C}$, the $\mathrm{H}_{2}$ and carbon rates are about a factor of two higher for NB31, as compared to NS31. The higher rate for NS31 at $800^{\circ} \mathrm{C}$ could be due to oxidation of the Si that was introduced into the porosity during material fabrication. The trend toward reduced oxidation for NS31 at high temperatures could be due to the influence of reduced porosity and $\mathrm{SiO}_{2}$ formation in NS31, factors that could affect mass transport and diffusion of the steam and the gaseous reaction products.

Figures 31 and 32 compare the results of this work for NS31 and NB31 with corresponding results obtained in a previous study $[3,4]$ for DUNLOP, FMI HDFG and FMI 4D carbon fiber composite samples. A comparison of the average $\mathrm{H}_{2}$ generation rates as a function of test temperature is given in Figure 31, and a similar comparison of carbon reaction rates is given in Figure 32. All results are presented based on geometric surface areas for the test samples. The results are directly comparable at $1100^{\circ} \mathrm{C}$ indicating that the steam reaction rates are substantially higher for DUNLOP, FMI HDFG and FMI 4D CFC's than for NS31 and NB31. A linear extrapolation of the results for NS31 and NB31, as plotted in Figures 31 and 32, to higher temperatures appears to agree with results observed for the other $\mathrm{CFC}$ materials at $1300^{\circ} \mathrm{C}$.

Noting that NS31 is more dense and less porous than NB31 and that the NS31 and NB 31 materials are more dense than the previously tested materials, it is tempting to conclude that the reactivity results at $1100^{\circ} \mathrm{C}$ indicate that steam reactivity for $\mathrm{CFC}$ materials is inversely proportional to the material density. However, there were substantial differences in the experimental conditions between the present experiments and the previous ones that could have affected the absolute reaction rates. For example, the 


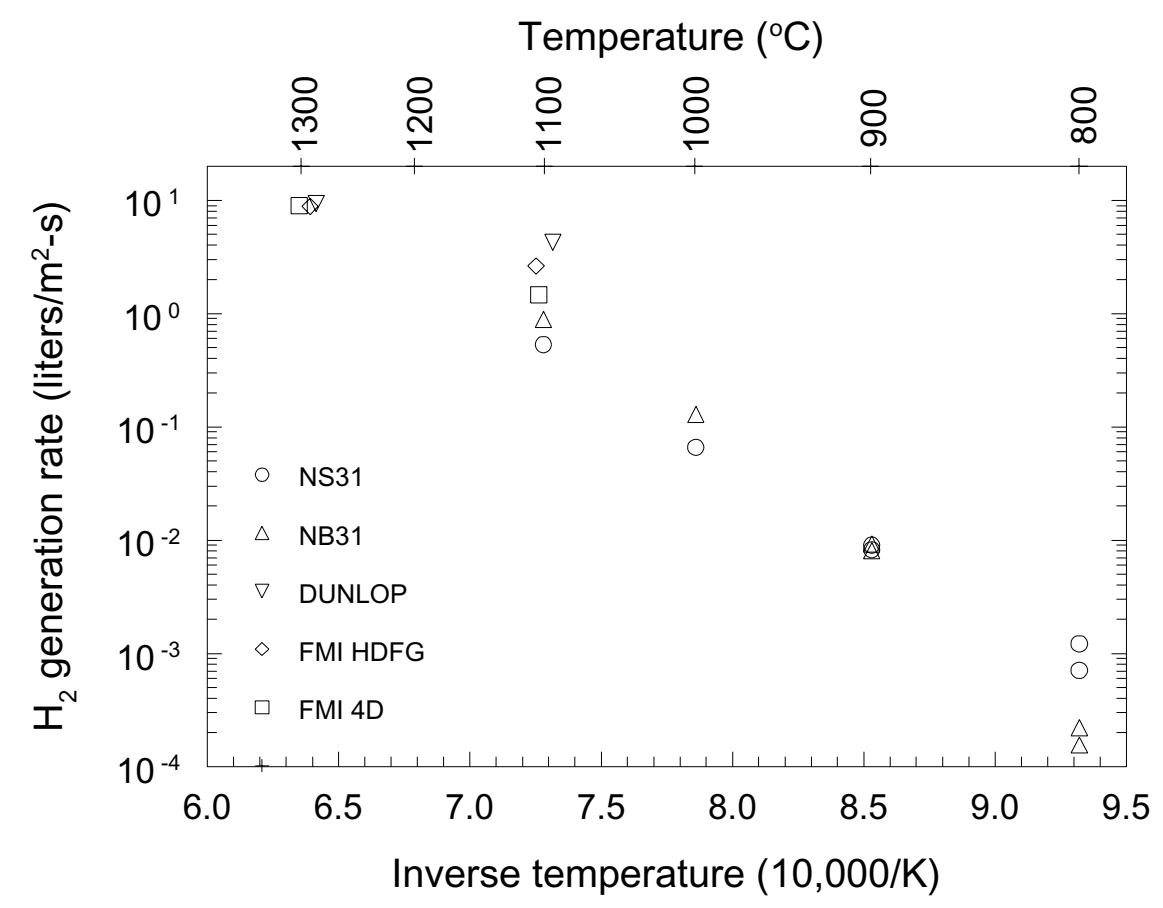

Figure 31. Comparison of average $\mathrm{H}_{2}$ generation rates for NS31 and NB31 CFC samples with the average $\mathrm{H}_{2}$ generation rates from a previous study $[3,4]$ for the DUNLOP, FMI HDFG and FMI 4 CFC samples. Rates are based on the geometric surface areas.

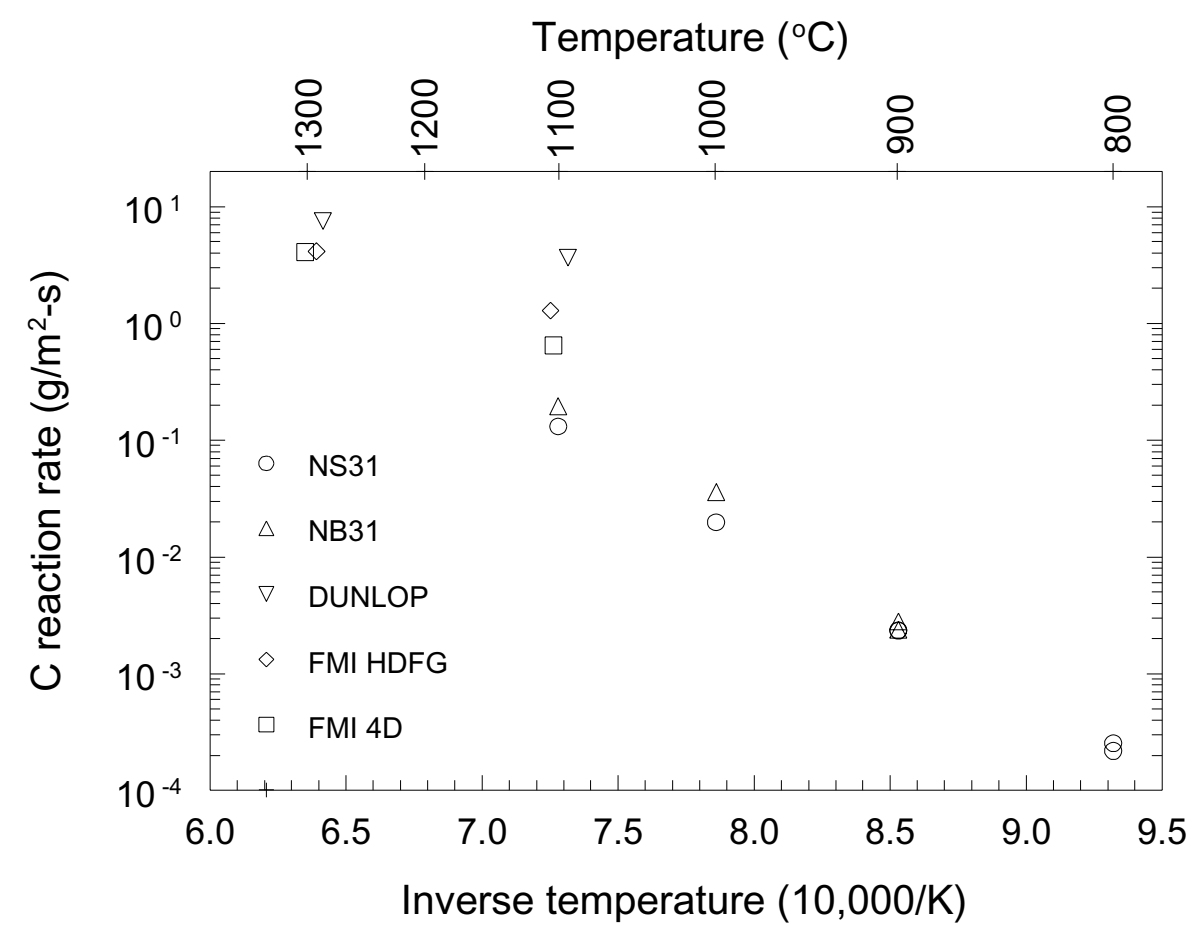

Figure 32. Comparison of average carbon reaction rates for NS31 and NB31 samples and those observed previously $[3,4]$ for the DUNLOP, FMI HDFG and FMI 4D samples. All results are based on geometric surface areas. 
steam flow velocity was substantial higher in the earlier experiments, a condition that could have contributed to an enhancement of the reactivity. This comparison suggests the need for additional measurements on all materials at common experimental conditions to determine the correlation reactivity with material density.

The results of these studies are relevant to the use of CFC materials in the divertor regions of an ITER-like tokamak, in particular to an evaluation of the PFC materials under steam ingress accident conditions. The infiltration of Si into the CFC matrix for NS31 resulted in a more-dense, less porous CFC than NB31. NS31 appeared to be more resistant to steam oxidation at temperatures of 1000 and $1100^{\circ} \mathrm{C}$ by about a factor of 2 . The trend for reduced steam oxidation of NS31 suggests that it might have some advantage over NB31 in its use as a PFC material. However, NS31 was more reactive at $800{ }^{\circ} \mathrm{C}$. The results suggest that further studies are important to unambiguously establish the role that Si plays in the steam reactivity process at all tokamak-relevant temperatures.

\subsection{REFERENCES}

1. T. J. Clark, R. E. Woodley and D. R. De Halas, "Gas-Graphite Systems", Ch. 14 in Nuclear Graphite, R. E. Nightingale, Editor, Academic Press, 1962, New York.

2. M. J. Gaeta, B. J. Merrill, H. W. Bartels, C. Laval and L. Topilski, "Short Term Hydrogen Production issues for ITER," Fus. Technol. 32, \#1(1997) 23-34.

3. G. R. Smolik, B. J. Merrill, S. J. Piet, and D.F. Holland, "Evaluation of Graphite/Steam Interactions for ITER,” EGG-FSP-9154, September 1990.

4. G. R. Smolik, B. J. Merrill, S. J. Piet, and D.F. Holland, "Evaluation of Graphite/Steam Interactions for ITER Accident Scenarios," Fusion Technology 19 (1991) 1342-1348.

5. J. P. Bonal, D. Moulinier, CEA Technical Report DMT/95-495.

6. S. Brunauer, P. H. Emmett and E. Teller, J. Amer. Chem. Soc. 60 (1938) 309.

7. G. R. Smolik, R. A. Anderl, P. Hembree, M.A. Oates, and R. J. Pawelko, "BET Surface Area Measurements of Materials for Fusion Safety Studies," Engineering Design File, EDF.: ITER/US/97/TE/SA-20, Fusion Safety Program, Idaho National Engineering and Environmental Laboratory, September, 1997.

8. G. R. Smolik, R. A. Anderl, R. J. Pawelko, W. J. Carmack, P. B. Hembree and M. A. Oates, "BET Surface Area Measurements of Materials for Fusion Safety Studies," paper presented at the $17^{\text {th }}$ IEEE/NPSS Symposium on Fusion Engineering, San Diego, CA, October 6-9, 1997. 
9. R. A. Anderl, "Performance and Scoping Test Results for Steam-Metal Chemical Reactivity System," Engineering Design File, EDF.: ITER/US/96/TE/SA-17, Fusion Safety Program, Idaho National Engineering and Environmental Laboratory, October 17, 1996.

10. R. A. Anderl et al., "System for Steam-Reactivity Measurements on Fusion-Relevant Materials, "Fusion Technology 30, (1996) 1435-1441. 


\section{APPENDIX A: CHARACTERIZATION OF CFC MATERIAL}

In this appendix, we summarize additional measurements and analyses that were made to characterize the as-received CFC materials. The approach entailed optical microscopy and scanning electron microscopy (SEM) to characterize the material microstructure and energy-dispersive X-ray EDX analysis to identify elemental components in the material.

Micro-structural characterization results of the NB31 CFC material are shown in Figures A-1 to A-11. Figures A-1 to A-3 are optical micrographs of this material at magnifications of 50X to 200X. These micrographs show both the fiber structure in two dimensions and the surrounding impregnated carbon matrix. We note that NB31 contains sizable voids, porosity and cracks along interface surfaces. The needle-like, lightappearing phase illustrates in-plane and out-of-plane fibers in the weave comprising the composite. The impregnated material comprises the fine-grained, honeycomb-like material both within the weave fibers and at interstitial spaces of the preformed composite, thin layered material along the outside of the fiber structure and the larger honeycomb-like material filling the remainder of the volume. Voids are manifested as the larger uniformly gray areas with irregular shapes in the impregnated regions. The gray material is mounting compound that has been infiltrated into the material. We also note from Figure A-2 and A-3 that the interface areas between the fiber structure and the thin layered material and the honeycomb structure and the thin layered material show signs of separation or cracks in the material.

Figures A-4 to A-7 present SEM micrographs for an NB31 CFC specimen that was mounted in a holder and polished. Two back-scattered electron (BSE) images of the microstructure surrounding a void are shown in Figures A-4 and A-5. Image contrast is enhanced by varying the incident electron energy from $15 \mathrm{kV}$ to $5 \mathrm{kV}$. Figure A-5 illustrates layering of the impregnated material around the fiber regions with significant separation of the layers at the material interfaces. In this figure the fibers are oriented perpendicular to the photo. EDS analysis was done to provide semi-quantitative indication of the elemental compositions of selected locations as shown in Figure A-4. The composition from a void region shown by spot 1 in Figure A-4 was $83 \% \mathrm{C}$ and 17\% $\mathrm{O}$, a composition attributed to the mounting compound. Elemental composition at spot 2 in the impregnated fiber region was $89 \% \mathrm{C}, 3.4 \% \mathrm{O}, 6.8 \% \mathrm{Al}$, and $0.6 \% \mathrm{Si}$, indicating that this region is basically carbon with some potential impurity pickup from the polishing compound.

SEM micrographs shown in Figures A-6 and A-7 provide additional characterization of the fiber structure and surrounding impregnated material. Figure A-6 illustrates the intersection of horizontally- and vertically-oriented fiber bundles. The higher magnification BSE image shown in Figure A-7 shows a fiber structure in the plane of the micrograph with spots identified for EDX analysis. The analysis at spot 1 shows a composition of $89 \% \mathrm{C}, 4 \% \mathrm{O}$ and $7 \% \mathrm{Al}$. At spot 2 , the analysis indicated $54 \% \mathrm{C}$, $11 \% \mathrm{O}, 31 \% \mathrm{Al}$, and $4 \% \mathrm{Si}$. The analysis for spot 3 indicated $100 \% \mathrm{C}$. The presence of $\mathrm{Al}, \mathrm{O}$ and $\mathrm{Si}$ indicate the potential pickup of residual material during polishing operations. 


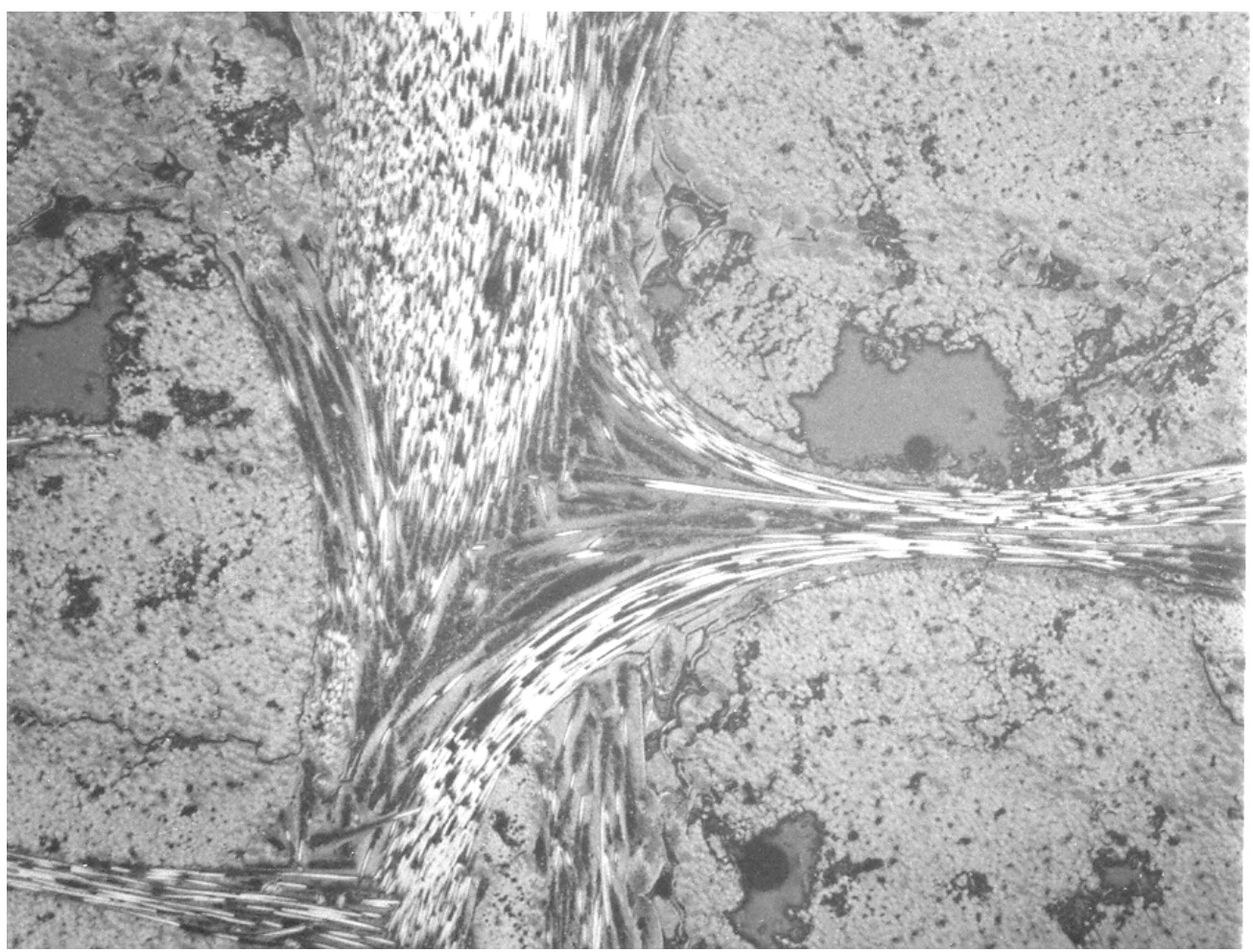

Figure A-1. NB31-1, optical micrograph for NB31 sample at 50X.

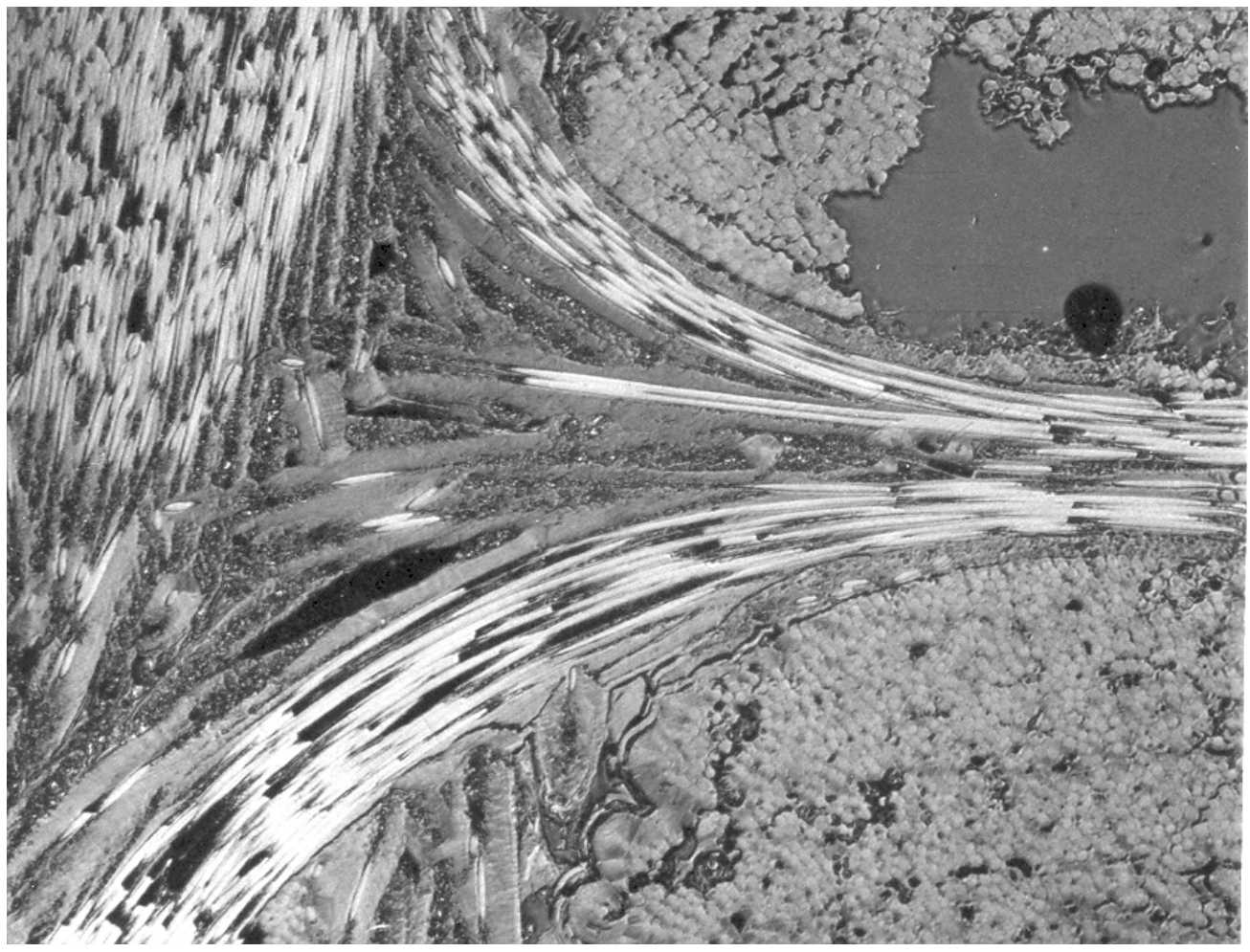

Figure A-2. NB31-2, optical micrograph for NB31 sample at 100X. 


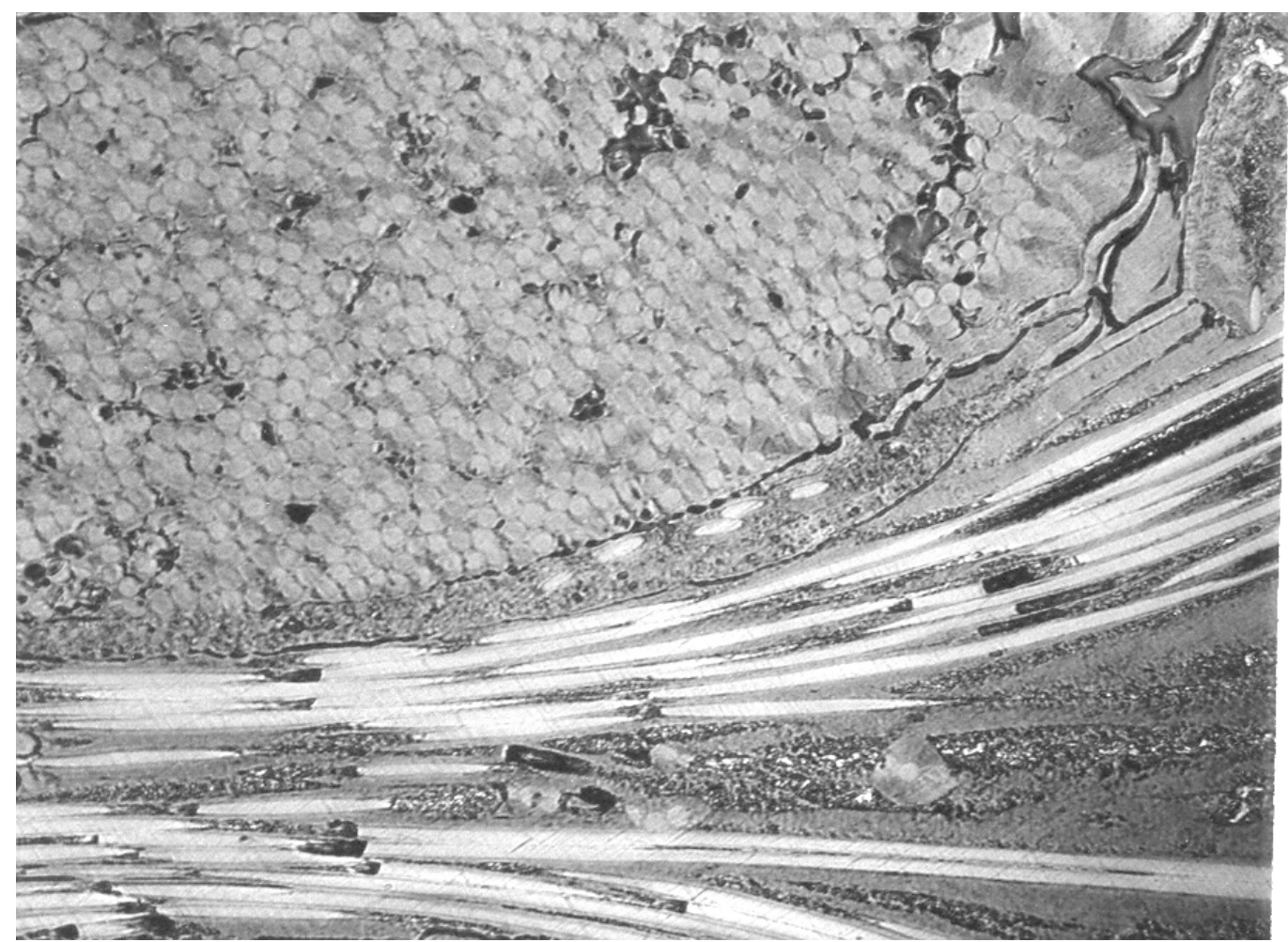

Figure A-3. NB31-3, optical micrograph for NB31 sample at 200X. 


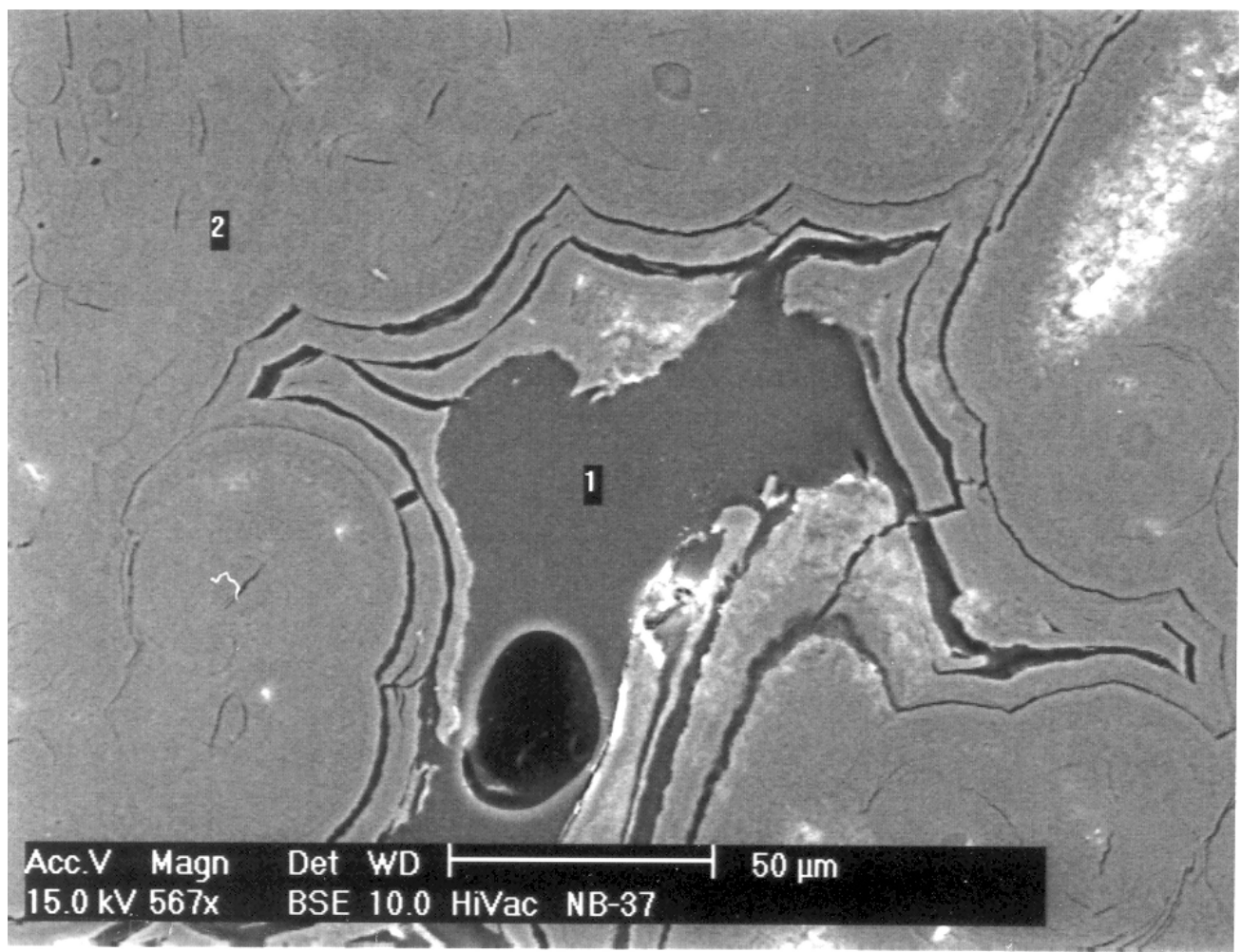

Figure A-4. NB31-4, back-scattered electron, scanning electron micrograph for NB31 sample at 567X, EDX analysis regions identified by numbers.

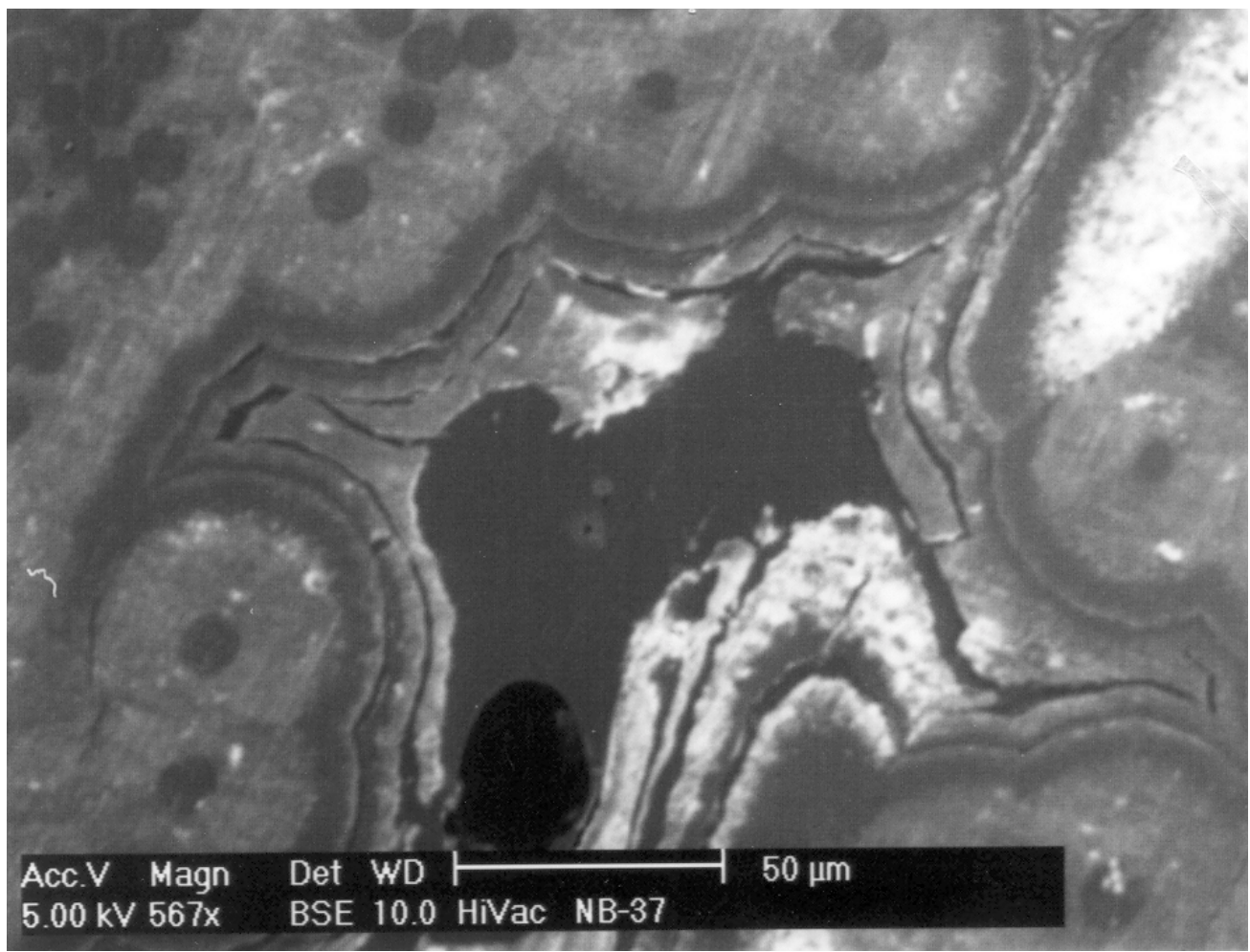

Figure A-5. NB31-5, back-scattered electron, scanning electron micrograph for NB31 sample at $567 \mathrm{X}$. 


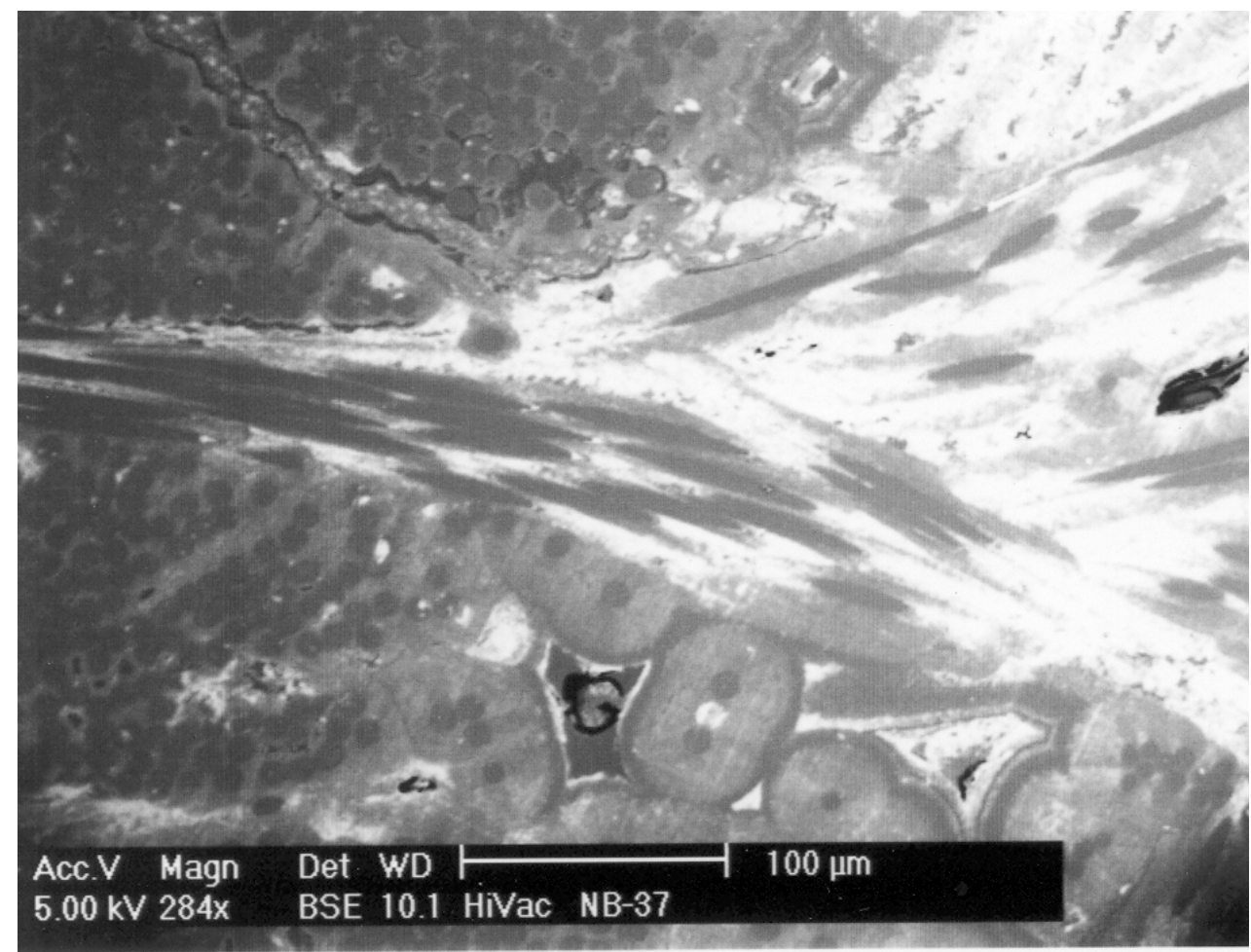

Figure A-6. NB31-6, back-scattered electron, scanning electron micrograph for NB31 sample at $284 \mathrm{X}$.

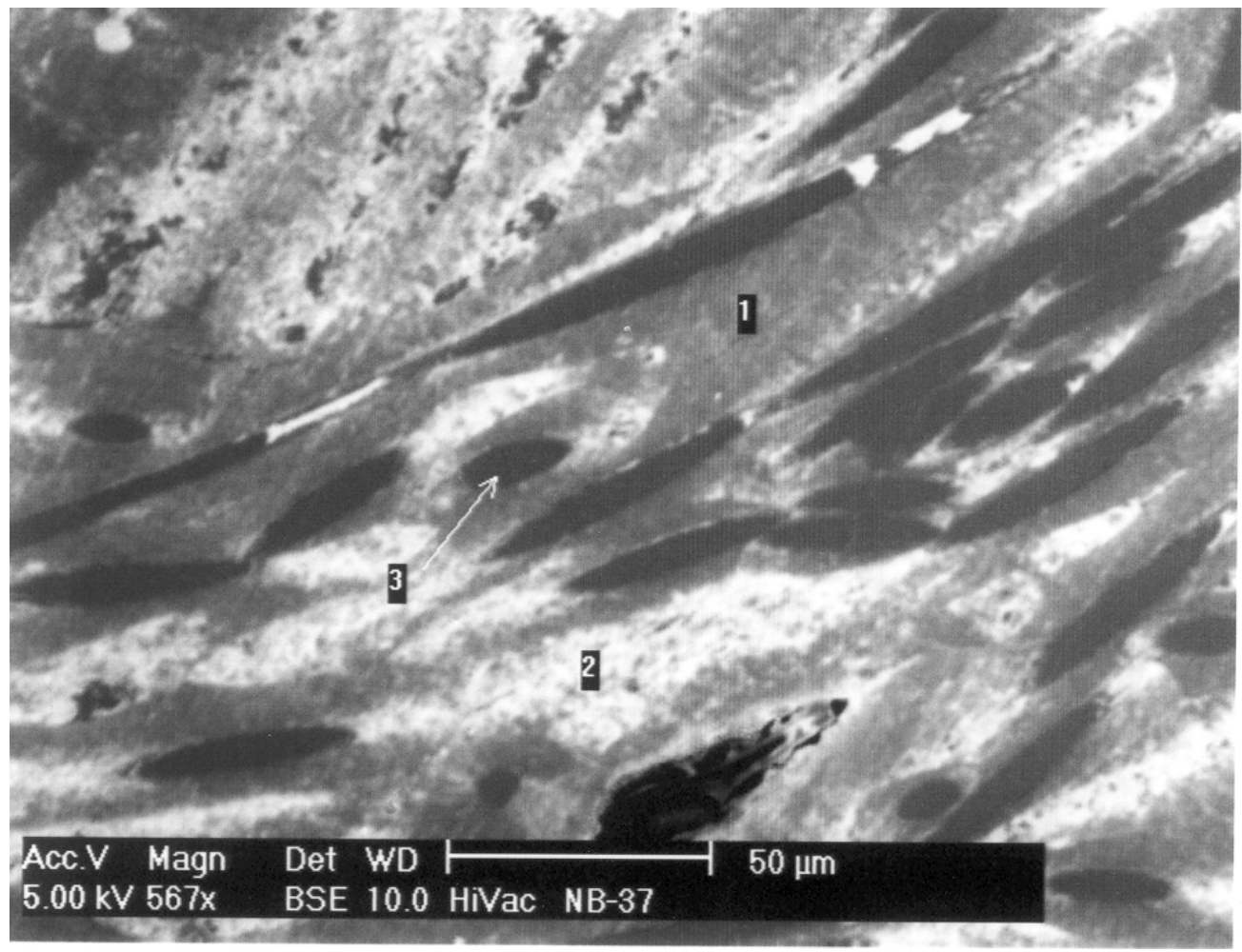

Figure A-7. NB31-7, back-scattered electron, scanning electron micrograph for NB31 sample at 567X, EDX analysis regions identified by numbers. 
The results of our micro-structural characterization of the NS31 CFC material are summarized in Figures A-8 to A-11. Figures A-8 to A-10 present optical micrographs of the material at magnifications from $50 \mathrm{X}$ to $200 \mathrm{X}$. The micro-structural picture is similar to that for the NB31 material with one principal difference. Some of the porosity is filled with silicon as shown by the lightest regions in the figures. Further evidence of porosity filling is illustrated by the SEM BSE image shown in Figure A-11 for a mounted polished NS31 sample. EDX analysis at various spots provided semi-quantitative analysis.

Spot 1, the lightest-appearing spot, showed $100 \% \mathrm{Si}$. The measured elemental composition of spot 2 was $61 \% \mathrm{Si}, 39 \% \mathrm{C}$ and $0.4 \% \mathrm{Al}$. Spot 3 indicated $100 \% \mathrm{C}$ and spot 4 comprised $44 \% \mathrm{C}$ and $56 \% \mathrm{Si}$. These analyses indicate that the final infiltration of the CFC composite with liquid silicon resulted in substantial filling of the porosity and the formation of both pure silicon and mixtures, possibly some $\mathrm{SiC}$, in the $\mathrm{CFC}$ matrix. However, the microscopic results indicate that interfaces between different material regions contained some degree of separation that provided access to gas penetration as shown by the BET measurements. 


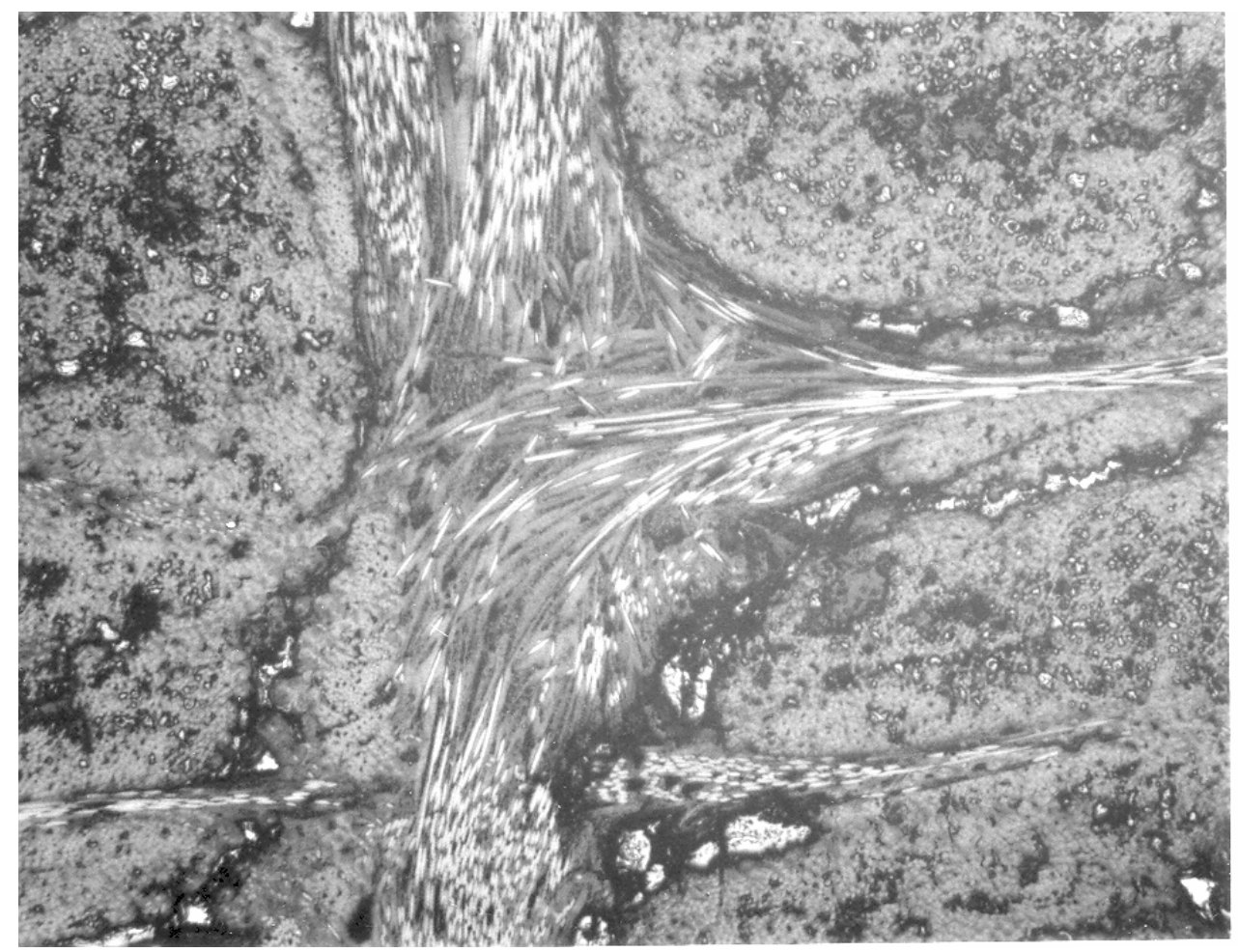

Figure A-8. NS31-1, optical micrograph for NS31 sample at 50X.

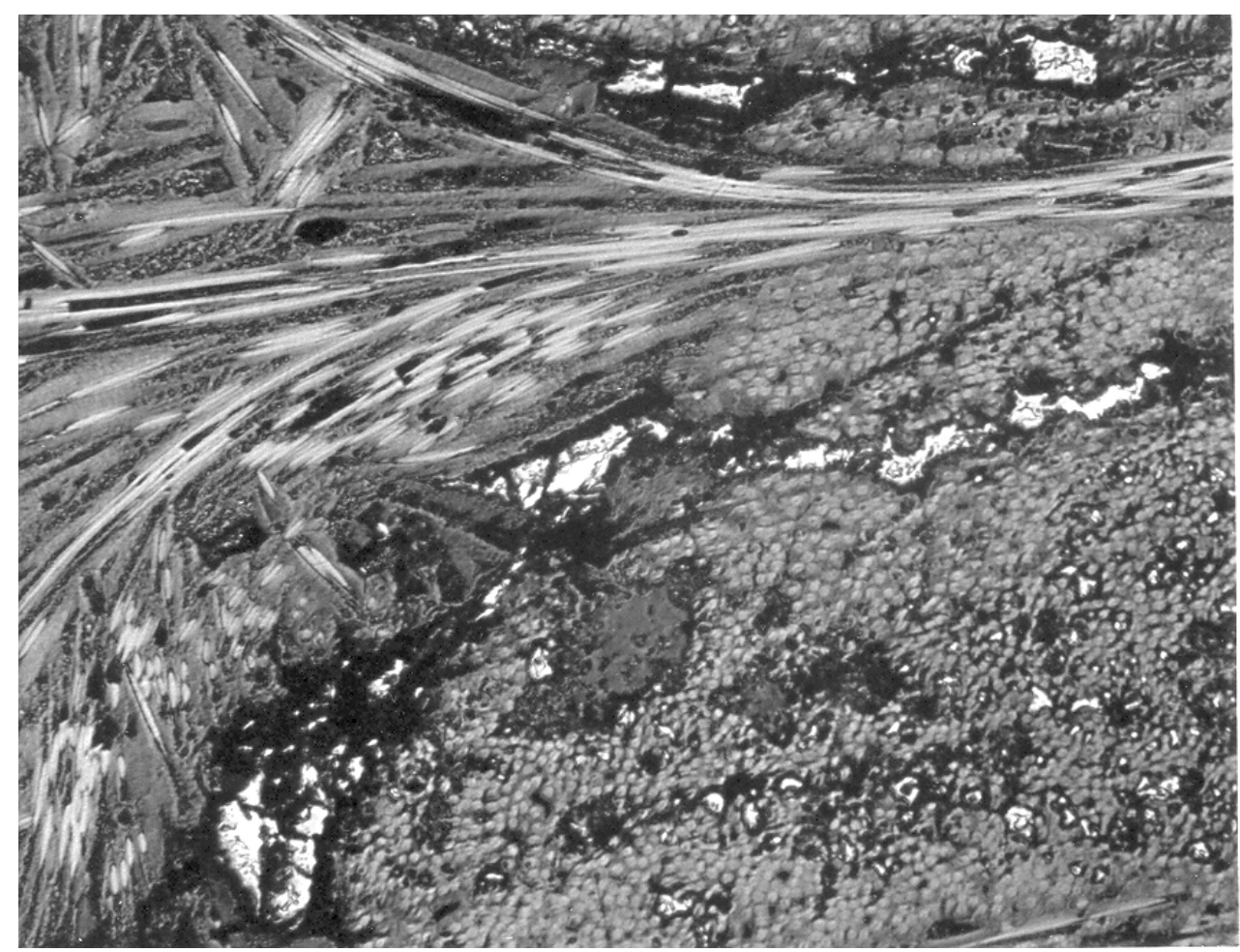

Figure A-9. NS31-2, optical micrograph for NS31 sample at 100X. 


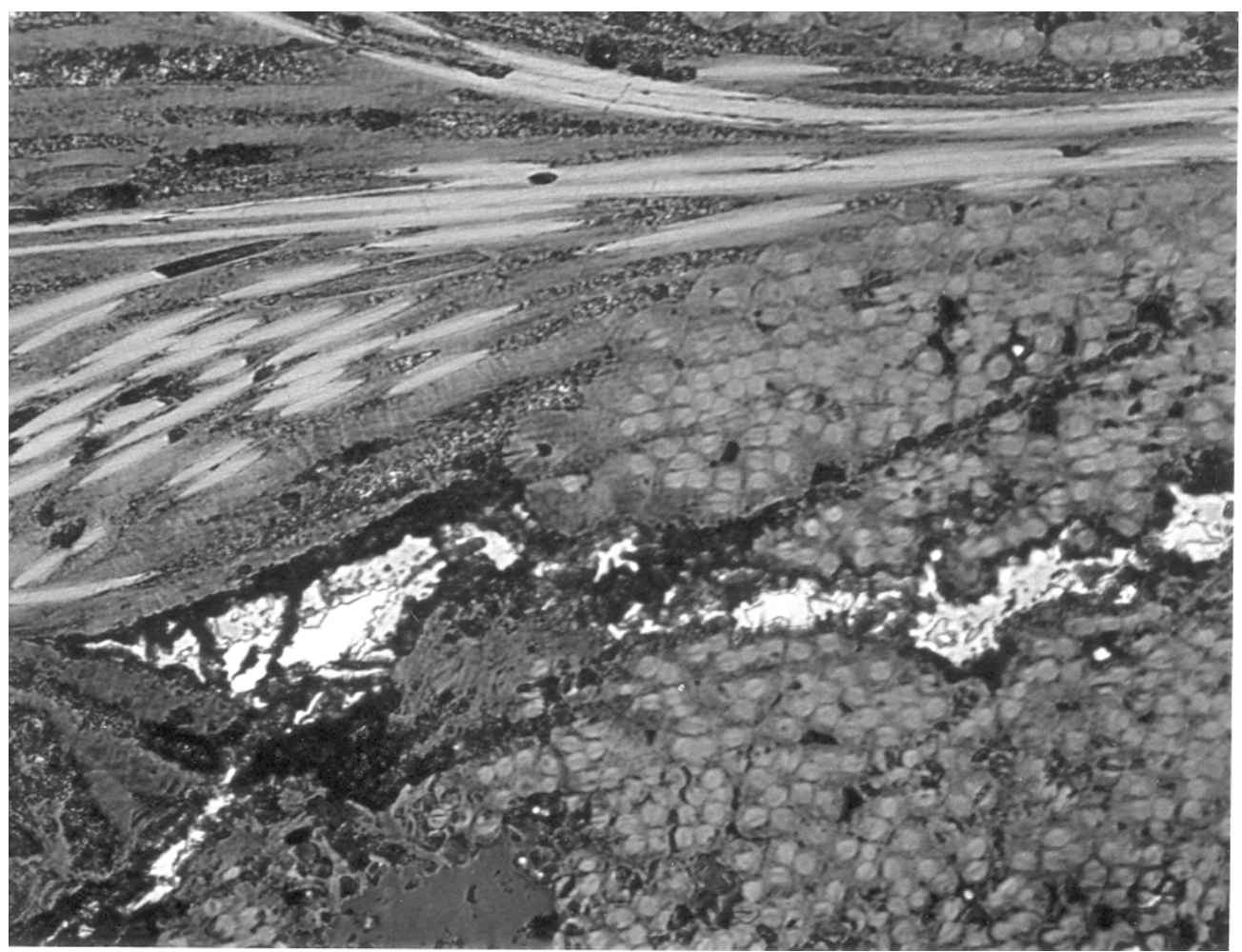

Figure A-10. NS31-3, optical micrograph for NS31 sample at 200X.

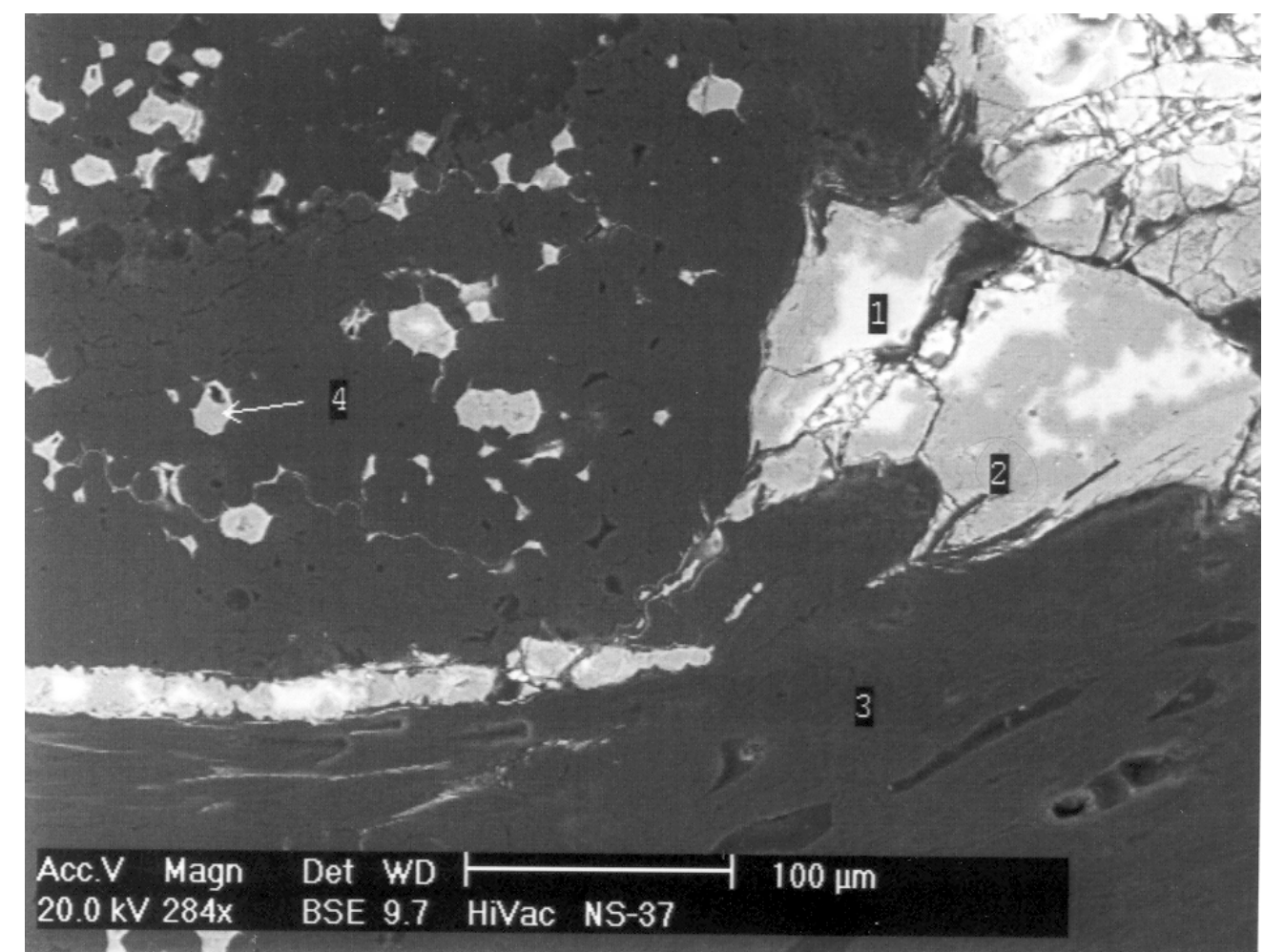

Figure A-11. NS31-5, back-scattered electron, scanning electron micrograph for NS31 sample at $284 \mathrm{X}, \mathrm{EDX}$ analysis regions identified by numbers. 